\title{
AFFIRMING WHITENESS: A CRITICAL DISCOURSE ANALYSIS OF THE AFFIRMATIVE ACTION DEBATE IN THE FISHER CASE
}

A dissertation proposal presented to the Faculty of the Graduate School University of Missouri

In Partial Fulfillment

Of the Requirements for the Degree

Doctor of Philosophy

by

MARLO GOLDSTEIN HODE

Dr. Rebecca Meisenbach, Dissertation Advisor

AUGUST 2014 
(C) Copyright by Marlo Goldstein Hode, 2014

\section{All Rights Reserved}


The undersigned, appointed by the dean of the Graduate School, have examined the dissertation entitled

\section{AFFIRMING WHITENESS: A CRITICAL DISCOURSE ANALYSIS OF THE AFFIRMATIVE ACTION DEBATE IN THE FISHER CASE}

presented by Marlo Goldstein Hode, a candidate for the degree of doctor of philosophy of communication, and hereby certify that, in their opinion, it is worthy of acceptance.

Professor Rebecca Meisenbach

Professor Debbie Dougherty

Professor Ben Warner

Professor Jeni Hart

Professor Astrid Villamil 


\section{ACKNOWLEDGEMENTS}

It is hard to believe that I am finally here at the top of Dissertation Mountain. It was the most arduous and rewarding challenge of my life. As I look back at my path, I see the many kind faces and helping hands that supported and guided me along the way. I'd like to thank all of the faculty, staff, and my fellow students in the Communication Department for creating a healthy learning environment and helping me get into shape for the big climb. I owe an extra debt of gratitude to Angela Gist, Holly Holladay, and Kristi Wenzel who were always there to pick me up off the ground and pull me along with them. I had additional support from my family and friends who cheered me on from afar. And finally, my darling husband was relentless in his encouragement. All this love and support got me through this process, but were it not for Rebecca Meisenbach and Debbie Dougherty, I never would have thought I could do it in the first place. Not only did they provide me with the tools I needed to make the journey, they got me to see my own potential. They kept telling me that I could do it; finally, I believed them. When Dr. Meisenbach took over as my full-time coach, she gave me both the space and guidance that I needed to find my way. And when it came to that final climb from base camp to the top of the mountain, I had the additional support and encouragement from Jeni Hart, Astrid Villamil, and Ben Warner. Finally, no climbing expedition is possible without sponsorship. For that, I must thank the Chancellor's Diversity Initiative. Not only did this office provide financial support, my colleagues also provided critical emotional support when the climb was particularly tough. As I plant my flag at the top of this mountain, I dedicate this journey to all of those who have come before me in the ongoing struggle for social justice and equality. 


\section{TABLE OF CONTENTS}

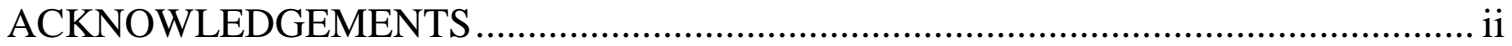

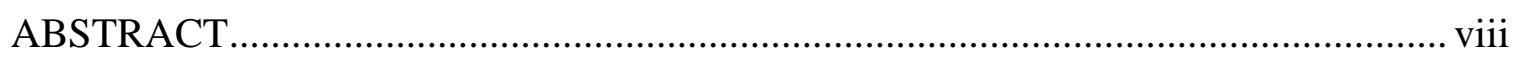

CHAPTER 1: INTRODUCTION AND RATIONALE .......................................... 1

The Current State of the Debate......................................................... 5

A Discursive Approach to the Affirmative Action Debate....................... 9

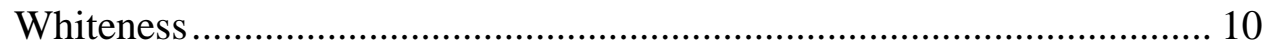

Race and Organizational Communication ........................................ 11

Organizational Communication and Public Policy ............................. 12

Project Overview …................................................................ 14

Conclusion ................................................................................. 15

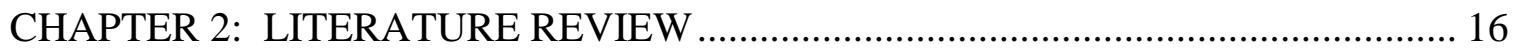

Affirmative Action ....................................................................... 17

The affirmative action debate in higher education. ............... 19

The importance of landmark cases. ................................... 20

Constitutional concepts and terminology........................... 21

Regents of the University of California v. Bakke................. 22

Grutter v. Bollinger .................................................... 24

The Importance of the Fisher case................................................... 26

Race and the affirmative action debate............................... 26

Race and the legislative context........................................ 27 
Structuration Theory

Structuration theory and organizational communication

research.

Structurational concepts

Extending Structuration Theory. 43

Ideology, discourse, and power.

Summary of Structurational-Discursive Framework 50

Theorizing Whiteness 52

Defining Whiteness and race. 52

Revealing Whiteness in discursive practices. 55

Whiteness as a structural principle. 57

Whiteness, Discursive Resources, and the Affirmative Action Debate.... 63

Innocence and fairness. 64

Merit and the American Dream. 65

Colorblindness. 67

Diversity. 68

Summary and Research Questions... 71

Conclusion 73

CHAPTER 3: METHODOLOGY AND METHODS 75 
Critical Discourse Analysis.

Feminist critical discourse analysis. 79

Towards a race-centric approach to CDA 81

Critical Race Theory......................................................... 83



Selection and justification of topic and texts...................... 89

Phase 1: Analysis of Discursive Resources ......................... 94

Phase 2: Close Textual Analysis and Ideological Critique..... 97

Phase 3: Answering Research Questions ........................... 98

Evaluation ............................................................................ 100

Conclusion .................................................................................. 102

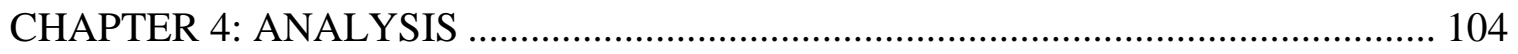

Grutter as a Discursive Structure .................................................. 105

The compelling Interest in student body diversity.............. 106

Critical mass............................................................ 108

Narrowly tailored..................................................... 109

Amicus Briefs: Discursive Resources and the Struggle for Meaning.... 111

Equality versus inequality............................................. 112

History................................................................ 115

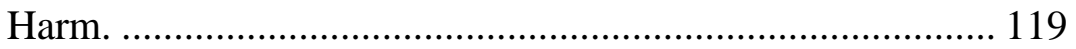


Emotional cost versus material cost.

Critical mass and quantification.

Diversity and race.

Section summary

Transcript of the Oral Arguments

Critical mass.

Diversity and race.

Section summary

The Court's Final Ruling ..... 148

Critical mass and quantification. 150

Diversity and race.

Harm and White normativity. 159

Contesting race-neutral universalism. 161

Section summary. 162

Research Questions 163

(Re)producing Whiteness through White Interests 164

The Constitution of Racialized Subjects 170

Contesting Whiteness.

Conclusion 188 
Summary of Results 190

Phase one. 191

Phase two. 192

Phase three.

Methodological Contributions 198

Theoretical Contributions 200

Contributions to Affirmative Action Scholarship................................... 202

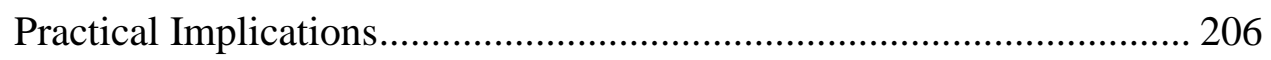

Confront Critical Mass......................................................... 206

Rethink the Compelling Interest in Diversity........................ 208

Historicize Affirmative Action ................................................ 209

Limitations and Future Directions ....................................................... 210

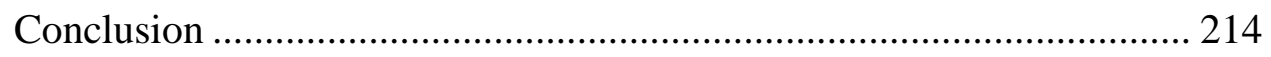

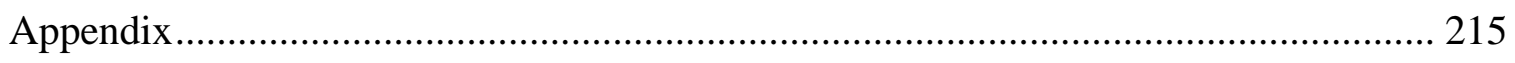

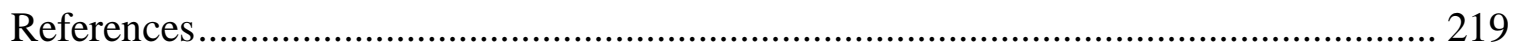

VITA … 


\begin{abstract}
For the past decade, the Grutter v. Bollinger (2003) decision has served as the constitutional basis for the consideration of race in university admissions (Lawrence, 2001; Ledesma, 2013). The recent Fisher v. University of Texas (2013) case attempted to challenge this ruling. Although the Supreme Court did not overturn the Grutter decision, the consensus among legal analysts is that the Court's decision in the Fisher case will impact the ways that universities construct and implement their admissions policies (Schmidt, 2013). However, Supreme Court decisions about affirmative action in higher education do more than impact how admissions policies are structured. The discourse produced in these decisions structures how race can be talked about, understood, and enacted in the context of higher education.

In order to critically examine and destabilize the dominant affirmative action discourse as it is being deployed in the current debate around race-conscious admissions in higher education, I conducted a race-centric critical discourse analysis of the amicus briefs, the transcript of the oral argument, and the Court's final ruling in the Fisher case. My analysis revealed that dominant arguments produced by both liberal and conservative ideological positions in the debate around race-conscious admissions engaged the concepts of race and diversity in ways that were produced by and (re)produced Whiteness. Practical applications for pro-affirmative action advocates and policy makers are offered.
\end{abstract}




\section{CHAPTER 1: INTRODUCTION AND RATIONALE}

The battle over race-conscious admissions in higher education is one of the most hotly contested areas of affirmative action policy in the United States (Glazer, 1998). Affirmative action has always stood on shaky legal ground within narrowly decided and tightly contested court rulings (Katznelson, 2006). Even the landmark Supreme Court case, Grutter v. Bollinger (2003), that has served as the constitutional bedrock for affirmative action policy in higher education admissions for the past decade was wrought with dissent in its 5-4 decision (Cummings, 2005; Devins, 2003; Ledesma, 2013). Public opinions are as divided as judiciary opinions. For example, a recent nationwide poll found that almost $80 \%$ of African American and Latinos supported government regulation of racial equality in schools, while slightly less than $50 \%$ of White Americans supported such policies (Ford Dowe, 2010). To understand why both public and judicial opinions are so deeply divided on this issue, the affirmative action debate must be understood as a conflict of ideological perspectives about race and inequality.

There are powerful and convincing arguments on both sides of the affirmative action debate. Arguments made in favor of affirmative action policies draw upon moral and utilitarian arguments by contending that such policies (a) contribute to closing the economic and social gap between Black and White people, (b) serve as reparations for the historical harm caused by slavery, segregation, and societal and government-sanctioned discrimination; and (c) increase diversity, which is beneficial to learning and working environments (Greenberg, 2001; Katznelson, 2006). These 
arguments are based upon a belief that race matters, that U.S. society is not a 'colorblind' society, and that our history is still ever-present. While these arguments may seem self-evident to affirmative action proponents, they seem vague and theoretically indefensible to those on the other side of the debate (Katznelson, 2006).

Opponents of affirmative action tend to draw upon constitutional principles and 'American values' such as equality, fairness, merit, and color-blindness to argue that such policies: (a) infringe upon the equality of all individuals, (b) undermine merit-based systems, (c) stigmatize policy recipients, (d) exacerbate racial tensions, and (e) provide unfair advantage to some who do not need it at the expense of others who do (Devins, 1991; Greenberg, 2001; Katznelson, 2006). These arguments attempt to turn the moral table on affirmative action policy by framing it as racist and discriminatory.

Affirmative action represents America's most ambitious attempt to eliminate racial, ethnic, and gender-based bias in employment, housing, and education (Leiter $\&$ Leiter, 2011). The vision for affirmative action as a broad public policy was to create equality among races not just as "a right and a theory but equality as a fact and equality as a result" (Johnson, 1965, para. 14). Thus far, however, affirmative action has failed to live up to this promise (Leiter \& Leiter, 2011). Although great strides have been made in the four decades since President Johnson signed the executive order that created the affirmative action mandate, racial inequality remains firmly entrenched in all of our social and economic institutions (Katznelson, 2006; Leiter \& Leiter, 2011). Racial inequality in higher education in terms of access and completion at selective institutions not only persists but is growing, even in states 
without bans on affirmative action (Carnevale \& Strohl, 2013; Gerald \& Haycock, 2006). Opponents of affirmative action might point to this failure as evidence that such policies are not effective; while supporters might argue that much more time is needed for such policies to curtail the impact of centuries of legalized and systematic discrimination. In either case, the decades-old debate seems trapped in insufficient and unsatisfactory arguments on both sides of the issue (Katznelson, 2006). The intractability of this debate stagnates progress in resolving the growing problem of racial inequality in the United States.

Racial inequality is a critical social issue, particularly in the context of the shifting demographic make-up of the U.S. population. According to a U.S. Census Bureau report, the United States is projected to be a "majority minority" population by the year 2050 ("U.S. Census Bureau Projections Show a Slower Growing, Older, More Diverse Nation a Half Century," 2012). This demographic shift means that racial and ethnic minorities will together make up as much as $54 \%$ of the total population and that White people will no longer be in the demographic majority. As these minority populations are growing, the income gap between White people and minorities is the biggest it has been in 25 years, with the median wealth of White households being 20 times more than that of African American households and 18 times more than Hispanic households (Kochhar, Fry, \& Taylor, 2011). These income gaps are attributable to the racial distribution of types of jobs held and the salaries associated with such jobs (Kochhar et al., 2011). In other words, although the overall percentage of the population of White people is decreasing, their relative economic power is increasing. These trends are not sustainable, as argued in an article written during the Fisher deliberations: 
[A]mid America's demographic transformation, the allocation of higher-education opportunities now raises different issues of competitiveness and social stability. With the absolute number of whites in the workforce expected to decline through 2030, the U.S. will struggle to compete if it cannot move more low-income and minority youths through college. And a society that relies on minorities to fill most of its future workforce needs but reserves the best opportunities primarily for the children of white, college-educated parents will court endemic social tension. (Brownstein, 2013, para. 8)

As this quote argues, it is critical to the functioning of U.S. democracy that growing minority populations are educated and widely represented across public and private sector jobs, as well as in political and leadership positions. Failure to achieve broad representation creates social and economic instability for society overall (Greenberg, 2001). Furthermore, research in public health has shown links between economic inequality and poor health outcomes (including mortality), not only for poor people, but for middle and upper class populations as well (Daniels, Kennedy, \& Kawachi, 2007; McLaughlin \& Stokes, 2002; Mellor \& Milyo, 2001). In other words, economic inequality may negatively impact the health and well-being of all sectors of society, not just the poor (Daniels et al., 2007). Since minority access to higher education, particularly selective institutions, plays such an important role in developing talent and creating opportunities (Gerald \& Haycock, 2006; Glazer, 1998), affirmative action policy in university admissions is a critical social issue.

In order to address the important issue of growing social and economic inequality, policy makers and society as a whole must find ways to move the 
stagnant debate around affirmative action forward by rethinking and revitalizing understanding of the problems and solutions needed. The language and rhetorical strategies engaged to shape debates about social issues are part of an ideologically laden discourse that may, in fact, reproduce social problems, inequality, and the dominant power structure (Blommaert \& Verschueren, 1998). In other words, the ways in which affirmative action policy is currently articulated and debated in the context of U.S. higher education might actually be part of the problem. Therefore, the purpose of the current project is to destabilize the affirmative action debate in order to illuminate new ways to think and talk about affirmative action policies in higher education. In the remainder of this chapter, I introduce the recent Supreme Court case around race-conscious affirmative action, which serves as my entry point into the affirmative action debate and the focal point of this project. Then, I delineate the importance of a discursive approach to exploring the debate. And, finally, I offer an overview and the intended contributions of this project.

\section{The Current State of the Debate}

Grutter v. Bollinger (2003) is the landmark Supreme Court case that has formed the legal cornerstone of race-conscious admissions policies for the past decade (Ledesma, 2013). The majority opinion in Grutter upheld the constitutionality of "narrowly tailored" race-conscious admissions in order to obtain "the educational benefits that flow from a diverse student body" (Grutter $v$. Bollinger, 2003, p. 343) for the students, employers, and society overall. Narrowly tailored means that race is given minimal consideration or weight in the application 
process and does not reach beyond the specific goal of achieving student body diversity. The ruling further concluded that:

It has been 25 years since Justice Powell first approved the use of race to further an interest in student body diversity in the context of public higher education. Since that time, the number of minority applicants with high grades and test scores has indeed increased. We expect that 25 years from now, the use of racial preferences will no longer be necessary to further the interest approved today (Grutter v. Bollinger, 2003, p. 343).

In other words, the Justices recognized that progress had been made through such policy initiatives, but still more time and more progress is needed before affirmative action policies are no longer necessary to "further the interest" of student body diversity. And yet, less than ten years after this hopeful prediction, the resistance to race-conscious affirmative action is so strong that it has been challenged in the Supreme Court again.

In the current case, Abigail Fisher, a White applicant, sued the University of Texas at Austin (UT) for alleged racial discrimination in violation of the Equal Protection clause under the $14^{\text {th }}$ Amendment (Fisher v. University of Texas at Austin, 2013). Fisher's lawyers argued that UT's admissions policy creates a disadvantage for White students because the application scoring process awards points for minority status (among several other factors). Both the U.S. District Court and the Fifth Circuit Appeals Court ruled in favor of UT, finding that the university's consideration of race met the criteria as laid out in Grutter, which will be explained in detail in chapter two. Fisher's lawyer petitioned the Supreme Court and was 
granted judicial review of the case. Judicial review refers to the court's authority to examine and invalidate a previous ruling or legislative act that the Court determines runs contrary to constitutional principles (Tanenhaus, 2008). Therefore, Fisher sought to have the Supreme Court overrule the lower court's decision to uphold UT's consideration of race in its application review process.

Affirmative action proponents feared that the Supreme Court, led by a conservative majority (many of whom had dissented against the Grutter decision to uphold race-conscious admissions), would rule against UT's use of race-conscious admissions. Such a ruling would effectively overturn the Grutter framework and undo the legal cornerstone of race-conscious admissions policies (Howe, 2013). This type of precedent would make many higher education institutions highly susceptible to legal challenges to their race-conscious admissions policies as well as pave the way for affirmative action challenges in other areas, such as government contracts (Howe, 2013). However, after over a year of deliberations, the court did not decide the fate of affirmative action. Instead, the Supreme Court decided that the lower court had failed to apply the appropriate level of scrutiny in its review of the case and sent it back to the lower court for a stricter review of the facts and a new ruling.

The Supreme Court's ruling was good and bad news for both sides of the debate. On the one hand, supporters of affirmative action breathed a collective sigh of relief that the Grutter decision was not overturned altogether (Chemerinsky, 2013), which would effectively have made the consideration of race in higher education admissions unconstitutional (Jaschik, 2013). On the other hand, although the legal precedent that supports the use of race-conscious admissions was upheld, 
the narrow technical ruling can be viewed as weakened judicial support for raceconscious admissions (Bollinger, 2013). Therefore, the Fisher case caused broad speculation that anti-affirmative action advocates will draw upon this ruling to bring many more legal cases against both public and private institutions' affirmative action policies (Schmidt, 2013).

In effect, the Supreme Court's decision put campus administrators on notice that they will need to be able to defend their policies under very strict judicial review (Bollinger, 2013; Jaschik, 2013). Because race-conscious admissions policies stand on shakier legal ground after the Fisher ruling, many institutions may turn to 'raceneutral' options to affirmative action in order to avoid lawsuits (Schmidt, 2013). This potential shift to race-neutral policies is why one pro-affirmative action lawyer went so far as to call the Fisher ruling "a very quiet death sentence for affirmative action that is race-conscious" (Jaschik, 2013, para. 28). A race-neutral policy would indeed be a dramatic shift from the original vision set out by President Lyndon Johnson in 1965, which was explicit in framing the intent of affirmative action policy as a redress for the past harms of slavery and legalized discrimination of African Americans and other minorities (Katznelson, 2006; Zarefsky, 1980). A raceneutral approach also seems to ignore the "organizing power of race in American life" (Katznelson, 2006, p. xiii). So, although the Fisher ruling did not dismantle the constitutionality of race-conscious admissions policies, it did provide a framework under which such policies could be challenged (Chemerinsky, 2013; Jaschik, 2013; Schmidt, 2013). 
Supreme Court opinions are forms of public discourse that both shape and reflect national debates about controversial subjects such as race (Brown-Nagin, 2005). In this sense, the importance of Supreme Court rulings such as in the Fisher case goes beyond the material impact of the policies they influence. Judicial decisions about discrimination create and perpetuate ways of talking about, or constituting, women and minorities (Schneyer, 1993). In this light, Supreme Court decisions about affirmative action in higher education do more than impact how admissions policies are structured. The discourse produced in these decisions structures how race can be talked about, understood, and enacted in the context of higher education. Therefore, the contentious issue of affirmative action should be understood as a discursive and ideological battle for meaning.

\section{A Discursive Approach to the Affirmative Action Debate}

A discursive approach to the affirmative action debate means exploring the ways that dominant interests are produced and sustained through arguments around policy meanings and implementation practices. Policies define what the problems are and impose limits on how these problems can be addressed (Bacchi, 1999). In this light, policy discourse is more than just a way of talking about an issue; discourse produces practices with material consequences. The effects produced by policy discourse serve to

(a) draw our attention to certain bodies and away from others, (b) delineate what types of bodies should be considered and why, and (c) naturalize a system of thought around who benefits from and who is harmed by such policies (Bacchi, 1999). Understood this way, affirmative action is not only a policy about race, it is also a discourse that organizes or 
structures race by delineating if, when, why, and how race can be legitimately considered in admissions.

However, affirmative action policy discourse is explicit only in its treatment of non-White racial identities, while Whiteness remains unmarked in the discourse. The invisibility of Whiteness within the policy discourse is an effect of its structural position of dominance. Thus, this project engages Whiteness as a theoretical lens through which to critique the debate around affirmative action policy in higher education.

\section{Whiteness}

The power of Whiteness as an enduring structure lies in its invisibility and universality (Frankenberg, 1993; Grimes, 2002; Nakayama \& Krizek, 1995; Owen, 2007). As a universal lens, Whiteness is perceived as the 'norm' from which 'Others' are marked. In this way, Whiteness as a dominant category remains unmarked and "epistemologically unproblematic" (Brekhus, 1998, p. 38). As a result, when scholars focus on "difference," they tend to focus on the margins, leaving the center uncritically examined or invisible, which serves to perpetuate its position of power (Brekhus, 1998; Nakayama \& Krizek, 1995). Therefore, I purposefully maintain Whiteness as the object of study in this project about raceconscious admissions in order to dismantle its cloak of invisibility and its position of centrality, which are power effects of White racial dominance (Frankenberg, 1993). By articulating a standpoint of Whiteness within the debate, its privileged position as the standard or norm can be denaturalized and revealed as a particular, and limited, lens through which to interpret our social context (Hunt, 2005; Owen, 2007). In so doing, Whiteness may be de-centered as the normative perspective (Grimes, 2002) 
and alternative views that are pushed to the margins of our dominant discourses may be legitimized. By maintaining Whiteness as a central theoretical and analytical concept, this project answers the call to bring a raced perspective to research in organizational communication scholarship.

\section{Race and Organizational Communication}

More than two decades ago, Nkomo (1992) denounced the insufficient, incomplete, and often absent theorization of race in organizational communication scholarship. There are a handful of organizational communication scholars who continue to call out the lack of attention to race in our scholarship (e.g., Allen, 1995; Ashcraft \& Allen, 2003; Mumby, 2011). There are also a few scholars who have studied the ways that race is implicated in organizing processes such as leadership (Parker, 2001), diversity management (Grimes, 2002), decision-making (Grimes \& Richard, 2003), and power (Petitt, 2009). And yet, there are other scholars who admit the significance of race and other marginalized identities, but explicitly exclude these identities from their analysis in favor of focusing on organizational roles, professions, and group identities (e.g., Kuhn \& Nelson, 2002; Scott, Corman, \& Cheney, 1998; Silva \& Sias, 2010). It seems that the field of organizational communication "has developed resilient mechanisms of defense and deflection ---framing tactics that permit [scholars] to dodge the racial roots of organizing" (Ashcraft \& Allen, 2003, p. 30).

The present study heeds the call to address the raced nature of organizing (Allen, 1995; Ashcraft \& Allen, 2003; Mumby, 2011; Nkomo, 1992) by explicating the discursive organizing of race in affirmative action policy. Whiteness is an everpresent organizing structure, yet it remains mostly invisible or unmarked in 
organizational communication scholarship. Since Whiteness occupies a place of power and privilege in society and organizations, it should be of primary theoretical concern to critical organizational communication scholars (Grimes, 2002). Research or theorization that does not take race into account may inadvertently serve to reproduce the status-quo by privileging Whiteness through 'unmarking' it as an organizing construct. In this light, 'universal' theories (e.g., leadership, identity negotiation, socialization) that are developed through the experiences of White people without consideration of race are limited and incomplete (Nkomo \& Cox 1990). In other words, our scholarship on organizing will be strengthened by taking a raced perspective on our work. In fact, given the future 'minority majority' population of the United States, the field of communication risks becoming obsolete if it does begin to seriously engage race as part of our scholarship (Martin \& Nakayama, 2006).

Policy research is one area of organizational communication scholarship that may provide a fruitful avenue for the analysis of Whiteness in organizing practices. In the following section, I discuss how this project seeks to extend current organizational communication research on policy issues.

\section{Organizational Communication and Public Policy}

By taking broad public policy decision-making as an entry point to the exploration of how Whiteness is institutionalized across organizational sites, I hope to contribute to the small body of organizational communication scholarship that focuses on public and workplace policies, as will be discussed in the literature review. Current communication research in this area tends to focus on how policy 
meanings are constructed and negotiated through discursive practices of organizational members (e.g., Buzzanell \& Liu, 2005; Canary, 2010; Hoffman \& Cowan, 2010; Meisenbach, Remke, Buzzanell, \& Liu, 2008). These studies offer critical insights into how policy discourse, such as work/life or maternity policy that purports to support women and families, is taken up in ways that reproduce the organizational status quo rather than improve the lives organizational members (particularly women). While there is much to be learned from exploration of the ways that policies are enacted, there may be much to be gained by expanding our critical gaze to the production of such policies, particularly of broad public policies that transcend specific organizational sites.

The present project builds upon communication research that has engaged structurational approaches to the analysis of policy texts and communicative processes involved in policy-making (e.g., Canary, 2010; Hoffman \& Cowan, 2010; Kirby \& Krone, 2002). By denaturalizing the power-laden practices of public policy development, organizational communication scholars can enhance understanding of organizing processes at the broad systemic level and the ways these processes structure organizing at specific sites of practice. Critical organizational communication scholars have an extensive theoretical and methodological toolbox that can be aptly applied to contribute to this important conversation. In the present project, I draw upon these critical concepts to extend the use of Structuration Theory in organizational communication scholarship, particularly as applied to the study of policy making. 


\section{Project Overview}

Because of its importance in the discursive field and material practices of higher education, the Fisher v. University of Texas case is an opportunity to critically examine and destabilize the dominant affirmative action discourse as it is being deployed in the current debate around race-conscious admissions in higher education. To this end, I applied critical discourse analysis to explore the affirmative action debate as enacted in the recent Supreme Court case on the use of race in higher education admissions. As a scholarly endeavor to contest Whiteness, this analysis served to open pathways to an “oppositional consciousness" (Crenshaw, 1997, p. 257) by revealing the ongoing struggle of the discursive construction of race within this debate.

Supreme Court decisions shape and are shaped by the way society thinks about, talks about, and understands particular issues, such as race. Furthermore, these rulings serve to enable and constrain the way that affirmative action policies are constructed. Thus, Supreme Court decisions impact how race is organized in institutional life. Given this powerful constitutive force, affirmative action discourse produced within Supreme Court decision-making processes merits critical scrutiny and, therefore, served as the focus of this project. In the literature review, I provide the theoretical framework that informed my analysis as well as the constitutional terminology and brief summaries of the two landmark Supreme Court rulings on the use of race in college admissions policies. This background information informed my reading of the data collected around the Fisher case. In chapter three, I describe the method of critical discourse analysis that I used to identify the dominant and marginalized arguments that demarcate the current debate. In chapter four, I provide 
my critical analysis of the data and bring this analysis into a broader discussion about the organizing power of Whiteness. Finally, in the last chapter, I discuss potential practical applications for policy makers, lines of future research, and theoretical and methodological implications of the findings for the field of organizational communication.

\section{Conclusion}

In order to contribute to a broader discussion about Whiteness and organizing practices in the U.S., this project sought to problematize affirmative action policy discourse and denaturalize the dominant rhetoric and ideology deployed in the current affirmative action debate. My hope is that this analysis may assist higher education administrators as they contemplate the legal admissibility of raceconscious admissions policies in light of the Fisher ruling. I strongly believe that affirmative action initiatives, however problematic they may be in their current discursive formation, are essential to the growth and sustainability of our increasingly diverse society. I also believe that we need to construct policy rationales that better serve minority groups both in terms of access to higher education as well as their presence in organizations. And finally, I hope to contribute to a community of organizational communication scholars that heeds the call to confront the issue of race in our scholarship. Race continues to be a relentlessly problematic, challenging, and divisive social issue. I believe that we organizational communication scholars should use our power and privilege to help forge pathways forward out of the mire. 


\section{CHAPTER 2: LITERATURE REVIEW}

This project was guided by several overarching goals: (a) to explicate Whiteness as a central theoretical and social concern for organizational communication scholarship, (b) to encourage organizational communication inquiry into the discursive practices of one of the most influential institutions, the legal system, (c) to extend the use of Structuration Theory as a useful approach to policy analysis, and (d) to problematize the long-standing affirmative action debate in higher education. With these goals in mind, this literature review develops the historic-discursive background and theoretical framework that informed my critique of the legal debate around race-conscious admissions policies in higher education. My entry point into the affirmative action debate was the most recent U.S. Supreme Court case concerning this issue, Fisher v. University of Texas (UT), as described in chapter one. In the present chapter, I contextualize the Fisher case within the previous cases that served as legal precedent, and then I provide the sensitizing theoretical concepts that inform this project's conceptualization, methodology, and analysis. This chapter proceeds as follows.

This first part of this literature review covers the historic and discursive features of the affirmative action debate related to race conscious admissions in higher education. I start by providing a brief overview of affirmative action as a broad public policy and how it has played out in the field of education. I then define the constitutional terms and concepts needed to understand the Supreme Court rulings and their importance. With these definitions in place, I summarize the cases that serve as legal precedent for raceconscious admissions. After providing this background information, I explain the 
importance of the Fisher ruling and why it is an appropriate object of study for an analysis of Whiteness.

The rest of the chapter is devoted to laying out my theoretical and analytical framework. Giddens' (1984) Structuration Theory (ST) served as the overarching explanatory framework that informed this project. Therefore, I start that section with a brief overview of ST, discuss how it has been applied to communication research, and how I will build upon this literature. Then, I define the structurational concepts that inform my theoretical framework and discuss how these concepts operate through the mutually constitutive relationship between discourse, power, and ideology to produce subjects and objects of power-laden knowledge. With my theoretical framework in place, I develop an analytical lens that draws upon these concepts to conceptualize Whiteness as a structuring principle that produces and is reproduced by discursive structures and resources in the affirmative action debate. Finally, I summarize this chapter and present my research questions.

\section{Affirmative Action}

On June 4, 1965, President Lyndon Johnson delivered the commencement address to the Howard University graduating class in which he outlined his vision for a broad public policy that sought to redress the past harms of slavery and legalized discrimination of "the American Negro." In this speech, Johnson argued that removal of legal barriers, as provided by equal opportunity law, was not enough to achieve true equality because:

You do not take a person who, for years, has been hobbled by chains and liberate him, bring him up to the starting line of a race and then say, 'you are free to compete with all the others,' and still justly believe that you have been completely 
fair. Thus it is not enough just to open the gates of opportunity. All our citizens must have the ability to walk through those gates (Johnson, 1965, para. 12). Johnson's vision for affirmative action as a broad public policy was to create equality among races not just as "a right and a theory but equality as a fact and equality as a result" (Johnson, 1965, para. 14). To accomplish this goal of racial equality, affirmative action moved beyond addressing specific instances of disparate treatment of individuals to confronting the disparate impact of social bias on particular groups (Leiter \& Leiter, 2011). In other words, affirmative action marked a policy shift from protecting individuals against intentional discrimination to providing remedial action for past discrimination of particular groups, specifically racial/ethnic minorities and women.

In practice, affirmative action is an umbrella term for a wide array of mandated and voluntary policies and practices designed to "redress the disadvantage under which members of disparately impacted groups are said to labor" (Leiter \& Leiter, 2011, p. 1). Affirmative action policies are those that "consciously take race, ethnicity, or gender into account (to whatever extent) in making decisions about employment, admissions, or the allocation or awarding of other valuable benefits or resources" (Cose, 1997, p. 98). For example, at the federal level there are several programs and policies designed to increase contracting and procurement with women and minority-owned businesses ("Office of Federal Contract Compliance Programs (OFCCP) - Facts on Executive Order 11246 Affirmative Action," 2002). There are also programs in place to increase hiring and advancement of women and minorities in government and private sector jobs. Voting rights and fair housing laws are also subsumed under the affirmative action umbrella (Leiter \& Leiter, 2011). In higher education, affirmative action takes the form of grants, 
fellowships, training, recruitment and retention efforts geared towards advancing women and minorities. Thus, affirmative action touches nearly every institution in American life. It is also one of the most widely disputed, contested, and misunderstood public policies (Cose, 1997; Glazer, 1998; Greenberg, 2001; Katznelson, 2006; Leiter \& Leiter, 2011). Perhaps no area of affirmative action garners more public debate than the use of race-conscious affirmative action in higher education admissions policies.

\section{The affirmative action debate in higher education.}

The affirmative action debate in higher education, as played out in the legal context, is dominated by two opposing arguments. The dominant anti-affirmative argument contends that affirmative action is a form of racial discrimination, or reverse discrimination, because racial preferences create an unfair disadvantage for White students (Greenberg, 2001; Lawrence, 2001). On the other side of the debate, proaffirmative action advocates have relied primarily on the argument that racial diversity, along with other types of diversity, contributes to positive educational and social outcomes for students and society as a whole (Flagg, 2003; Lawrence, 2001; Ledesma, 2013). This diversity argument has been persuasively supported by higher education researchers (e.g., Bowen \& Bok, 1998) and has served as the primary rationale, in both legal and educational contexts, for supporting race conscious admissions. While there are other rhetorical and legal arguments engaged in the debate, these two dominant perspectives are representative of the mainstream affirmative action debate as it has played out in the major legal battles in higher education to date (Lawrence, 2001).

The legal battle over affirmative action has been waged at the state, circuit, and federal levels in a long line of tightly contested and conflicting judicial rulings 
(Katznelson, 2006; Leiter \& Leiter, 2011). The most important cases, those with the broadest impact and most power, are those decided by the Supreme Court. In terms of higher education, two landmark Supreme Court cases have served as the legal bedrock for race-conscious admissions: Regents of the University of California v. Bakke (1978) and Grutter v. Bollinger (2003). In the next section, I first explain the importance of landmark cases, define some key legal terms, and discuss the key findings in these cases as they relate to the current project's focus, the Fisher v. University of Texas (2013) case.

\section{The importance of landmark cases.}

Landmark cases are Supreme Court decisions that establish a new interpretation

on an existing law, create new case law upon which other cases may rely, and/or establish a 'test' or standard that can be applied by lower courts in their decision making (Tanenhaus, 2008). Landmark cases determine the legality and legitimacy of a particular law, principle, or policy and therefore are heavily relied upon in legal as well as policy making decisions.

As will be further explained in my theoretical framework, these landmark Supreme Court decisions serve as discursive structures and resources that shape how affirmative action can be understood, argued, and legitimized in the broader discursive field of higher education. In order to understand the landmark rulings related to affirmative action in higher education admissions, I will first define the legal concepts and terms that are most relevant in understanding the importance of these rulings; then I will discuss the importance of the cases themselves. 


\section{Constitutional concepts and terminology.}

In this section, I will delineate and define the constitutional concepts and principles needed to understand and make sense of affirmative action cases. Affirmative action cases are argued as a violation of the equal protection clause of the U.S.

Constitution's $14^{\text {th }}$ Amendment, which guarantees all U.S. citizens equal protection under the law (Tanenhaus, 2008). To uphold the equal protection clause, any laws or policies that discriminate on the basis of race or other protected classes/groups are presumed to be unconstitutional and are therefore subject to strict scrutiny, the most rigorous form of judicial review (Tanenhaus, 2008). The strict scrutiny test consists of two parts. First, the use of race must be proven as necessary to meet a state or national compelling interest. A compelling interest means that the law or policy (that considers race) is imperative or necessary to further state or national concerns, such as national security, constitutional rights, and public safety (Tanenhaus, 2008). Second, strict scrutiny requires that the race-conscious policy be narrowly tailored to meet that interest, meaning that race can only be taken into account to the least degree necessary to meet the identified compelling state or national interest. Because the consideration of race is presumed to be unconstitutional, the court has the burden of proving that the challenged policy is constitutional by applying standards of strict scrutiny to review of the case (Barron \& Dienes, 2005). As will be discussed later in this chapter, these terms ---equal protection, strict scrutiny, compelling state interest, narrowly tailored--- are a set of rules and resources that structure the affirmative action debate within the legal context. 


\section{Regents of the University of California v. Bakke.}

The first landmark case related to affirmative action in higher education was Regents of the University of California v. Allen Bakke (1978). In the Bakke case, the question before the court was whether the equal protection rights of a White, male applicant had been violated when he was denied admission to the University of California (UC) Davis School of Medicine (Regents of the University of California v. Allan Bakke, 1978). The UC Davis Medical school admissions process set aside or reserved sixteen of its one hundred openings for qualified racial minorities. Bakke's lawyers argued that these racial set-asides constituted a violation to Bakke's right to equal protection under the law because he would likely have been admitted were these 16 places not reserved for minority applicants. The California Supreme Court ruled in favor of Bakke and determined that the consideration of race in the UC Davis Medical School admissions process was unconstitutional. The case garnered broad public debate and eventually was brought before the U.S. Supreme Court (Leiter \& Leiter, 2011). In the 5-4 split decision, the Supreme Court upheld the lower court's decision and ruled that the University's policy of using racial set asides, or quotas, was unconstitutional. However, what gave this decision landmark status was its reversal of the lower court's decision on the consideration of race.

Justice Powell's opinion in the Bakke case determined that the limited use of racial preferences, but not quotas or set-asides for non-White applicants, could be applied under the standard of strict scrutiny because of a compelling interest in diversity (Leiter \& Leiter, 2001). Justice Powell argued that "the nation's future depends upon leaders trained through wide exposure to the ideas and mores of students as diverse as this 
Nation" (p. 313). Thus, Justice Powell legitimized the educational benefits produced by a diverse body of students as a compelling national interest. Justice Powell further specified that "the diversity that furthers a compelling state interest encompasses a far broader array of qualifications and characteristics of which racial or ethnic origin is but a single though important element" (Regents of the University of California v. Allan Bakke, 1978, p. 315). Therefore, Justice Powell allowed that consideration of race and ethnicity was constitutional as a 'plus' factor in an applicant's file, as long as it was considered along with other factors such as "exceptional personal talents, unique work or service experience, leadership potential, maturity, demonstrated compassion, a history of overcoming disadvantage, ability to communicate with the poor, or other qualifications deemed important" (Regents of the University of California v. Allan Bakke, 1978, p. 315). The two key ideas articulated in Justice Powell's opinion were (a) diversity of student body is important because of the education benefits that it produces and (b) race and ethnicity can be considered as one aspect of diversity. However, there was another key point produced in Bakke that continues to influence affirmative action jurisprudence (Selmi, 2002).

In reviewing UC Davis' arguments for the consideration of race, Justice Powell flatly rejected the university's stated goal of remedying past societal discrimination as a compelling interest on the grounds that it rested on "an amorphous concept of injury that may be ageless in its reach into the past" (Regents of the University of California v. Allan Bakke, 1978, p. 307). Justice Powell's concern was that the concept 'societal discrimination' could not be defined nor confined sufficiently to prevent broad abuse (Liu, 1998; Selmi, 2002). He feared that people "innocent of any actual discrimination" 
would be unfairly burdened by race-conscious policies designed to benefit victimized groups rather than victimized individuals (Selmi, 2002). Thus, the legitimized rationale for the consideration of race in the education context shifted from Johnson's remedial vision of affirmative action as a means to remedy the effects of past discrimination to affirmative action as a means to promote diversity of student body for the purpose of educational benefits for all.

The Bakke decision remained unchallenged until the Fifth Circuit court ruled against the University of Texas' law school in another case of 'reverse discrimination' brought by Cheryl Hopwood, a White woman who was not accepted to the UT's law school (Hopwood v. State of Texas, 1996). The Fifth Circuit concluded that diversity cannot be considered a compelling interest and therefore the university's rationale for race-conscious admissions did not meet the requirements for strict scrutiny. The decision effectively made the consideration of race in admissions illegal in the states under Firth Circuit jurisdiction (Kain, O’Brien, \& Jargowsky, 2005). This decision held for seven years until it was overturned in the U.S. Supreme Court's second landmark decision related to affirmative action in higher education, discussed below.

\section{Grutter v. Bollinger}

The second landmark case related to affirmative action in higher education, Grutter v. Bollinger (2003), involved a White female applicant denied admission to the University of Michigan's Law School (UM). Drawing upon the principles as laid out in Bakke, the majority opinion, written by Justice $\mathrm{O}$ 'Connor, confirmed that the equal protection clause "does not prohibit the law school's narrowly tailored use of race in admissions decisions to further a compelling interest in obtaining the educational benefits 
that flow from a diverse student body" (Grutter v. Bollinger, 2003, p. 308). In a narrow 5-4 decision wrought with judicial dissent, the court ruled in favor of the UM, thus reaffirming the constitutionality of the consideration of race in admissions policies. However, the Supreme Court heard another case in conjunction with Grutter that served to restrict the way that race-conscious admissions can be practiced.

The second case involved another White woman denied undergraduate admission to the University of Michigan (Gratz v. Bollinger, 2003). Gratz' lawyers contended that the UM's admissions policy, which automatically awarded extra points to minority students in the review process, was discriminatory and a violation of the equal protection clause. In the Gratz decision, the court again drew upon the Bakke decision, but this time ruled against UM's use of racial preferences. In a 6-3 decision, the court concluded that the point system was not narrowly tailored and violated the equal protection clause under the $14^{\text {th }}$ Amendment. In other words, the strategy of automatically giving advantage (extra points) to non-White applicants was considered too expansive an application of racial preferences.

The Gratz case helped clarify forms of racial preferences that do not meet the requirement of narrow tailoring, while the Grutter case served to affirm the constitutionality of the consideration of race. For the past decade, the Grutter decision has served as the legal basis for the consideration of race in university admissions (Lawrence, 2001; Ledesma, 2013). However, as previously noted, this was a narrow 5-4 decision that garnered several dissenting opinions. In other words, although the Grutter decision lent support for the use of racial preferences in admissions policies, the Court's 
support was tentative, limited, and contested. Therefore, it is unsurprising that the issue was brought before the Supreme Court again.

\section{The Importance of the Fisher case.}

Like the previous cases, the Fisher case involves a White college applicant challenging the constitutionality of admissions policies that provide some advantage for minority students. Unlike the previous cases, the Fisher $v . U T$ case is not a landmark case. The ruling did not change or overrule existing legal precedent on race conscious admissions as pro-affirmative action advocates feared. However, according to the opinions of legal analysts and other experts, the Supreme Court's ruling in the Fisher case in effect destabilized constitutional support for the consideration of race in college admissions, which will likely impact the way that administrators and policy makers think about, create, and apply race-conscious admissions policies (Goodwin, 2013; HannahJones, 2013; Schmidt, 2013). Although the compelling state interest in diversity was ultimately upheld in the Fisher case, the narrow ruling indicates that the rhetorical power of this discursive resource may be waning and perhaps new discursive resources, both for and against affirmative action, are emerging. Therefore, the Fisher case provided an important entry point into exploring the shifting ground in the long-standing debate as it is being enacted in the contemporary legal and social context. However, the importance

of the Fisher case goes beyond theoretical interest. This case is also a site of discursive struggle about race in America.

\section{Race and the affirmative action debate.}

With the exception of the Bakke case, the major lawsuits described above and the current Fisher case were all filed on behalf of White women, which highlights why the 
controversy around affirmative action is about race and not gender. As a group, White women have been a primary beneficiary of affirmative action policies in terms of employment (Blumrosen, 1995) and have flourished in terms of numbers in higher education as a result of these policies (Meyers \& Ríos, 2012). And yet, even though White women are beneficiaries of affirmative action, they are rarely the subject of debate when it comes to affirmative action policies in education (Cose, 1997). The fact that affirmative action preferences applied to White women are normalized, while racial preferences are so controversial, suggests that the affirmative action debate is a fruitful site of inquiry into the ways that race is discursively organized and structured by Whiteness within this field of discursive practice. However, the importance of the Fisher case extends beyond the issue of race in higher education admissions.

\section{Race and the legislative context.}

The Fisher case is part of a larger legislative agenda focused on dismantling racerelated preferences in all arenas of public policies and laws. The Fisher case was funded by a non-profit organization that explicitly seeks to "influence public policy, law, and public attitude towards race and ethnicity by financially supporting litigation that challenges voting rights laws, race-based affirmative action policies and programs, contracting preferences for women and minorities, and racial discrimination of applicants and employees" ("Project on Fair Representation," n.d.). In other words, the Fisher case is part of a broader legislative agenda that seeks to challenge the Equal Protection Clause

of the $14^{\text {th }}$ Amendment and the subsequent policies and laws that provide protections and remediation for protected classes (Hannah-Jones, 2013). In fact, the day after the Fisher ruling was handed down, the Supreme Court produced its decision on another case 
financed by the Project on Fair Representation (Biskupic, 2012). In Shelby County v. Holder, the Supreme Court reversed a key provision of the Voting Right of 1965 meant to protect Black voters from discrimination in voting practices in many Southern states. Given this legislative climate and the fact that the Supreme Court now consists of a conservative majority, including three justices who dissented in the Grutter case, the Fisher ruling must be understood as part of larger body of legislative discourse around race in the United States. In this light, although the Supreme Court's decision in the Fisher case did not have a direct or immediate impact on college admission policies, the discourse produced in this case may have a lasting impact on a new era of challenges to affirmative action. Therefore, this case served as an important entry point into this broader conversation about race and America.

\section{Early research on the Fisher case.}

Because of its potential impact on the discursive field of affirmative action in higher education, some critical race scholars have already begun the scholarly conversation around the Fisher case. In order to explore the evolution of anti-affirmative action arguments around race-conscious admissions that informed the Fisher case, Ledesma (2013) conducted a critical discourse analysis of the amicus briefs submitted in the Gratz and Grutter cases. Amicus briefs reproduce and are produced by existing and new knowledge, information, and opinions about issues in order to influence the Court's decision (Ledesma, 2013). Therefore, the amicus briefs tendered in the Gratz and Grutter cases provided a fruitful site to explore the dominant narratives engaged to "frame, contextualize, and inform the arguments in defense of, and against, the use of race-conscious policies in university admissions" that informed the Fisher case 
(Ledesma, 2013, p. 231). Ledesma's thematic analysis revealed that the dominant narratives produced to challenge race-conscious admissions framed affirmative action as discriminatory, non-meritorious, outdated, and harmful to all students. The dominant narratives engaged to defend affirmative action all centered around diversity (i.e., as a learning tool, leadership benefit, necessity to the global market place, a public good, etc.). Informed by Critical Race Theory, Ledesma (2013) concluded that anti-affirmative arguments were framed by ahistorical and acontextual understandings of the contemporary role of race and racism in shaping educational access and opportunities. In contrast, the arguments made in favor of race-conscious admissions were grounded in the "socio-historical legacy of racism and discrimination that necessitated the use of affirmative action practices in the first place" (Ledesma, 2013, p. 232). Ledesma then discussed the Justices' opinions in the Grutter ruling in light of her findings in the amicus briefs and concluded that "new challenges against race-conscious affirmative action are on the horizon and that these challenges are likely to be more nuanced than in the past" (p. 232). The Fisher case is the first of such challenges.

In order to explore the shifting discourse produced in the Fisher case and how it constructs meaning around race, Acholonu (2013) drew upon Critical Race Theory and Cho's (2009) critical framework of post-racialism to conduct a critical race discourse analysis of the transcript of the oral arguments heard in the Fisher case. After identifying the top ten words that appeared in the transcript with the most frequency (i.e., race, percent, critical mass, plan, diversity, admissions, minority, African American, etc.), Ancholuno located excerpts within the transcript that engaged these words. In his analysis of these interactions from the oral arguments, Ancholonu contended that the 
discourse produced by Fisher's lawyer and the conservative Justices relied heavily upon the logic of 'white racial innocence' and post-racial ideology, two rhetorical strategies that will be discussed further in the last section of this chapter. Ancholonu concluded that these rhetorical strategies served to distance the concepts of equal opportunity, diversity, and critical mass from the concepts of historical discrimination and power in ways that "undercu[t] the potential of affirmative action as a tool to improve the conditions for students of color" (p. 217) and reproduced the racial hierarchy within higher education.

Both of the above described articles contribute to critical perspectives on the evolving affirmative action discourse in the debate around race-conscious admissions as most recently engaged in the Fisher case. The present project built upon and extended these studies in two important ways. First, both Ledesma's (2013) and Ancholonu's (2013) critical race discourse analyses centered on anti-affirmative action arguments and did not critically examine the arguments made in defense of race-conscious admissions. In order to explore how these pro-affirmative action arguments may also contribute to the reproduction of the racial hierarchy, the present project turned its critical lens on both sides of the debate. Secondly, the previous articles analyzed specific single groups of texts related to the cases, while my analysis included multiple text groups: court briefs, the transcript of the oral arguments, and the Court's final ruling. By including the texts produced at each stage of the decision making process, I was able to analyze the data from a structurational perspective, examining how structures produced in one stage were reproduced and/or excluded in the next stages. My structurational approach to critical discourse analysis, as will be delineated in this chapter, enhanced the explanatory 
potential of both critical discourse analysis and Critical Race Theory to understand the ways that Whiteness produced and was reproduced by arguments made in the Fisher case.

As argued in chapter one, racial socio-economic inequality is a pervasive, persistent, and growing problem in U.S. society and access to higher education is intimately intertwined with this issue (Gerald \& Haycock, 2006). Given this context, the Fisher case engages "one of the most consequential legal and moral debates in American history" (Bollinger \& Steele, 2012, para. 2). On a broader level, America continues to struggle with the meanings of race, the effects of racism, and solutions to these problems in a post-Civil Rights era (Bonilla-Silva, 2001). In search of ways to better understand the problems and move the conversation forward, I now develop the theoretical framework that guided my conceptualization and approach to this project.

\section{Structuration Theory}

My theoretical framework draws upon and extends Giddens' (1984) Structuration Theory. According to Giddens (1984), structuration is the process of, and conditions for, the reproduction and/or transmutation of social systems. Structuration Theory (ST) provides a framework for conceptualizing the mutually constitutive relationship between macro-level social institutions and micro-level social interactions. It has been widely noted (e.g., Kuhn, 2012; Putnam \& Nicotera, 2009; Taylor \& Van Every, 2000) that many social science theories tend to privilege either macro-level structures or microlevel social interaction as the explanatory mechanism for understanding human organizing. ST rejects the either/or dualism and instead conceptualizes structure and social interaction as a both/and duality. As a duality, structures do not exist apart from 
the social interactions that (re)produce them. Instead, structures and social action are understood to be perpetuated in what Giddens' (1984) named the duality of structure. The duality of structure refers to the mutually constitutive relationship between macrolevel social institutions (or structures) and micro-level social interactions. Based on this concept of duality of structure, ST provides a powerful explanatory framework for understanding how institutions and social systems are produced, reproduced, and transformed over time. Because structuration occurs through social interactions of individuals within groups and organizations, it is a very useful approach for studying organizational communication processes (Poole \& McPhee, 2005; Poole, Seibold, \& McPhee, 1985; Yates \& Orlikowski, 1992).

\section{Structuration theory and organizational communication research.}

Structuration Theory (ST) can be understood as a 'meta-theory,' because rather than theorize a particular practice or phenomenon, ST provides an ontological framework for conceptualizing the holistic functioning and reproduction of entire social systems (Poole \& McPhee, 2005). ST was first introduced to organizational communication by researchers interested in group communication (i.e., Poole, Seibold, \& McPhee, 1985) and has since been taken up in a variety of ways. Some scholars have applied ST to develop new theories of organizational processes, such as institutionalization (Barley \& Tolbert, 1997) and identification (Scott, Corman, \& Cheney, 1998). ST has also been applied to enhance the explanatory power of existing theories such as genre theory (Yates \& Orlikowski, 1992), resource dependency theory (Garner, 2006), and situated activity theory (Canary, 2010). Other communication scholars applied particular structurational concepts, such as structural contradictions and unintended consequences, to understand 
issues within specific organizational contexts such as conflict in a healthcare organization (Nicotera, Mahon, \& Zhao, 2010), downsizing in a government agency (Fairhurst, Cooren, \& Cahill, 2002), and the tensions generated in at-home daycare services (Butler \& Modaff, 2008). Particularly relevant to the present study is communication research that draws upon ST to study workplace and public policies.

Organizational communication scholars have fruitfully applied ST to study how workplace policies are taken up and discursively organized among those subject to these policies (e.g., Canary, 2010; Hoffman \& Cowan, 2010; Kirby \& Krone, 2002). For example, Canary (2010) combined ST with Situated Activity Theory to understand how professionals and parents generated policy knowledge and managed structural contradictions around the federal Individuals with Disabilities Education Act. By integrating Situated Activity Theory, Canary was able to theorize and explore communication that involved learning-by-doing, or situated action, as an integral part of managing and integrating new policy knowledge. Kirby and Krone (2002), and later Hoffman and Cowan (2010), analyzed how employee discourse around work/life policy served to structure how the policy was implemented in practice. Kirby and Krone highlighted the influence of coworker discourse in the structuring of employees' choices about taking time off for family leave and how these micro-level discourses reflected broader social discourses such as individualism and meritocracy. Building upon this study, Hoffman and Cowan (2010) explored the strategies that employees engaged when asking for work/life accommodations. The dominant strategies drew upon social knowledge that served to reinforce organizational domination and foreclosed potentially transformative understandings of work/life policy. The three studies discussed here 
exemplify the application of structuration theory to the analysis of interview data to explore how policy meanings are negotiated and enacted in practice.

Rather than focus on interview data about policies, some communication scholars have applied ST to explore policy texts and production processes. For example, Olufowote (2008) conducted a structurational analysis of a series of laws regarding informed consent to treatment in medical practice to trace the (re)production and changes of meaning systems around these practices over time. His analysis revealed how sociohistoric contexts shape, and are shaped by, discourses produced through law and policy texts. Exploring this socio-historic dimension of discourse (re)production provided deeper understanding of contemporary meanings of informed consent practices and the problems that arise in enactment of informed consent laws. Olufowote's study illustrates the usefulness of taking a structurational discursive approach to analyzing the historic development of policy logics and laws.

Another fruitful approach to structurational policy analysis involved multiple types of texts and levels of discourse. Drawing upon interviews, policy texts, newspaper articles, and menus, LeGreco (2012) explored the ways that new child nutrition policy mandates structured the enactment of nutrition program practices in a U.S. school system. Her analysis revealed the tensions, unintended consequences, and paradoxes that arose as multiple stakeholders negotiated and implemented new rules and practices. Informed by structuration theory, this study highlighted the theoretical and applied utility of a discursive approach to policy discourse for exploring the relationship between policy text and policy talk in order to develop more effective and collaborative policy making and implementation practices. 
This small body of communication literature on policy discourse opens up an important line of research at the intersection of policy, discourse, and applied communication and demonstrates the utility of applying ST to discourse-centered policy research. The current project is located within this body of literature. However, while the previously cited studies focused on policy discourse at the level of its implementation and enactment by publics, my interest lies in the structuration of policy discourse at the level of its construction by those who have the power to make public policy. In other words, previous studies explored how individuals take up policies that have already been decided, while the present study focuses on the process of debating and defining policy mandates. Few organizational communication studies focus on this level of policy development (Browning \& Beyer, 1998). A notable exception is Browning and Beyer's (1998) research on intra-organizational standards setting processes in the semi-conductor industry. Rather than focus on those who must implement policies, such as in the previously cited studies, Browning and Beyer's study focused on the communicative processes of social actors who have the power to create structures that control actors in other settings, distant from them in time and space. They argued that it is important to study the process of creating intra-organizational standards because "standards are everywhere and have such substantial consequences for individuals, groups, organizations, and the whole society, how they come into being and how they are used and applied deserves careful study" (Browning \& Beyer, 1998, p. 240). This assertion applies to the present project's focus on the affirmative action policy debate in the Supreme Court, which can also be understood as a communicative process among powerful social actors that creates "standards" to which public educational institutions 
must comply. Supreme Court decision-making is an important site for the exploration of policy discourse because the assumptions, logics, and meaning systems generated at this high level of policy making have far reaching consequences. Through ST, these rulings can be analyzed as discursive resources for thought and action across organizations and throughout time and space. As will be discussed later in this chapter, Supreme Court decisions and other legal rulings serve to legitimize particular interests, while simultaneously marginalizing or obscuring others (Baez, 1999; Hasian, 1994). Therefore, analyzing policy discourse generated at this level of communicative action opens up an important area of research for critical scholars.

Despite its versatile applicability to communication research, ST has been relatively underutilized in the field (Haslett, 2013; Heracleous, 2013). In order to encourage scholars to take up this fruitful approach, a recent issue of Management Communication Quarterly featured articles and essays that highlighted new applications of ST to the exploration of communication processes at the interpersonal, organizational, and global level (Haslett, 2013). With the hope of contributing to this growing body of scholarship, the present study applied ST to theorize and analyze Whiteness, policy, and discourse. In what follows, I first define and discuss the structurational concepts that inform my theoretical framework. Then, I enhance this framework through a discussion of discourse, power, and ideology. Next, I bring these concepts together to develop a structurational-discursive framework to theorize Whiteness as an analytical lens for my project. 


\section{Structurational concepts.}

Structuration, or the (re)production of social systems, occurs through the enactment of structures, structural principles, and institutions. These concepts are not conceptually divisible, but rather are interrelated and mutually constitutive. In order to conceptualize this relationship, I will first define these terms and related concepts and then explain how they function together in the duality of structure.

\section{(Re)production of structures.}

Structures are the rules and resources that are reproduced in social practices as agents draw upon them in order to take action (Giddens, 1984). Since rules cannot be conceptualized apart from resources, they are often referred to as 'rule-resources sets.' Rules are the "techniques or generalizable procedures applied in the enactment/reproduction of social practices" (Giddens, 1984, p. 21). In other words, rules constitute a body of knowledge that guides social interaction. Resources refer to the power to enforce rules, such as authority and command over material goods, as will be further explained after discussing rules. Some rules are the tacitly agreed upon norms for how to 'go on' in the day to day activities within a social system (Giddens, 1984), such as turn-taking in conversation or standing at the appropriate distance from another person in an elevator. Other rules are explicitly codified in the form of laws and policies. Rules carry power through signification and legitimation. Signification refers to the constitutive power that generates meaning in the form of knowledge that agents draw upon in social interaction, as will be illustrated in the example below. Legitimation is the sanctioning power, or normative function, that makes people follow rules. For example, in many organizational contexts there is a normative rule or expectation regarding 
wearing a business suit to work. There is no inherent meaning in pieces of cloth sewn together; rather, signification is manifest in the implicit rule that imbues the cloth with a particular meaning (i.e., professionalism, power, respect). If a manager or employee breaks the rule and wears jeans to a meeting, he or she may be sanctioned by disapproving stares or a reputation as unprofessional, for example. And so, to maintain the reputation of professionalism, employees and managers wear suits and reproduce that normative rule.

Normative rules for behavior are manifestations of legitimation, but more formalized and explicit rules carry stronger sanctions. For example, if a student does not write a paper in Standard English or does not employ linear logic, she may receive a low grade. This example highlights the power relationship between rules and resources. As previously mentioned, rules can only function in connection with resources, the structure of domination. Domination is enacted through two types of resources: allocative (command over material goods, such as the ability to give grades) and authoritative (command over social actors, such as the ability to give instructions that are followed). Together, rules and resources (or 'rule-resources sets') carry meaning (signification), serve a normative function (legitimation), and are enforced through power (domination). Rules and resources are structures enacted in social interaction that produce and are reproduced by social systems.

According to Giddens (1984), social interaction systems do not have structures, rather they exhibit structural properties, which are both "the medium and outcome of the practices that they recursively organize" (Giddens, 1984, p. 25). In other words, structural properties and social interaction do not exist apart from each other, because 
agents must draw upon structures to take action, and structures only exist to the extent that they are drawn upon in social interaction. The mutually constitutive relationship between structures and social interaction is referred to as the duality of structure. Within the duality of structure, structures serve to both enable and constrain social interactions and practices. For example, when a student writes her paper in Standard English following linear logic as required by the structure or rule-resource set of academic writing, she reproduces that structure and thus she is enabled to succeed as student. At the same time, she is constrained by that rule-resource set, because she cannot express herself in ways that do not reproduce that structure without suffering the consequences. Often times, social actors reproduce structures as routinized practices, meaning that people do or do not do things without giving thought to how or why. Other times, social actors make conscious choices about whether or not to reproduce or contest structures; this is called agency.

For Giddens (1984), agency is the ability to reflexively monitor one's surroundings and make decisions about what to do or not do. In making decisions about action, agency always involves power and choice because the capacity "to 'act otherwise' means being able to intervene in the world, or to refrain from such intervention, with the effect of influencing a specific process or state of affairs" (Giddens, 1984, p. 14). Thus, agency is linked to both change (resisting structures) and reproduction of structures. However, Giddens did not assume a perfectly equal world in which all individuals have agency, or the ability to act otherwise, should they just be reflexive enough to do so. Rather, agency is limited or enabled by material and structural constraints or access. As will later be discussed, agency is directly linked to power because those with fewer 
constraints have more capacity to 'act otherwise' and shape the structures that they are in turn shaped by.

\section{Structural principles.}

Structural properties that are the most deeply embedded and implicated in social reproduction are structural principles. Structural principles are the "principles of organization which allow recognizably consistent forms of time-space distanciation on the basis of mechanisms of social integration" (Giddens, 1984, p.181). In other words, structural principles serve to organize social systems and are the medium and outcome of social interaction in situated practices that extend far beyond any particular instance of interaction. For example, gender is a structural principle that is (re)produced by drawing upon particular structures (rule-resource sets) related to sex, work, parenting, etc. In any instance of social interaction when social actors talk about or enact what it means to be a man or a woman, the structuring principle of gender is the condition that enabled that interaction, as well as the product of that interaction. In a sense, the structuring principle of gender pre-exists that situated moment of interaction, but gender only exists because of its consistent reproduction through interactions and institutionalized practices over time and space.

Social systems are structured by a variety of structural principles that "operate in terms of one another but yet also contravene each other" (Giddens, 1984, p.193), such as public vs. private life, free market vs. environmental protection, individual vs. group identity, globalization vs. nationalism, etc. These structural contradictions are an inherent feature of social systems that account both for reproduction and transformational processes (Giddens, 1984). Structural contradictions serve to reproduce social systems 
when they generate processes that serve to maintain the contradiction (Canary, 2010;

Poole et al., 1985). For example, people in organizations and societies depend upon rules and laws to organize social life, while at the same time they need a sense of autonomy and choice (Canary, 2010). This tension between autonomy and control may be resolved when people actively participate in the development and implementation of policies (Canary, 2010). However, sometimes oppositional tensions in structural contradictions result in change processes that create new structures. For example, new rules imposed by a policy change may require employees to change the way that certain tasks are accomplished, but previously existing structures may preclude the enactment of these new rules. As a result of this structural contradiction, new structures may emerge that resolve the tension by transforming the structure (Canary, 2010). This generative aspect of structural contradictions accounts for social and system change processes (Poole et al., 1985). However, structural principles exist in a complex matrix of power in such ways that may cancel out or dilute changes to the system, even as new structures emerge (Poole et al., 1985). In other words, structures may change, but structural principles may still endure. While previous research has revealed and critiqued structural contradictions (e.g., Butler \& Modaff, 2008; Canary, 2010; Fairhurst et al., 2002), a deeper analysis of the structural principles may provide new understandings of the dynamics that resist radical change. Structural principles that are the most enduring, deep-level, and resistant to change are, in Giddens' terms, institutions.

\section{Institutions.}

According to Giddens, institutions are structural principles that are produced by and reproduced through social interaction over long periods of time, such that structural 
principles take the form of routinized social practices. This definition implies the key role of communication in creating and sustaining institutions. To further theorize the role of communication in institutional processes, Lammers and Barbour (2006) defined institutions as "constellations of established practices guided by formalized, rational beliefs that transcend particular organizations and situations" (p.364) and are reproduced through communicative practices (i.e. routines, meetings, policies, etc.). Similarly, Phillips, Lawrence, and Hardy (2004) argued that institutions are constituted through discourse in the sense that the activities that become institutionalized practices are reproduced through discourse, defined as a "structured collection of texts that exist in a particular field and that produce the social categories and norms that shape the understandings and behaviors of actors" (p. 638). Discourses enable and constrain action through their power to "make certain ways of thinking and acting possible, and others impossible or costly" (Phillips et al., 2004, p. 638) through normative and sanctioning power. In this light, institutions are encoded into people's practical or unconscious knowledge and influence how people communicate, enact power, and determine which behaviors to reward or sanction (Barley \& Tolbert, 1997). As "historical accretions of past practices" (Barley \& Tolbert, 1997, p.99), institutions stretch across time and space serving as templates for action that are maintained and reproduced through social interaction.

To clarify, institutions are not analytically distinct from structural principles, but rather institutions are the deepest and most enduring structural principles, those that serve to organize society overall and over time. Later in this chapter, I build upon the above definitions to conceptualize Whiteness as deep-level structural principle that has endured 
through U.S. history and permeates all facets of social life such that Whiteness is also an institution.

Structuration Theory is an intricate and complex theory; the concepts outlined above only highlight the primary mechanisms involved in understanding social reproduction and change processes. As previously discussed, organizational communication scholars have been drawn to this meta-theory due to its powerful explanatory potential. However, ST is not typically used in critical scholarship (Poole \& McPhee, 2005), by which I mean scholarship that seeks to reveal and dismantle oppressive systems of power. In the following section, I explain why and how I endeavored to extend ST to such an end in this project.

\section{Extending Structuration Theory}

In order to extend ST's potential for critical scholarship, I drew upon

Foucauldian, post-structuralist, and critical theories in order to supplement and enhance Giddens' theorization of discourse, power, and ideology in structurational processes. While Giddens' did address discourse, power, and ideology, his treatment of these concepts seems tangential to or subsumed in the mechanics of the duality of structure. Although Giddens acknowledged that "[1]anguage use is embedded in the concrete activities of day-to-day life and is in some sense partly constitutive of those activities" ( $p$. xvi), he argued that the social reproduction process mainly occurs at the level of practical consciousness. Practical consciousness refers to social actors' tacit knowledge about how to 'go on' in the world, without being able to articulate the reasons or motivations for such actions. So, for Giddens, the inability to give discursive expression to motivations for action means that practical consciousness is cognitive rather than discursive. 
For Foucault, on the other hand, such a distinction between the cognitive and discursive is not possible because "knowledge and language are rigorously interwoven" (Foucault, 1971, p. 86); one cannot 'know' what is impossible to 'say.' And so, for Foucault (1971), a central question is what constitutes knowledge at a particular historical period and how this knowledge is produced through discursive practices. In contrast to Giddens, Foucault's theory of discourse and discursive practices offers a deep and complex understanding of discourse, power, and ideology as a framework for critique. However, Foucault rejected the systematic approach required by social science because of its implication in the production of knowledge as domination (Poster, 1989). Therefore, Foucault intentionally provided little guidance to applying his concepts. In order to enhance the theoretical potential of Structuration Theory for critical scholarship and to develop a systematic approach to applying Foucauldian concepts within a structurational framework, I emulated Giddens' (1984) practice of drawing upon sources from diverging traditions because "what matters much more than their origin is to be able to sharpen them so as to demonstrate their usefulness, even within a framework which might be quite different from that which helped to engender them" (p. xxii). Therefore, in what follows, I draw upon a variety of theoretical perspectives on ideology, discourse, and power to finish building my theoretical framework, which will be then be used to theorize Whiteness as an analytical construct.

\section{Ideology, discourse, and power.}

Ideology, discourse, and power are inextricably linked. In fact, Fairclough (2010) argued that these concepts are more aptly considered together as an 'ideologicaldiscursive' formation that maintains dominance through economic and 
political power. Ideology and discourse exist in a mutually constitutive relationship, maintained through power, in which "ideology provides the underlying logics which guides and constrains discourse, while at the same time discourse is the means by which ideology is continually produced and reproduced" (Mumby, 1987, p. 302). Even though these concepts can only be understood in terms of each other, I will define each of them separately to help clarify this relationship.

\section{Ideology.}

Ideology can be understood as the implicit values or logics that guide thinking and action, yet lay below the surface of consciousness and typically remain closed off to discussion (Deetz, 2005). Importantly, ideology is a system of beliefs that creates a "particular representation of the world from the perspective of a particular interest," (Fairclough, 2010, p. 46). However, the connection between the representation and the underlying interest it serves is not a transparent relationship, even though it appears to be natural or real (Fairclough, 2010). In this way, ideology, as a function of power, serves to naturalize and reify the social order by representing dominant interests as universal; denying or obscuring contradictions; and controlling actions through active consent (Giddens, 1984; Mumby, 1987). In other words, ideological assumptions are (re)produced through discourse and serve to create a particular representation of 'reality' that is a taken-for-granted norm and body of knowledge. In this way, ideology has material effects that create and sustain the power relations through the constitution of subjects and objects that populate the social world (Fairclough, 2010). Individuals are born into ideological formations and struggles for meaning produced through language (Crenshaw, 1997). Since ideology is (re)produced through discursive practices, discourse 
can be understood as the tangible form of ideology (Blommaert \& Verschueren, 1998; Fairclough, 2010).

\section{Discourse.}

Weedon (1987) conceptualized discourse as a "structuring principle of society" (p.41) that is enacted in social institutions and taken up in modes of thought and individual subjectivity. Discourses are manifestations of relations of power and political interests that constitute individuals as subjects who reproduce and/or transform discourse through social practices (Weedon, 1987). In this light, a feminist post-structuralist approach to discourse fits well with my structurational framework because it emphasizes the duality of structure between discursive structures and social interaction. To further conceptualize discourse in structurational terms, I draw upon Heracleous and Hendry's (2000) conceptualization of discourse as a mutually constitutive duality between the surface level of communicative action and the deeper level of discursive structures. These two levels are recursively linked through the modality of actors' interpretive schemes. Interpretive schemes are ways of knowing and understanding that are exhibited in both practical and discursive consciousness of social actors. Within this framework, discursive structures (rules and resources) are persistent features of discourse that "transcend individual texts, speakers or authors, situational contexts and communication actions, and pervade bodies of communication action as whole and in the long term" (Heracleous \& Hendry, 2000, p. 1266). At the level of communicative action, individuals enact agency as they draw upon and reproduce discursive structures to have their views be heard as legitimate, appropriate, and effective (Heracleous \& Hendry, 2000). In the duality of structure, communicative action (or social interaction in Giddens' terminology) 
is enabled and constrained by discursive structures, while at the same time, discursive structures are constituted and (re)produced in communicative action. For example, a teacher draws upon the discourse of 'good education' through interpretive schemes (e.g., the importance of the development of subject matter skills) in order to be constituted as a 'good teacher.' In this sense, the teacher's agency is enabled by drawing upon and reproducing the power and legitimacy of the 'good education' discourse. Thus, the teacher's agency and the 'good education discourse' exist in a mutually constitutive relationship (the duality of structure). However, at the same time that the teacher's agency is enabled, he is also constrained from drawing upon other types of logic that are not legitimate within the 'good education' discourse. For example, if he were to talk about the importance of teaching children to reject normative ideas about marriage, employment, or sexuality, he might lose his job. In this way, (re)producing the dominant discourse of 'good education' obscures or closes off other ways of thinking, seeing, and knowing about education. Because discourse carries ideological force to create and foreclose meaning, discourse and ideology are linked through power.

\section{Power.}

According to Giddens (1984), power is an inherent aspect of all social relations and is manifest in structures of signification, legitimation, and domination that both enable and constrain action. In this sense, power can be both productive (enables action) and oppressive (constrains action). Similarly, Foucault $(1977,1980)$ conceived of power as 'relations of power,' meaning that power does not exist apart from relationships and it is an inherent part of all relationships. Also similar to Giddens, Foucault conceived power as productive. Foucault (1977) theorized that "power and knowledge directly 
imply one another; that there is no power relation without the correlative constitution of a field of knowledge, nor any knowledge that does not presuppose and constitute at the same time power relations" (p. 27). In this sense, knowledge and power exist in a mutually constitutive relationship: knowledge is the medium and outcome of power relations produced in discursive practices (Weedon, 1987). Knowledge, constituted and maintained through discourse, naturalizes the world in a particular way, creating objects and subjects (Alvesson \& Karreman, 2000). Power is manifest in taken-for-granted ideological assumptions or "knowledge/power" regimes that seem fixed and naturalized (Foucault, 1978, 1980). In this way, discourse structures what can be talked about, how, and by whom, thus producing objects of knowledge (what it is possible to know) and subjects (who we are and who we can be). Hence, social actors are constituted as subjects in knowledge/power relations produced through discursive practices (Weedon, 1987).

\section{The discursive production of subjects.}

Discourses produce particular power-laden meaning systems that constitute subjects in asymmetrical relations of power (Weedon, 1987). Subjects can be understood as the personification of the particular knowledge produced in a discursive regime (Hall, 1997), such as the 'madman' produced in psychiatric discourse (Foucault, 1965). Social actors are socialized into a set of pre-existing discursive formations that function to naturalize, or make true, a set of social practices that governs who we are, how we feel, and what we believe to be true about ourselves and others (Weedon, 1987).

Policy discourse is a particularly powerful form of discursive practice in the constitution of subjects because policies are ubiquitous in organizations and often 
legitimized or mandated by law (Bacchi, 1999; Codd, 1988). Although policy language is usually presented as factual, rational, and natural, it is based on taken-for-granted assumptions involving relations of power that serve to define what is normal and abnormal (Iverson, 2010). For example, Iverson (2010) found that diversity policies produced by land-grant universities constituted minority students as 'outsiders' in relation to 'insiders' produced in discourse as the norm or standard by which outsiders are judged. Minority students were also constituted as 'at risk' in terms of academic achievement and 'victims' of discrimination who are in need of protection by the university. At the same time, diversity policy language also reproduced the language of the marketplace (i.e., effectiveness, reputation, quality), which constituted minority students as a 'valuable commodity.' In this way, the knowledge produced in diversity policies constituted the subject positions of minority students as both deficient compared to the dominant norm as well as useful to meeting instrumental goals. Although diversity policies are ostensibly created to address problems of discrimination and access to education, Iverson's analysis revealed how the discursive resources engaged in diversity policies actually served to produce the subject of minority student in a subordinated position at the service of dominant interests.

In order to de-naturalize subject positions constituted as 'truth' through discursive practices, it is necessary to understand "how and in what senses the subject becomes constituted within a particular social context or set of relations" (McKerrow, 2011, p. 257). This particular project is concerned with how racialized subjects are produced through the discursive practice of debating race-conscious admissions policies in the Supreme Court. 
In summary, discourse, power, and ideology function together to serve dominant interests (and marginalize or obscure non-dominant interests) through the naturalization of particular ways of knowing (knowledge/power) manifest in discursive practices (ways of talking or writing about something in a particular context) that produce subjects and objects of knowledge. Put in terms of ST, the interrelated concepts of discourse, power, and ideology are roughly equivalent to structural principles, deep-level systems of meaning that produce and are reproduced by structures (rule-resource sets) taken up in discursive practices and social interaction. This critical lens helps to strengthen structurational analysis by explicating the underlying, power-laden mechanisms of the duality of structure.

In the present project, I used the preceding theoretical framework based on Structuration theory and enhanced by theories of discourse, power, and ideology to (a) conceptualize and define the analytical constructs in my critical discourse analysis and (b) to theorize Whiteness as a deep-level structural principle and enduring institution. I end this section by summarizing and defining the structurational-discursive concepts and terms that guide this project's conceptualization and analysis. Then, in the following section, I proceed to develop an analytical lens of Whiteness based on this framework.

\section{Summary of Structurational-Discursive Framework}

In order to apply the above structurational concepts to communication research, I now define how these concepts were operationalized in this project. As previously defined, structural principles serve to organize social systems and are the medium and outcome of social interaction in situated practices that extend far beyond any particular instance of interaction, for example race and gender. In my framework, deep-level, 
underlying structural principles produce and are produced by discursive structures. Discursive structures are ideological meaning systems constituted by power (domination) and ideology (signification) that normalize (legitimation) particular knowledge/power regimes or ways of knowing. Discursive structures are instantiated in discursive practices through discursive resources. Discursive practices are ways of talking about particular topics (e.g., affirmative action) and/or in particular contexts (e.g., a court case). Discursive resources are the "concepts, expressions, or other linguistic devices that, when deployed in talk, present explanations for past and/or future activity that guide interactants' interpretation of experience while molding individual and collective action" (Kuhn, 2006, p. 1341). In other words, discursive resources are the logics, rationales, and arguments that people draw upon to persuade others of the legitimacy of their reasoning or desires. The relationship between these discursive structurational concepts is as follows: When people talk about issues, ideas, or concepts in a given context (discursive practice), they pull from particular logics, rationales, and ways of knowing (discursive resources) that emerge from and reproduce legitimized forms of knowledge/power (discursive structures), which in turn are also produced by and reproduce dominant systems of ideological meaning (structural principles). This latter part of this mutually constitutive relationship (re)produces institutions, defined as routinized communicative practices that transcend particular organizations and situations. In the following section, I build upon Giddens' (1984) concept of structural principles and institutions to theorize Whiteness as an analytical lens. 


\section{Theorizing Whiteness}

The purpose of this section of the literature review is to develop Whiteness as an analytical construct to be applied in my critical analysis of the Fisher case. To this end, I first define Whiteness and explain how it is analytically different from, but also dependent upon, the concept of race. Then, I conceptualize Whiteness in terms of my theoretical framework. Specifically, I theorize Whiteness as a structural principle and enduring institution that emerges in discursive structures and resources, as previously defined. As will be discussed, Whiteness is an elusive and challenging concept to apply because of its naturalized position of dominance. Therefore, in order to illustrate how Whiteness has emerged thus far in the discursive practice of arguing for and against affirmative action, I end this section by drawing upon existing critiques of Whiteness in the affirmative action debate. This historic-discursive background informed my critique of the current case.

\section{Defining Whiteness and race.}

As a way of seeing and understanding the world, Whiteness is an embodied standpoint (of White people) that constitutes practical knowledge about how to 'go on' in social practices (Owen, 2007). Whiteness is not a race, but it served to create the knowledge/power regime from which race is (re)produced as a discursive structure and resource. Race can be understood as a system of hierarchically structured categories of difference, as well as a system of social relationships, that delineates the subjectivities of White and non-White subjects (Haney-López, 2006). Race has also been defined as a social construction that is constituted and (re)produced through social practices and discourses that are historically situated, contingent, and fluid (Frankenberg, 1993; Haney- 
López, 2006; Horton, 2005; Omi \& Winant, 1986). Legal decisions are the primary discursive practice through which the concept of race has been historically constructed and legitimized (Haney-López, 2006; Harris, 1998).

Early definitions of race were constructed in the courts and defined in biological terms. For example, the "one drop of blood rule" legally defined people as negro if they had any African ancestry and; in turn, a "white person" was defined as a "person who has no trace whatsoever of any blood other than Caucasian"("Racial Integrity Act of 1924," 2012, pt. 5). This dualistic, biological categorization was deployed in a series of naturalization, anti-miscegenation, and Jim Crow laws that served to fix racial identities in relation to rights and privileges (Haney-López, 2006). In this way, these laws served not only to legalize and reify racial categories, but also created a system that "defined and affirmed critical aspects of identity (who is white); of privilege (what benefits accrue to that status); and of property (what legal entitlements arise from that status)" (Harris, 1998, p. 104). From this historical-legal perspective, Whiteness can be understood as a powerful ideology that served to rationalize, legalize, and legitimize the meaning of, and value ascribed to, those who were defined as White and those who were not. In this way, race is a socially constructed category of identity and difference produced through Whiteness and, in turn, Whiteness is the medium and outcome of legal decisions about racial classifications. Thus, in ST terms, Whiteness, as a structural principle, structured and was structured by the discursive structure of race engaged through discursive legal practices.

Although biological definitions of race have largely been replaced by cultural, ethnic, and social conceptualizations (Haney-López, 2006; Omi \& Winant, 1986), race 
continues to persist as a meaningful system of social practices that is "organized and enforced by the continuity and reciprocity between micro-level and macro-level of social relations"(Omi \& Winant, 1986, p. 67). For example, the process of racial classification based on physical features and ancestry continues as institutionalized practice in almost every area of U.S. society including education, government, health care, etc. (Yanow, 2003). Individuals perpetually reproduce and are reproduced by racial classifications every time they fill out a form and check a box that defines their racial identity. In ST terms, race can be understood as a reified social construction and a dominant discursive resource in U.S. society that has been created and sustained through legal decisions and subsequent policies that produce advantage for White people (Haney-López, 2006; Katznelson, 2006). However, the structural advantage of Whiteness is not explained nor maintained through law alone.

To understand the enduring power of Whiteness, it is useful to conceptualize it as a set of interconnected dimensions. First, Whiteness is a social position of structural advantage or race privilege (Frankenberg, 1993; Owen, 2007) meaning that economic, social, political, and cultural arrangements serve to advantage people who are defined as White relative to those who are not. Second, Whiteness is a particular, limited, and unacknowledged standpoint or perspective from which White people understand themselves, others, and society (Frankenberg, 1993; Owen, 2007). And third, Whiteness is a set of unmarked cultural practices that are defined as natural, normal, or mainstream (Frankenberg, 1993; Owen, 2007). For example, concepts such as etiquette, professionalism, and beauty are defined by White standards (Butler, 2012). Thus, in terms of ST, these dimensions of Whiteness, which generally remain invisible to White 
people, serve to constitute a body of practical knowledge about how to 'go on' in the world (Owen, 2007).

\section{Revealing Whiteness in discursive practices.}

As a structural principle and institution, Whiteness is manifest as a set of culturally embedded discursive practices, marked as universal or mainstream, that function to naturalize and reify the social order (Frankenberg, 1993; Haney-López, 2006; Okun, 2010; Owen, 2007). In the U.S. context, Whiteness invisibly emerges in terms that are discursively engaged as universal markers of a type of cultural knowledge, but are in fact representations of Whiteness, such as 'Western' or ‘American' (Frankenberg, 1993). In discursive practices, Whiteness emerges and is obscured through a variety of rhetorical strategies that serve to render Whiteness both universal and invisible (Frankenberg, 1993; Nakayama \& Krizek, 1995). Because of its invisibility and universality, Whiteness is usually only discussed in relation to different 'others' (Nakayama \& Krizek, 1995). Therefore, texts that address issues of race or diversity provide a fruitful site to analyze how Whiteness emerges in discursive practices.

In an interpretive analysis of diversity management texts, Grimes (2002) identified two strategies that functioned to obscure Whiteness: re-centering and masking. Re-centering emerged in texts that employed the progressive language of inclusivity and embracing difference, yet functioned to re-center Whiteness by implicitly framing it as the norm. For example, an article arguing for inclusionary management practices continually used the term 'non-traditional manager' to refer to managers who were not White, thus reinforcing the White/other dichotomy. 
While re-centering functioned to maintain Whiteness as the norm, masking whiteness actively preserved the invisibility of Whiteness (Grimes, 2002). According to Grimes, the strategy of masking Whiteness was analytically difficult to pull out from the texts because Whiteness was obscured, naturalized, and implicit. In other words, Whiteness was manifest in what was not said, rather than in what was said. The most blatant types of masking Whiteness that Grimes identified were (a) conflating Whiteness with 'American' (i.e., describing a manager as American, rather that identifying him as White) and (b) focusing on individualism rather than group identities (e.g., ignoring group experiences of racial minorities). Grimes' analysis highlighted two of the defining and contradictory features of Whiteness. On one hand, re-centering functioned to place Whiteness at the center as the norm. In in this sense, Whiteness was discursively constructed as universal. On the other hand, masking Whiteness served to hide its position of dominance, which functioned to make Whiteness invisible.

Nakayama and Krizek (1995) argued that the positioning of Whiteness as both invisible and universal is a rhetorical accomplishment, which they described as a strategic rhetoric. In order to deconstruct Whiteness as the center from which 'Others' are produced and organized, Nakayama and Krizek (1995) traced the ways that Whiteness is constituted in everyday language. Informed by Foucault's (1989) concept of power as manifest through discursive formations, they explored the discursive formation of Whiteness by drawing upon a multiplicity of texts including interviews, survey data, and popular culture articles. Their analysis revealed various rhetorical strategies that maintained Whiteness as both the invisible and universal center. For example, White people discursively constructed their race as a 'non-ethnicity' or 'non- 
color,' something that cannot be named except in contrast with what it is not. In this way, Whiteness was conceptualized in everyday language as natural or the norm, thus eluding any recognition of the power relations within which it is embedded.

Universality and invisibility are the central and contradictory features of Whiteness that serve to maintain its subject position of dominance. Therefore, in order to reveal how Whiteness emerges in discursive practices, analysis must focus on taken-forgranted knowledge, logics, and assumptions as well as knowledge, logic, and assumptions that are marginalized or obscured by dominant structures. Understanding how Whiteness emerges in discursive practices only sheds light on part of the (re)productive process. In order to understand how Whiteness functions in the overall reproduction of a racialized social order, I draw upon ST to conceptualize Whiteness as a deep-level structural principle.

\section{Whiteness as a structural principle.}

Conceptualized within ST, Whiteness is a deep-level structural principle constituted and reproduced through discourse, power, and ideology. As a deep-level set of ideological assumptions, beliefs, and normative rules, Whiteness:

shapes the consciousness of individuals and hence the cognitive and evaluative frameworks for action, the patterning of social practices, the terms and rules for the operation of social institutions of the economy, the educational system, the legal system, the representations of value that define the culture and so on. Thus, whiteness systematically informs --and deforms---every aspect of the social world (Owen, 2007, p. 208). 
In this way, Whiteness functions as an enduring structural principle through the (re)production of ideological meaning (signification), norms (legitimation), and power (domination) manifest in unconscious and practical knowledge. As a structural principle, Whiteness emerges through dominant, ideologically-laden discourses or structures (ruleresource sets) that organize the totality of society through social interactions and institutionalized practices. Thus, Whiteness is a structural principle that has been reproduced through time and space and serves to organize the overall racialized social order. Therefore, Whiteness also must be understood as an institution. In what follows, I discuss various discursive structures, or underlying logics, that emerge from and reproduce Whiteness as an institution.

One of the ways that the institution of Whiteness is produced and reproduced is through ideologically-laden discursive structures that constitute a body of practical or common sense knowledge shared broadly and overtime in social practices. Okun (2010) identified three dominant discourses produced by and reproducing of Whiteness: right to profit, individualism, and binary thinking. Okun (2010) defined the 'right to profit' discourse (or discursive structure in my theoretical framework) as the unquestioned values and assumptions produced throughout the history of U.S. socio-economic development that serve to maintain the domination of Whiteness. The 'right to profit' discursive logic is based on capitalist ideology that (re)produces the cultural beliefs that the ability to make a profit is a right, not a privilege, and that more of everything (e.g., income, consumption, material goods) is better. As a discursive structure, the right to profit is (re)produced through culturally dominant discursive resources such as profit, success, marketplace, workplace, competition, and consumption. This profit motive 
generates a "cultural ethos of production at all costs" (Okun, 2010, p.11) that has justified a long history of White dominance.

Every period in U.S. history is marked by policies, laws, and narratives that produced, and continue to produce, an accumulation of wealth for White people at the expense of non-White people (Okun, 2010). Starting with colonization, slavery, westward expansion, the industrial revolution, all the way to today's neo-liberal trade policies, the right to profit has served as the legitimized rationale for the commodification and exploitation of workers, particularly people of color (Okun, 2010). Today, the right to profit is manifest in widely held cultural ideals around wealth and consumption that both perpetuate and obscure White cultural, economic, and political dominance. The right to profit creates a set of values and ideals that encourages and is maintained through the discursive structure of individualism.

The second discursive manifestation of Whiteness ideology that Okun (2010) identified was individualism. In the U.S. culture, individualism is "synonymous with personal self-reliance, with individual merit irrevocably connected to (deserved) wealth" (Okun, 2010, p. 16). Individualism emphasizes individual rights and freedoms, as well as an equality of opportunity for material success. Individualism runs deep in (White) American ideology exemplified by dominant discursive resources such as rugged individualism, the level playing field, and the bootstrap theory (Okun, 2010). Individualism is tightly intertwined with the right to profit discursive logic.

The need for continued economic growth has opened the doors for some individual members of historically targeted and oppressed groups to access the pathways to individual upward mobility. Thus, even while the majority of non-White communities 
remain exploited and underserved, the fact that some individual people of color have accessed the benefits and privileges previously reserved for White people provides evidence for the myths perpetuated by individualism. The discursive resources produced by individualism, such as merit, credit the individual with success and, thus, create a set of values that encourages people to buy into the policies and ideals that perpetuate the production of wealth for some and the reproduction of inequality for others (Okun, 2010).

The third discursive manifestation of White ideology identified by Okun (2010) is binary thinking. Binaries serve to reify power by demarcating particular boundaries that are almost always hierarchically structured (Weedon, 1987). Male/female, gay/straight, White/non-White, immigrant/American are all sets of terms that impose a 'center' and create an 'other.' As a naturalized system of thought, binary thinking perpetuates power differentials and the systemic subjugation of those constituted as 'other.' For example, in the previous section on the discursive production of subjects, minority students were constituted by an outsider/insider binary within diversity policy discourses. Again, these are not just categories of difference, but rather one term is structurally advantaged over the other. Thus, the agency of social actors is enabled and constrained by the logic of binary thinking.

Together, right to profit, individualism, and binary thinking serve as a powerful system of meaning and logic that both maintains and obscures Whiteness. These deeplyembedded unacknowledged structures (rules and resources) are part of the body of practical knowledge that individuals draw upon as they go about daily life and engage in discursive practices. These discursive structures are (re)produced through discursive resources that are broadly understood as true, real, and valid. Thus, drawing upon and 
reproducing these underlying logics enables and constrains agency in social practices. In this way, Whiteness produces and is reproduced by a naturalized system of meaning that serves to organize society in such a way that success is defined by material consumption; individuals are solely responsible for their success or failure; and systemic dominance is naturalized through binary logic.

Another newly emerging system of meaning that Whiteness produces and is reproduced by is post-racial ideology. Post-racial ideology, or post-racialism, is a "twenty-first century ideology that reflects a belief that due to racial progress the state need not engage in race-based decision-making or adopt race-based remedies, and that civil society should eschew race as a central organizing principle of social action" (Cho, 2009, p. 1589). Cho (2009) conceptualized post-racialism as a descendent of 'colorblind' ideology that does similar ideological work in centering Whiteness, but does so in a slightly different, and perhaps more dangerous, way. Cho argued that while colorblindness offers an aspirational ideal for moving away from consideration of race, post-racialism contends that society has transcended race. In other words, colorblindness is based on the idea that race should not matter, while post-racialism contends that race did matter, but society has evolved past it. In the end, however, colorblindness and postracialism do the same ideological work.

Similar to colorblindness, post-racialism functions as an ideological discursive resource that serves to maintain White privilege and Whiteness in three main ways. First, post-racialist ideology serves to obscure the centrality of race as an organizing principle by insisting that race no longer matters. Second, the discourse of post-racialism "provides a common-sense rhetoric and reasoning to fuel the state's retreat from racial 
remedies"(Cho, 2009, 1595), such as race-based affirmative action, race-based admissions, and voting rights. And third, post-racialism serves to maintain White normativity by "disaggregating unjust enrichment and complicity from whiteness through the redemptive and symbolic "big event" of racial transcendence" (p.1596). Both colorblindness and post-racialism contend that race should no longer be taken into account or even noticed. However, while colorblindness looks back to the Constitution and the Civil Rights era for its discursive resources, post-racialism looks forward.

Cho (2009) outlined four key features of post-racialist discourse: racial progress, race-neutral universalism, moral equivalence, and a distancing move. The first discursive structure or logic is racial progress, which asserts that "racial thinking and racial solutions are no longer needed because the nation has 'made great strides,' achieved an historic accomplishment, or transcended racial divisions of past generations (Cho, 2009, p. 1601). The second discursive resource produced by post-racial ideology is raceneutral universalism, which demands a post-racial norm that frames racial remedies in the United States as "partial and divisive, and benefiting primarily those with 'special interests' versus all Americans" (Cho, 2009, p. 1602). Instead, post-racialism calls for race-neutral laws and policies that seek to remedy broader issues such as social class. The third discursive logic identified by Cho (2009) is moral equivalence, which posits that any consideration of race is inherently wrong. By this logic, race-conscious admissions policies are equally as unconscionable as racial profiling in traffic stops, for example. And finally, a distancing move refers to the strategic rhetorical moves away from civil rights language and logics, such as the transition from 'remedy' to 'diversity' as a discursive resource in the affirmative action debate. In terms of my theoretical 
framework, racial progress, race-neutral universalism, moral equivalence, and a distancing move are conceptualized as discursive structures or logics produced by and that reproduce the structural principle of Whiteness.

As argued in this literature review, Whiteness functions below the level of consciousness; it is enacted through naturalized, normalized, taken-for-granted assumptions embedded in our practical knowledge about how to go on in the world. As an invisible yet universal ideological construct, Whiteness emerges implicitly through discursive logics such as individualism, right to profit, binary thinking, racial progress, race-neutral universalism, moral equivalence, and a distancing move away from racial remedies. Given the rhetorical force of these dominant and legitimized logics, even those with the best intentions may unconsciously perpetuate Whiteness as they engage in work to support racial equality (Baez, 2000; Frankenberg, 1993; Lawrence, 2001; Okun, 2010). Therefore, this project aims to reveal how Whiteness, as a deep-level structural principle and enduring institution, produced and was reproduced by discursive structures and resources engaged on both sides of the affirmative action debate in the present context.

\section{Whiteness, Discursive Resources, and the Affirmative Action Debate}

As delineated in the previous section on ST, discursive resources are ideas, values, logics, and norms that are drawn upon in discursive practices in order to have one's claims be understood as valid and legitimate (Heracleous \& Hendry, 2000). In what follows, the rhetorical strategies used in the affirmative action debate are conceptualized as discursive resources that are manifestations of the structural principle of Whiteness. The purpose of this section of the literature review is to illustrate how 
Whiteness emerges in the dominant discursive resources that have sustained the debate thus far, which will serve to inform my analysis of the current case.

The two sides of the debate are usually categorized as conservative vs. liberal or anti-affirmative action vs. pro-affirmative action. The majority of literature focusing on affirmative action rhetoric is aimed at critiquing conservative arguments. Therefore, in this section, most of the discussion centers on critiques of three dominant anti-affirmative discursive resources: innocence and fairness, merit and the American Dream, and colorblindness. On the other side of the debate, diversity is the dominant discursive resource because it is the legitimized argument that has thus far served to maintain the legality of race-conscious admissions. Because of its dominance in the discursive field, diversity will also be discussed as a manifestation of Whiteness. And finally, I end this section with a discussion of post-racialism as an emerging discursive resource engaged by both conservatives and liberals within the debate about race, inequality, and raceconscious public policies in America. I begin with a critique of anti-affirmative action discursive resources.

\section{Innocence and fairness.}

One of the dominant arguments engaged by conservatives against race-conscious admissions is that the preferential considerations given to minorities are unfair (to White students). The rhetorical force of this argument is built upon the discursive structure of individualism that produces the discursive resources of fairness and innocence, or what Ross (1990) calls the rhetoric of innocence. The rhetoric of innocence functions based on an understanding of discrimination as an individual act perpetrated by one person onto another, which creates a two-fold argument. First, conservatives conclude that it is unfair 
that White students, innocent of any wrong doing, are being punished for previous instances of past discrimination. Second, in contemporary society, minority students are not 'actual victims' of slavery or Jim Crow laws and therefore are 'undeserving' of special consideration (Ross, 1990). In this way, the rhetoric of innocence, as a discursive resource, constitutes the subject position of the White person as an innocent victim of unfair admissions practices. As innocent victims, White subjects are also implicitly constituted as innocent of race, a racial perspective, racism, and a legacy of benefits perpetuated by racism (Hunt, 2005). The rhetorical construction of innocent White victim simultaneously implies its rhetorical opposite "the undeserving black taker" (Ross, 1990, p. 310) who benefits from special treatment at a cost to White students. Flagg (2003) argued that the rhetorical frame of 'undeserving' as applied to African American students is not only a reference to their lack of 'actual victimhood,' but their lack of 'standardized' qualifications for access to elite universities. In this later rhetorical usage of undeserving, conservative arguments draw upon another powerful set of intertwined discursive resources: merit and the American Dream.

\section{Merit and the American Dream.}

The ideals, logics, and assumptions of meritocracy and the American Dream emerge from the discursive structures of individualism and right to profit. The American Dream consists of an even playing field upon which individuals can achieve upward mobility if they work hard enough and have enough skill or talent to succeed (Hochschild, 1996). Those who pursue the American Dream must believe they have the ability to make it if they work hard enough. Those who 'win' in this game cling tightly to the belief that their success was won based upon individual merit (Hochschild, 1996). 
By extension, those who fail to achieve success do so because of their lack of ability or some other justifiable cause (Cose, 1997; Frankenberg, 1993; Okun, 2010). By this logic, conservatives argue that all college applicants should be judged on their ability to meet the (supposedly neutral) standards set by universities and that the preferential consideration provided by affirmative action is antithetical to fairness, merit, and the American Dream.

In the current context of higher education admissions, standardized test scores are one of the dominant criteria used to measure 'merit'(Alon \& Tienda, 2007). Alon and Tienda (2007) explained that the dramatic increase in the valuation of test scores as a proxy for merit came about after the turn of the century when colleges and universities saw sharp increases in applications after introduction of the GI Bill. Given the increased competition, standardized testing was originally introduced in order to identify and provide opportunity for talented students from disadvantaged backgrounds. However these tests have actually had the opposite result (Lemann, 2000). Research has shown that due to a variety of factors, economically disadvantaged students, who are disproportionately Black and Latino, score lower on standardized admissions tests than their White counterparts (Bowen \& Bok, 1998). Race-conscious admissions were meant to remedy this gap, which is why anti-affirmative action advocates argue that such policies run counter to merit and fairness. Such arguments contend that performance on the tests is an objective assessment of merit and other considerations, such as racial preferences, for admissions undermine the principles of fairness. However, in a statistical analysis of university admissions practices, Alon and Tienda (2007) found that the "seemingly inevitable tension between merit and diversity exists only when merit is 
narrowly defined by SAT scores" (p.508). In other words, there are other standards by which to define merit and by constraining the meaning of merit to test scores, which advantage White students, merit is engaged as a discursive resource that both obscures and maintains White privilege.

\section{Colorblindness.}

The third dominant discursive resource that has been perpetuated in the affirmative action debate is the concept of 'colorblindness' (Cose, 1997; Morrison, 1993). The term 'colorblind' was born out of the civil rights movement and was meant to conjure a vision for a society in which the color of one's skin did not bestow privileges or obstacles (Cose, 1997). Opponents of affirmative action appropriated the ideal of colorblindness as the basis of their moral argumentation. Pointing to the historical injustices perpetuated through racial classifications, conservative arguments contend that any consideration of race is inherently problematic and must not be inscribed upon laws and policies (Morrison, 1993). The discursive resource of colorblindness drawn upon in conservative arguments does not distinguish between consideration of race to exclude individuals from access to institutions and those designed to include them (Morrison, 1993). In fact, conservatives argue that any consideration of race is in itself racist (Cose, 1997) and therefore racial preferences for minorities constitute racial discrimination against White applicants (Baez, 1999; Cummings, 2005; Glazer, 1998; Greenberg, 2001). The rhetorical logic of colorblindness evokes an ideal of sameness under which all people have an equal chance to succeed.

In this section, I have highlighted some of the dominant discursive resources that have been drawn upon in anti-affirmative action arguments. In terms of my theoretical 
framework, these discursive resources are the logics, assumptions, and values that emerge from and constitute discursive structures such as individualism and right to profit, which are understood as manifestations of Whiteness as a structuring principle. I now turn to the liberal, or pro-affirmative action, side of the debate.

\section{Diversity}

The liberal argument for affirmative action is based upon the diversity rationale as produced by the Grutter (2003) decision (Chang, 2005; Flagg, 2003; Lawrence, 2001; Ledesma, 2013). As previously explained, the decision in Grutter argued that diversity in the student body represents a compelling state interest because "diversity promotes learning outcomes and better prepares students for an increasingly diverse work force, for society, and for the legal profession" (Grutter v. Bollinger, 2003, p. 308). The logic of this argument can be understood as 'the business case' for diversity because it draws upon a market-driven rationale to bolster support for diversity initiatives (Litvin, 2006; Mease, 2012; Perriton, 2009), including race-conscious admissions. The Grutter opinion further relied on the business-case rationale by arguing that "[m]ajor American businesses have made clear that the skills needed in today's increasingly global marketplace can only be developed through exposure to widely diverse people, cultures, ideas, and viewpoints" (Grutter v. Bollinger, 2003, p. 308). In this way, the rationale for diversity in higher education is entwined with capitalist discourses that serve economic interests. Ironically, the business case for diversity, which now serves as the dominant rationale for the compelling interest in support of race-conscious admissions, was born in the corporate environment in response to a backlash against affirmative action. 
The 1960's and 70's were marked by landmark legislation such as Title VII (Civil Rights Act) and the Equal Employment Opportunities Act. In this time period, social justice, anti-discrimination, and employee empowerment were the central discursive forces behind workplace diversity practices (Prasad, 2001). The 1980's, however, were marked by the rise of neoliberal policies and values focused on individuality, market forces, and merit, which generated a backlash to affirmative action policies and practices (Kelly \& Dobbin, 1998; Litvin, 2006; Prasad, 2001). In response to this backlash against the idea of 'protected groups' deserving of special consideration, consultants who had previously worked with organizations on matters of affirmative action and EEOC regulations, changed strategy and began to promote the 'business case' for diversity (Kelly \& Dobbin, 1998).

The business case for diversity draws upon enlightened self-interest and concern for the bottom line (Litvin, 2006). The rationale for the business case is that diversity, when effectively managed, can lead to a more productive workforce, a broader, happier customer base, and a competitive advantage in the marketplace (Litvin, 2000, p. 9). These pragmatic, instrumental arguments became the primary tools for 'selling' diversity services and products to managers and making the case to employees (Kirby \& Harter, 2001; Litvin, 2000, 2006). Through the (re)production of diversity texts and practices in the corporate world, the 'business case' has become the taken-for-granted logic and the dominant discourse behind many diversity efforts and initiatives. By drawing upon the business case for diversity, the Grutter decision served to legitimize this rationale in higher education as well. 
Although the diversity rationale is engaged to support race-based practices, such as race-conscious admissions, the above discussion suggests that the business case logic of diversity serves to maintain dominant interests, or the status-quo of power relations. Thus, it is important to problematize both sides of the affirmative action debate. In a Foucauldian analysis of affirmative action in employment, Yount (1993) argued that both liberal and conservative arguments serve to rationalize current power/knowledge positions by focusing the debate within a narrow range of market modifications that are defined by and designed to benefit the existing system of differential power. In this light, the struggle between conservative and liberal sides of the debate is then a struggle about which view will count as 'the norm,' not which view will subvert the norm. Yount (1993) concluded that liberal arguments act in collusion with conservative ones because liberal affirmative action solutions "only contest the mechanisms, and not the more encompassing structure they all accommodate" (Yount, 1993, p. 211). In other words, the way that affirmative action is problematized within the conservative/liberal debate in the discursive field of employment policies served to (re)produce the existent knowledge/power regime around the meanings of and rationales for affirmative action policies.

The liberal argument in higher education may function the same way. The diversity rationale invites 'others' into the system so that they might contribute to and benefit from an elite education, but it fails to question the way that existing criteria and processes perpetuate race and class privilege (Lawrence, 2001). In this light, by drawing upon the business case for diversity as the dominant rationale for race-conscious 
admissions, liberal arguments may actually serve to reproduce the structuring principle of Whiteness.

\section{Summary and Research Questions}

Within the theoretical framework of this project, Supreme Court decisions are understood as a powerful form of discursive practice that (re)produces dominant discursive resources that serve to structure how race can be talked about, understood, and enacted in the context of higher education. Furthermore, the dominant discursive resources (re)produced on the discursive field of the affirmative action debate in the Supreme Court are conceptualized as manifestations of Whiteness, defined as a deeplevel structural principle and enduring institution perpetuated through discourse, power, and ideology. By nature of its privileged structural position (domination), Whiteness functions ideologically as a set of dominant underlying beliefs, values, and assumptions that constitute meaning (signification) and norms (legitimation). In this way, Whiteness, as a structural principle, emerges through discursive structures that enable and constrain discursive practices that serve to maintain its invisibility and universality. Therefore, in order to unmask and denaturalize Whiteness as a structuring principle in the affirmative action debate, this research project asked:

RQ \#1: How was the deep-level structuring principle of Whiteness producing and reproduced by the discursive practice of debating race-conscious admissions in the Fisher case?

Structured by Whiteness, legal rulings serve to "construct races through legitimation, affirming the categories and images of popular racial beliefs and making it 
nearly impossible to imagine non-racialized ways of thinking about identity, belonging, and difference" (Haney-López, 2006, p. 125). The discursive practice of law and policymaking serves to both construct and constrain the meanings of identities and the possibilities of social relations. Therefore, in order to reveal the underlying assumptions, ideas, and beliefs about race perpetuated in the affirmative action debate, the second question addressed was:

RQ \#2: How are White and non-White subjects constituted within the discursive practices of the Fisher case?

Despite the stability of Whiteness as a dominant structuring principle, it is not a reified, consistent, uncontested discursive structure. As Weedon (1987) argued:

Discourses represent political interests and in consequence are constantly vying for status and power. The site of this battle for power is the subjectivity of the individual and it is a battle in which the individual is an active but not sovereign protagonist. (p.41)

In other words, human subjects are not fully constrained by discourse and, in turn, discursive structures are susceptible to change through discursive practices. As the various participants in this debate enact agency by participating in this discursive practice, they consciously and unconsciously (re)produced particular discursive resources that may serve to reproduce, resist, and/or transform the structuring principle of Whiteness. By articulating structural contradictions that emerge in discursive practices structured by Whiteness and surfacing marginalized discursive resources, the structural power of Whiteness may be weakened and new possibilities for structural change may open up. Therefore, the final question this project explored was: 
RQ \#3: How might marginalized discursive resources and structural contradictions in the debate serve to de-center the normative power of Whiteness in the affirmative action debate?

\section{Conclusion}

In this literature review, I argued that the language and logics perpetuated through time and space in the decades old affirmative action debate are manifestations of discourse, power, and ideology that function together to (re)produce racial inequality. As a structural principle, Whiteness is the medium and outcome of structures of signification (meaning), domination (power), and legitimation (norms). As enacted in discursive practices, Whiteness is the standpoint from which "racial reality is interpreted, articulated, legitimized, conceived and imagined in juridical, political, and public discourse" (Hunt, 2005, p. 483). The privileged subject position of Whiteness is maintained, and potentially disrupted, through discursive practices that draw upon discursive resources, or practical and discursive knowledge, that serve to perpetuate its invisibility and universality (Nakayama \& Krizek, 1995).

The purpose of this current project was to explore and critique how Whiteness served as a structural principle that was drawn upon, reproduced, and/or contested as pro and anti-affirmative action proponents constructed arguments around if, how, and why race should be considered in higher education admissions policy. The affirmative action debate is not only a material issue about access to higher education. The debate is also a discursive field within which meanings of race and racialized identities become institutionalized discursive structures. However, the meanings of race and racialized identities are not fixed, but rather should be understood as the product of historically 
contingent discursive processes (Frankenberg, 1993; Omi \& Winant, 1986). By exploring the shifting and evolving discursive structures and resources that sustain the affirmative action debate through historic processes of (re)production, the vulnerability of such dominant structures can be exposed and thus opened to the possibility for redefinition, negotiation, and change (Baez, 2000). This project was motivated by an explicitly emancipatory agenda in that I sought to unmask and de-center Whiteness as a dominant yet invisible structuring principle. My hope is that by bringing an understanding of Whiteness to discursive consciousness, practitioners, advocates, policy makers, and scholars might create and engage new discursive resources within the discursive field of the debate.

In addition, this project was intended to contribute to organizational scholarship in two important ways. First and foremost, I hope to encourage scholars to critically address and theoretically integrate race into the ways that we study and understand organizational processes. Secondly, I hope to expand the discipline's gaze to the situated practices of organizing at the broad social and intra-organizational levels, such as public policy making. These ambitious goals are supported by the explanatory power of Structuration Theory. 


\section{CHAPTER 3: METHODOLOGY AND METHODS}

Inspired and informed by feminist scholarship that seeks to reveal and destabilize masculine ideology in organizing practices (e.g., Acker, 2006; Ashcraft \& Mumby, 2004; Tyler \& Cohen, 2010; West \& Zimmerman, 1987), I believe that Whiteness, as a dominant ideology, must also be explicated and denaturalized, so that its oppressive dominance can be disrupted and challenged. To this end, my methodological approach is informed by Structuration Theory (ST) and feminist post-structuralist theories of discourse in order to explore and critique how Whiteness is created and sustained through structurational processes involving discourse, power, and ideology in the affirmative action debate.

Although I do not draw directly upon traditional critical theories (e.g., Marxism), this project is firmly and unabashedly located within the critical paradigm, or discourse of "suspicion," which seeks to explore and reveal issues of power and ideology in the processes of organizing social life (Mumby, 1997). My ontological commitments, informed by Giddens (1984) and Foucault (1971, 1977, 1980), proceed from an understanding of reality as socially constructed and mediated through power relations. In this light, knowledge is intimately intertwined with power and ideology and is perpetuated through historically and culturally contingent discourses (Lindlof \& Taylor, 2011; Miller, 2005). These ontological and epistemological commitments inform my axiological orientation.

As a critical scholar, my axiological commitments direct me towards issues of "exploitation, repression, social injustice, asymmetrical power relations (generated from 
class, gender, or position), distorted communication, and misrecognition of interests" (Deetz, 2005, p. 86). I engage in this scholarship from a privileged structural position as an educated, able-bodied, middle class, heterosexual, married, White woman with U.S. citizenship. From a point of reflexivity, I understand myself to be a product and (re)producer of systems of privilege and oppression. However, I also understand that systems can (slowly) be changed because where there is power, there is also the possibility of resistance (Alvesson \& Deetz, 2006; Alvesson \& Willmott, 1992; McKerrow, 1989; Mumby, 1997). Therefore, I have a moral and ethical responsibility to use my privilege as a scholar and practitioner to help reveal and dismantle underlying structures of domination, to give voice to alternative ways of thinking about social problems, and to contribute to a more equitable, democratic society.

To this end, this project sought to reveal and denaturalize Whiteness as an enduring, deep-level structural principle that structures the affirmative action debate in higher education. As delineated in chapter two, the ideological power of Whiteness is understood to be manifest in discursive structures that produce and are reproduced by discursive resources that are drawn upon in discursive practices. Structured by Whiteness, discursive practices serve to (re)produce White subjects in a structurally dominant position relative to non-White subjects. The creation of laws and policies, such as affirmative action, is a particularly powerful form of discursive practice in that such practices (a) create and sustain structures of meaning (signification), norms (legitimation), and power (domination), (b) produce/constitute objects of knowledge, subjects, and subjectivities, (c) persist throughout space and time, and (d) are institutionalized across organizational sites. 
Structurational processes can be empirically analyzed through case studies that are marked by a change, challenge, or turning point (Barley \& Tolbert, 1997; Browning \& Beyer, 1998; LeGreco \& Tracy, 2009). Therefore, the Fisher case provided an opportunity to reveal and disrupt the reproduction of Whiteness as a deep-level structural principle enacted in the most powerful judicial body in the United States.

Discourses as structures can be identified and revealed in the (re)production of knowledge through discursive practices of organizing (Broadfoot, Deetz, \& Anderson, 2004). An analysis of discursive practices "provides insight into the ways discursive formations become articulated, negotiated and deployed to organize and pursue practical interest as well as reproduce relatively stable, sedimented social resources in interaction" (Broadfoot et al., 2004, p. 204). Broadfoot et al. (2004) suggested that researchers explore the structure of specific discourses, contextualized within broader social contexts, by tracing the discursive resources that are perpetuated, as well as those that are foreclosed, in organizing practices. CDA is the overarching methodological approach I used to undergo this task.

In the remainder of this section, I delineate the theoretical and methodological principles that guided my approach. First, I locate this project within the methodology of critical discourse analysis (CDA). Then, I describe how and why my methodological approach to analyzing Whiteness is informed by a feminist post-structuralist approach to CDA. I draw upon this feminist framework to delineate a race-centric approach to CDA that served as the analytical lens through which I engaged this critical analysis. 


\section{Critical Discourse Analysis}

Although CDA is not used frequently in U.S. organizational communication scholarship, this approach offers a useful and flexible framework that may enhance scholars' methodological toolbox (Tracy, Martinez-Guillem, Robles, \& Casteline, 2011). CDA is an appropriate method for critiquing Whiteness because it is a methodology that is "fundamentally interested in analyzing opaque as well as transparent structural relationships of dominance, discrimination, power and control as manifest in language" (Wodak \& Meyer, 2009, p. 10). CDA is not a fixed method, but rather it is an interdisciplinary methodology that can be adapted for use with various other disciplines and methods.

As an overarching methodology, CDA research consists of a systematic analysis of discourse to explore how critical theories are operationalized in social practice and how local texts link to broader social discourses (Wodak \& Meyers, 2009). Approaches to engaging CDA vary in terms of focus on agency vs. structure, micro vs. macro levels of discourse, as well as types of theories engaged (e.g., grand theories, micro-sociological theories, linguistic theories, discourse theories, etc.) (Wodak \& Meyer, 2009). However, the various approaches to CDA do share some fundamental assumptions and commitments around the concepts of discourse, critique, power, and ideology. The practice of engaging CDA research implies (a) a focus on social problems, (b) a political emancipatory agenda, (c) an assumption that discourses both construct and represent the social world, and (d) an understanding that discourses are doing ideological work (Wodak \& Meyer, 2009). The current project shares these commitments and also seeks 
to extend CDA scholarship by building upon a feminist research agenda to argue for and articulate a race-centered approach to CDA.

\section{Feminist critical discourse analysis.}

Lazar (2007) argued that while CDA has much to offer feminist scholarship in terms of theories of discourse/power relations and methods of analysis, an explicitly feminist approach to CDA is needed in order to develop a research agenda and community of scholars specifically focused on critiquing discourses that sustain the patriarchal social order. Lazar's (2007) argument for, and articulation of, a feminist CDA is particularly salient to the present project because Whiteness functions ideologically in the same way as masculine gender ideology. Therefore, in what follows, I will delineate Lazar's feminist arguments for privileging a critique of masculine gender ideology and then I will apply these arguments to delineate a critique of Whiteness in discourse analysis.

From a feminist perspective, the dominant conceptualization of gender serves to create binary subject positions of man and woman, with men located in the dominant structural position (Lazar, 2007). The gendered nature of social practices occurs on two levels: as an interpretive category of meaning and as constitutive of social relationships. As an interpretive category of meaning, gender is drawn upon to make sense of and to structure social practices. As a social relation, gender constitutes specific, asymmetrical meanings of 'male' and 'female,' which enter into all areas of social relations and practices, such as labor, family, and sexuality (Lazar, 2007). Although the nature of gendered structural and social relationships changes and evolves over time, and is manifest differently in different cultural contexts, the dominance of androcentric or 
masculine centered ideology persists (Lazar, 2007). Therefore, a primary aim of a feminist CDA research agenda is to reveal how social practices are gendered in ways that systematically privilege men and disadvantage, marginalize, or exclude women as a social group (Lazar, 2007).

A feminist CDA reveals how gender ideology functions through discursive practices that appear as common sense knowledge about naturalized differences between men and women. For example, the two-sex binary (male/female) is a taken-for-granted assumption in the ways that we talk about men and women. The normalized practice of strategically locating ourselves and others in particular, gendered structural positions both reifies gendered subjectivities and forecloses the potential of other gendered identities (e.g., gender fluidity, gender queer, transgender). Therefore, the ultimate goal of feminist $\mathrm{CDA}$ is the radical transformation of social relations and an opening of possibilities for both men and women based on social justice (Lazar, 2007).

As a form of critically reflexive praxis, Lazar (2007) argued that an important part of feminist CDA is a critique of discourses that may seemingly enable a feminist agenda, but may actually serve the dominant structures. For example, classical liberal notions of 'equality' and 'sameness' are drawn upon by equal opportunity advocates to argue that men and women should be treated the same way, should have the same opportunities, and are equally qualified to perform the same jobs. While these arguments may resonate with a women's equality agenda, the notion of sameness and equality as deployed in these arguments implies sameness to men, the yardstick by which women are compared (Lazar, 2007). In this light, women are expected to fit into the dominant structures of organizing, rather than subvert the androcentric system that normalizes masculine 
ideology. Lazar (2007) also called for a critique of post-feminism discourses that point to the visibility of women in employment, education, and politics to argue that the feminist equality agenda has been realized. This liberal notion of equality, based on the number of women who fit in to the extant social, political, and economic power structures, are inadequate for addressing the covert, deep-seated, naturalized ways that social practices are structured by patriarchal, androcentric ideology (Lazar, 2007).

Although feminist research is concerned with how other marginalized identities such as class, race, and sexual orientation intersect with gender in systems of oppression, a feminist research agenda privileges patriarchal power and gender ideology as the lens through which social relations are critiqued and analyzed (Lazar, 2007; Weedon, 1987). However, Lazar's arguments for and explication of a feminist CDA can aptly be applied to my argument for a critique of Whiteness as the ideological power through which racial identities and relations are structured in discursive practices.

\section{Towards a race-centric approach to CDA.}

Based upon the above arguments, I now outline a race-centric CDA that draws upon the theorization of Whiteness described in chapter two. I chose the term racecentric to describe my approach for two reasons. First, there is no racially equivalent term to feminist or feminism; the terms racist and racism have totally different implications. Second, although my intention is to focus on Whiteness, the term 'whitecentric' may cause confusion because it has been already used in theorizing Whiteness to refer to social and discursive practices that center Whiteness. Therefore, I use the term race-centric to communicate my emphasis on Whiteness as the analytical lens through which I critique discursive practices that serve to (re)produce White subjects in a 
structurally advantaged position relative to non-White subjects. The overarching goal of a race-centric approach to CDA, as I conceive it, is to dismantle White-centric organizing practices that perpetuate racial inequality and to transform institutionalized practices and social relationships in ways that generate possibilities for all social actors.

Although Whiteness intersects with and functions similarly to other systems of oppression (e.g., social class, gender, sexual orientation), a race-centric approach privileges the critical analysis of Whiteness as an omni-relevant category of difference institutionalized in social, cultural, economic, and political practices in the U.S. context. A race-centric approach to CDA analyzes discourse and social practices through a lens of Whiteness, understood as a dominant ideology that serves to structure American social practices, cultural representations, and the formation of racialized identities in ways that systematically, yet often invisibly or unconsciously, disadvantage and oppress nonWhite social actors (Owen, 2007). Therefore, maintaining a critique of Whiteness in CDA entails (a) identifying the naturalized, taken-for-granted assumptions about White and non-White racial identities that are (re)produced in discursive practices, (b) explicating the implicit ways that Whiteness is maintained as a universal and invisible structural principle that legitimizes the racial social order, and (c) revealing marginalized, silenced, and discounted perspectives that contradict White dominance. In order to inform my analytical approach to a race-centric CDA, I borrow concepts from Critical Race Theory; a scholarly and activist movement that seeks to transform the interwoven relationship among race, racism, and power (Delgado \& Stefancic, 2012). 


\section{Critical Race Theory.}

Critical Race Theory (CRT) developed from an earlier body of work called

Critical Legal Studies. Critical Legal Studies (CLS) was born in a post-Civil Rights era among activists, scholars, and lawyers frustrated by the lack of continued social justice progress and concerned with the subtler forms of racist ideology that permeate legal practices (Kelman, 1987). While CLS focused primarily on the law as an instrument of White Supremacy, CRT was later taken up as a framework for critique more broadly, primarily in the field of education (e.g., DeCuir \& Dixson, 2004; López, 2003; Solorzano, Ceja, \& Yosso, 2000; Solórzano \& Yosso, 2002; Yosso, Parker, Solorzano, \& Lynn, 2004). The basic principles of CRT were informed by CLS as well as radical feminist scholarship (Delgado \& Stefancic, 2012).

The first core principle of CRT is that racism is endemic rather than an aberration (Delgado \& Stefancic, 2012). Similar to the concept of Whiteness as a structural principle outlined in chapter two, CRT posits that racism is invisibly woven into the fabric of our organizations, institutions, practices, and structures (López, 2003).

Secondly, race is understood to be socially constructed through relations of power. Additionally, races are understood to be differentially racialized, contingent upon the interests of dominant society and labor markets. For example, in the 1800 's, Chinese immigrants in the U.S. faced government sanctioned discrimination and exclusion from the labor markets, while simultaneously being exploited as a source of cheap labor (Boswell, 1986). Later, however, Chinese and other Asian Americans were racialized as a 'model minority' or hard-working super-achievers who value family, education, and respect for authority; especially as compared to African Americans and Latinos (Ono, 
2005). Thus, CRT seeks to critique the racialized order as it is produced and maintained through historically contingent discourses (Frankenberg, 1993; Omi \& Winant, 1986). In order to destabilize dominant visions of reality, CRT research privileges stories and counter-stories told by people of color. By highlighting these marginalized accounts, CRT practice seeks to "demystify the notion of a racially neutral society and tell another story of a highly racialized social order"(López, 2003, p. 85). The final core principle of CRT is interest convergence. Interest convergence contends that programs and policies designed to attend to racial inequality will only be "pursued and advanced when they converge with the interests, needs, expectations, and ideologies of Whites" (Milner, 2008, p. 32). In other words, social change only comes at a pace that is comfortable for and in the interest of White people (Bell, 1979). Since racial equality cannot truly be achieved without altering the racial power structure, interest convergence asserts that policies, laws, and practices that seemingly advance people of color must also be understood as promoting White self-interest, namely the status quo of power relations (Bell, 1979). Together, these core principles of CRT serve to reveal the ways that dominant beliefs, practices, and knowledge function to maintain racial hierarchy and social inequality.

A race-centric approach to CDA, informed by feminist CDA and CRT, provides a potentially rich framework and direction towards a communication-centered research agenda focused on Whiteness. In some ways, my race-centric approach to CDA is very similar to a recently emerging methodological approach in education scholarship referred to as critical race discourse analysis (e.g., Acholonu, 2013; Briscoe \& Khalifa, 2013; Ledesma, 2013; Osei-Kofi, Torres, \& Lui, 2013). As applied in education scholarship, critical race discourse analysis involves using various approaches to CDA combined with 
various critical race theoretical concepts to identify and critique racially oppressive discourses that emerge from various types of text related to education, such as college admissions marketing materials (e.g., Osei-Kofi et al., 2013), stories about race-related school incidents (e.g., Briscoe \& Khalifa, 2013), and affirmative action cases in education (e.g., Acholonu, 2013; Ledesma, 2013). While my approach also draws on CDA and critical race theory, my structurational framework enhances both CDA and CRT by offering a more explanatory framework for understanding the systematic (re)production and potential transformation of discursive structures and practices. In this project, I developed this race-centric approach in order to reveal and critique: (a) how subjects are constituted in the discursive practice of debating affirmative action in the Supreme Court and (b) the strategic rhetoric (Nakayama \& Krizek, 1995) that functions to maintain Whiteness as invisible and/or universal. This analytical framework will be employed to answer the following questions:

RQ \#1: How was the deep-level structuring principle of Whiteness producing and reproduced by the discursive practice of debating race-conscious admissions in the Fisher case?

RQ \#2: How are White and non-White subjects constituted within the discursive practices of the Fisher case?

RQ \#3: How might marginalized discursive resources and structural contradictions in the debate serve to de-center the normative power of Whiteness in the affirmative action debate? 


\section{Methods}

CDA can be approached many ways, as long as the methods used to critique discourse are systematic, theoretically driven, and focused on social issues (Fairclough, 2010; Wodak \& Meyer, 2009). The present project draws upon a process of Foucauldian discourse analysis as outlined by Jäger and Maier (2009). This process is not meant to be rigidly followed, but rather it serves as a guide to conduct CDA inspired by Foucault's (1971, 1978, 1989) archeological and genealogical methods. Foucauldian analysis of discourse focuses on questions related to knowledge production, the constitution of subjects, and the consequences for the shaping and developing of society (Jäger \& Maier, 2009), which makes it an appropriate method for answering my research questions. In what follows, I define Jäger and Maier's key analytical terms and describe my adapted approach to this method of critical discourse analysis.

Jäger and Maier (2009) delineated some key terms that are useful for conceptualizing and defining a CDA project. The object of study in this approach to CDA is called a discourse strand, defined as a collection of discourse fragments (or body of texts) related to a particular topic (e.g., affirmative action) produced in a particular discourse plane. A discourse plane is similar to the concept of discursive practice as defined in my theoretical framework; it is a way of talking in a particular field (e.g., the legal field, education, business, science, media, etc.). Discourse strands emerge from discursive events, which are events that appear "on the discourse planes of politics and the media intensively, extensively and for a prolonged period of time" (Jäger \& Maier, 2009, p. 48). Discursive events, such as the Fisher case, are an important site for CDA because of their influence on the development of discourse (institutionalized ways of 
talking). And finally, this approach calls for attention to discourse positions. Discourse positions refer to the "ideological position from which subjects, including individuals, groups and institutions, participate in and evaluate discourse" (Jäger \& Maier, 2009, p. 49). In terms of the affirmative action debate, the dominant discourse positions as identified in the literature review are 'liberal' and 'conservative;' however, other discourse positions may emerge from the current analysis. Jäger and Maier (2009) noted that although discourse positions may differ around particular issues, "within a dominant discourse, discourse positions are fairly homogenous, which itself is already an effect of dominant discourse" (p.50). For example, although liberal and conservative discourse positions may offer different views about whether or not race should be considered in admissions policies, these positions may be informed by the same dominant ideology of Whiteness as manifest in right to profit or individualism.

Discourse strands produced within discursive events have a history, a present, and a future and therefore should be analyzed both synchronically and diachronically (Jäger $\&$ Maier, 2009). In other words, each individual project cuts into a slice of a particular discourse strand and provides an important synchronic data point that must also be understood diachronically. A diachronic analysis connects a discourse strand produced by a particular discursive event to the historic social knowledge and discursive practices from which the discourse strand was produced. In this way, various projects on the same social issues serve to build longitudinal knowledge, which is particularly important for exploring structurational processes. The current project contributes to the body of knowledge around the long-standing affirmative action debate by analyzing a particular historic moment that is built on the past and will impact the future. Defined within the 
set of terms described above, the texts produced in the Supreme Court decision around the Fisher case constitute a discourse strand produced in the discourse plane of the legal realm. The case itself is a discursive event because the year-long deliberation process generated wide discussion and it may have a lasting impact in the discursive field of higher education.

Jäger and Maier's (2009) approach to Foucauldian CDA starts with a justification of the topic and discourse plane selected for the project. Then, the researcher must explicate the choice, collection, and type of data selected for analysis. Once the data is collected and organized, the texts are analyzed through three levels of analysis. In order to avoid confusion with other terms engaged in this analysis, I do not use Jäger and Maier's terminology to label each level/phase of analysis. However, my analytical process followed their suggested steps quite closely. The first level of analysis explored the general themes and features of the broadest set of texts, the entire discourse strand. The second level of analysis involved a detailed analysis of a small sample of texts strategically chosen from the discourse strand. And finally, the third level of analysis interpreted the findings from the two previous levels of analysis in relation and comparison to each other. Each level of the analysis brought out different aspects of the texts in order to answer my research questions.

Tracing the (re)production and exclusion of discursive resources is a way to empirically examine structurational processes ( LeGreco \& Tracy, 2009). In this light, the texts produced at different stages of this decision-making process represent a narrowing down, or a selection and omission process, that served to legitimize certain discursive resources and marginalize others. The first body of texts, the briefs, represents 
the broadest set of discursive resources (as will be discussed below) from the discursive field. The second text is the transcript of the oral arguments, in which only lawyers and Justices participated. The questions and arguments made in this phase of the discursive practice drew upon certain discursive resources and omitted others; therefore, this text is understood to represent the first stage of narrowing in this decision making process. The final product produced in this discursive practice was the Supreme Court's ruling on the case, which consists of a majority opinion submitted on behalf of the Court as well as individual opinions of the Justices who felt compelled to clarify their position. In terms of the present project, the Supreme Court's ruling represents the set of dominant, legitimized discursive resources that were filtered down since the beginning of this process. Also, given the way that case law functions, it must be understood that all the texts produced around this case are structured by past affirmative action cases, as will be discussed in my analysis.

\section{Selection and justification of topic and texts.}

CDA starts with an interest in a particular topic related to a social issue. As argued in chapter one, the present project is concerned with the broad topic of racial inequality, which I have narrowed down here to focus upon the context of higher education as an important site of the reproduction of racial inequality (Gerald \& Haycock, 2006). There are many types of discourse production related to social issues, such as race in higher education. Therefore, the researcher must select and justify a particular discursive field and discourse plane (or discursive practice) upon which to focus. As delineated in my literature review, my interest in racial inequality is approached through the discursive practice of debating affirmative action in the Supreme 
Court. I will now explain why this choice of discourse plane is justified by my theoretical framework.

Structurational processes emerge during situations marked by a rupture or turning point (Barley \& Tolbert, 1997; LeGreco \& Tracy, 2009), such as passage of or change to a policy or legislation. Although the ruling in the Fisher case did not result in a mandated change in the ways that universities employ affirmative action in admissions, the case itself represents a destabilization of the constitutionality of race-conscious admissions (Schmidt, 2013; Stowes, 2013). For the past decade, the Grutter v. Bollinger (2003) decision has served as the constitutional basis for the consideration of race in university admissions (Lawrence, 2001; Ledesma, 2013). The recent Fisher v. UT (2013) attempted to challenge this ruling. Although the Supreme Court did not overturn the Grutter ruling, the consensus among legal analysts is that the Fisher ruling will impact the ways that universities construct and implement their admissions policies (Schmidt, 2013). Therefore, this case is a discursive event that presents a rupture or turning point in the affirmative action debate in higher education admissions and provides an opportunity to explore structurational processes in action.

\section{Data and data collection.}

After choosing the topic and discourse plane, the research must identify and collect appropriate texts for analysis. There are usually multiple types of texts, sources, and contexts from which an analysis might precede. Therefore, the data collection phase involves choosing a corpus of texts (discourse strand) and justifying a particular selection. The texts for the present project were selected because of where and why they were produced. In contrast to most communication research on policy, my focus is not 
on the enactment of policies that have already been created, but rather on the contentious process of debating and potentially changing policy. Therefore, I draw my data from a site of discursive practice that dominates the discursive field of affirmative action in higher education: Supreme Court decision-making on race-conscious admissions.

The data selected for this project were produced within the context of debating and deciding the Fisher case. All texts were collected online from the Supreme Court of the United States website ("Supreme Court of the United States," n.d.) and blog ("Fisher v. University of Texas at Austin : SCOTUSblog," n.d.). Because the main purpose of this project was to reveal the (re)production of dominant discursive structures (and the marginalization of non-dominant discursive structures) through the discursive practices around the decision-making process in the Fisher case, the data collected and analyzed were limited to texts produced within this case. However, my analysis is also contextualized within the texts produced in the preceding cases. I will now describe each set of texts as they appear on the timeline of the year-long deliberation of the case.

Briefs.

The first body of texts consists of the briefs produced by each side's lawyers and the amicus briefs filed by various individuals, organizations, and associations in support of one side or the other. Amicus briefs are formalized structured documents presented in court cases for the purposes of laying out arguments and providing information in support of a particular stance on the issue. All of the briefs followed a standard format that started with an explanation of who is submitting the brief, the credentials they have in relation to the issue being decided, and their particular interests in the outcome of the case. Then, the briefs provided a summary of their arguments, followed by a detailed 
explanation of each point. Arguments were supported by various types of research as well as legal precedent and quotes cited from previous affirmative action cases and legal opinions. I will now describe the briefs filed for each side of the Fisher case.

The briefs in support of the petitioner, Abigail Fisher (hereafter referred to as the Fisher briefs) were produced and distributed in May 2012. There were 17 briefs written in support of Fisher's case. The briefs ranged in length from 17 to 52 pages for a total of 637 pages of text. Some of the briefs were submitted by non-profit organizations with Civil Rights-related names such as American Civil Rights Union and American Center for Law and Justice; others were submitted on behalf of associations of scholars and lawyers; and a few were submitted by individuals. There were also two briefs submitted on behalf of Asian American and Jewish interest groups.

The briefs in support of the respondent, the University of Texas, (hereafter referred to as the UT briefs) were produced and distributed in August 2012. There were 72 briefs in total, ranging from 12 to 80 pages in length, for a total of 3,159 pages of text. Most of the briefs were submitted on behalf of organizations or groups of organizations with similar interests. For example, there were several briefs filed by medical and legal associations, groups of universities, student groups, business associations, UT alumni, as well as minority interest groups. Because this set of briefs was submitted after the briefs in support of Fisher were made available, several of the UT briefs responded directly to arguments raised in the Fisher briefs, while other briefs were focused more generally on supporting the principles as outlined in the Grutter decision. There were also briefs that offered arguments unrelated to the Fisher briefs and the Grutter decision. 


\section{Transcript of oral argument.}

After reviewing the amicus briefs, the Supreme Court Justices heard oral arguments presented by each side's lawyers. The oral arguments took place on October 10, 2012 and lasted for one hour and twenty minutes, resulting in an 83 page written transcript, plus 15 pages of indexed words. The text produced in oral arguments represents an aspect of this discursive practice that offers additional insights into discursive resources as lawyers and judges interact and struggle to control meaning. These texts are also important because at each stage of this discursive practice certain discursive resources are drawn upon, while others are omitted. Furthermore, the Justices control this stage of decision making process by asking particular questions, focusing on particular issues and foreclosing or omitting other questions and issues. Thus, the text produced in the questions and answers in the oral argument represent an expression of power that serves to legitimize what 'counts' as knowledge in this context and what does not. The indexed terms, or word count, included at the end of the transcript provided an additional data point to identify those ideas or concepts that dominated the text and those that were marginalized.

\section{Supreme Court opinion.}

The final product of this decision making process is the Supreme Court majority opinion in the Fisher case (16 single-spaced pages), plus the concurring and dissenting opinions offered by individual justices (25 single-spaced pages). The language and logics produced in legal rulings serve to constitute values and norms that shape public policy and organizational practices. Although this ruling is certainly not the last word in the affirmative action debate, it does have an impact on the discursive field of higher 
education because it (a) serves as a discursive resource (rules and resources) that structures the meaning (signification) of race in higher education, (b) provides normative reasoning (legitimation) as to why race should or should not be considered in admissions policies, and (c) determines the constitutionality (domination) of race-conscious policies. In this way, this Supreme Court ruling will enable and constrain future discursive practices on the discursive field of the affirmative action debate and therefore merits particular scrutiny.

Together, the briefs, the transcript of oral arguments, and the final ruling constitute the discourse strand of this discursive event. In what follows, I describe the three phase analytical process that I adapted from Jäger and Maier’s (2009) "a little toolbox of discourse analysis" (p.52). The first analysis phase explored the discursive struggle around the meaning of discursive resources engaged during this discursive practice. The second phase focused on the narrowing down of discursive resources from the amicus briefs through the oral arguments and final ruling. The final stage drew upon the findings from the first two phases in order to reveal and critique the ways that Whiteness (a) produced and was reproduced by discursive resources and structures, (b) constituted racialized subjects, and (c) was contested by marginalized voices. The analysis from this final phase was used to answer my research questions, which will be restated at the end of this chapter.

\section{Phase 1: Analysis of Discursive Resources}

The purpose of this initial stage of analysis was to identify and describe (a) the dominant discursive resources that emerged as rhetorical arguments, (b) the discursive resources and arguments that were non-dominant or marginalized, and (c) the terms or 
phrases that were repeatedly used as taken-for-granted knowledge in reference to race and racialized identities. There were three steps to this first phase of analysis: organization of data, initial coding, and initial interpretation.

Organization of data. In order to facilitate analysis and organization of such a large body of texts, I uploaded all the documents into ATLAS.ti qualitative coding software. The texts were organized into chronologically ordered units: initial briefs for each side, amicus briefs for Fisher (Fisher briefs), amicus briefs for the University of Texas (UT briefs), the transcript of oral argument, and the final ruling. After I uploaded and organized texts, I applied a multi-step coding process to all the texts in the chronological order in which they were produced.

Coding process. My coding process began by coding the main arguments in the briefs using both open-coding and a priori major codes identified in the literature review (e.g., innocence and fairness, merit, colorblindness, diversity, and race). I then went through and further refined the super-codes through an open-coding process. For example, quotes coded as 'diversity' yielded further sub-codes that presented the rationales, logics, or values around why diversity is or is not important (i.e. business case, anti-diversity, and educational benefits). Similarly, the a priori code 'race' generated sub-codes that focused on the meanings of race, how racialized identities were described, and how race is understood in relation to affirmative action. The application of the major codes and sub-codes was both descriptive and interpretive. In other words, some arguments were coded based on the appearance of specific terms (i.e., history, merit, discrimination, diversity, etc.), therefore my code was descriptive of the discursive resource as explicitly stated. Other quotes required a more interpretive labeling of the 
discursive resources that they represent (e.g., counter-story, Whiteness, interest convergence).

Initial interpretation of data. The purpose of the final step of the first phase of analysis was to generate some initial interpretations of the data in order to characterize or describe the discourse strand (Jäger \& Maier, 2009). This phase of the analysis focused on the discursive resources identified through coding and was guided by questions suggested by Bacchi's (1999) discursive approach to policy analysis, such as:

- Which discursive resources are drawn upon in arguments made from both subject positions (liberal and conservative)?

- Are there dissenting subject positions that reject both the liberal and conservative position?

- What values are drawn upon to support different discourse positions?

- Who supposedly benefits from race-conscious admissions? Why?

- Who supposedly is harmed by these policies? Why?

- How are White and non-White subjects constituted within the texts?

The findings generated from the first phase of analysis served to explicate the dominant understandings of race and race-conscious admissions policies, as well as to illuminate subjugated meanings and understandings, as (re)produced in the amicus briefs and the transcript of the oral arguments.

This first level of analysis focused on what was said in the texts, while the next phase of analysis focused on what was left unsaid, implied, and assumed. In other words, the next phase of analysis delved below the surface of the text to explore the underlying 
ideological underpinnings and discursive structures that produced and were (re)produced by the discursive resources.

\section{Phase 2: Close Textual Analysis and Ideological Critique}

In order to gain a deeper understanding of the ideological work of the discourse strand, the second level of analysis in this process entailed an in-depth reading and analysis of selected texts. Jäger and Maier (2009) suggested that a typical text or texts from the discourse strand be selected for this phase of analysis. Typicality is determined by the research project and the discourse strand being analyzed. For the purposes of the present project, I focused on the text that has the most rhetorical force in the discursive field of affirmative action: the Supreme Court's final ruling. In terms of my theoretical framework, the Supreme Court ruling constitutes a rule-resource set of affirmative action practice by delineating the legitimized purpose and meaning of affirmative action (legitimation and signification) and the ways that race can be considered (domination) in higher education admission policies.

The purpose of this part of the analysis was to explore how Whiteness functioned as an underlying structural principle that produces knowledge about race and raceconscious admissions policies. This analytical task was not straight forward because Whiteness does not reveal itself explicitly, but rather it is obscured by a cloak of normativity and articulated through various discursive structures and resources (e.g., merit, innocence, fairness, individualism, American nationality, etc.). To reveal how Whiteness structured and was reproduced by the Supreme Court's ruling, I drew upon CRT and the analytical concepts delineated in chapter two. With this framework in mind, this phase of the analysis was guided by the following questions: 
- What assumptions are implied or taken for granted in the way that raceconscious admissions are talked about in the Supreme Court's ruling on the Fisher case?

- How do these assumptions serve to make Whiteness normative?

This analytical process allowed me to identify the discursive resources and structures that were legitimized by the Supreme Court Justices and provided understanding into the ways that Whiteness produced and was (re)produced through the discursive resources and structures that emerged in this stage of the debate.

\section{Phase 3: Answering Research Questions}

This final step in my analytical process involved interpreting the findings from the first two stages of analysis in order to problematize this discursive practice and to reveal how Whiteness functions as an underlying structural principle in discourse about raceconscious admissions. To begin, I applied my structurational conceptualization of Whiteness to critique the discursive structures and resources that emerged as dominant in order to answer my first research question:

RQ \#1: How was the deep-level structuring principle of Whiteness producing and reproduced by the discursive practice of debating race-conscious admissions in the Fisher case?

Then, I went back to the coded data to do a deeper analysis of the ways that race and racial identities were constituted in this discursive practice. To this end, I pulled out the quotes attached to all the codes and sub-codes related to race and racial identities (i.e. race, race neutral, race and academics, stigma, Jews, Asians, White students/White people). These quotes were analyzed with the following questions in mind: How is race 
conceptualized? What words or phrases are used in reference to particular racial groups? How are racialized identities constructed by these words or phrases? This phase of analysis was informed by feminist and race-centric CDA as outlined in this chapter. My interpretation of the data was used to answer my second research question:

RQ \#2: How are White and non-White subjects constituted within the discursive practices of the Fisher case?

Until this point in the process, my analysis and interpretation focused on explicating the discursive resources engaged in this debate and revealing how they are structured by Whiteness. As explained in the literature review, Whiteness is not a reified, static concept. Understood in terms of Structuration Theory, Whiteness can only maintain dominance through discursive practices that constantly reproduce its structural dominance. Therefore, the third and final stage of analysis sought to weaken the normative power of Whiteness by foregrounding alternative logics, rationales, and values that may be obscured by or excluded from the discursive practice of debating raceconscious admissions in the Fisher case. Therefore, to answer my third research question, I shifted my focus from the dominant discursive resources to explore potentially transformative discursive resources that were marginalized in this decision-making process.

In my original readings of the texts, it became clear to me that the amicus briefs produced by African American organizations and interest groups told a different story about race-conscious admissions than many of the other UT briefs. Therefore, these texts seemed like a fruitful site to explore marginalized discursive resources, particularly since my project is informed by Critical Race Theory, a central tenant of which is to highlight 
voices of people of color. Therefore, I focused the final phase of my analysis on the texts produced by organizations that specifically advocate for African American interests in order to answer my last research question:

RQ \#3: How might marginalized discursive resources and structural contradictions in the debate serve to de-center the normative power of Whiteness in the affirmative action debate?

This latter part of the critique is particularly important because CDA involves a commitment to moving beyond a critique of domination to a generative agenda that seeks to "design and forge alternative ways of representing, being, and interacting in the world with the goal of creating a society free of oppression and domination" (Rogers, 2011, p. 5). In this light, this final phase of analysis is geared towards praxis or what this project can $d o$ in the world.

\section{Evaluation}

The final written product of research must be evaluated under some relevant set of criteria. Although I have engaged CDA as a methodological approach, what I have in fact produced is critical rhetoric. As articulated by McKerrow (1989), the task of a critical rhetoric is to construct an argument that "identifies the integration of power and knowledge and delineate the role of power/knowledge in structuring social practices" (p.102). The purpose of this argument is to challenge the status quo through critique of domination and critique of freedom. Similar to CDA, the critique of domination centers on demystifying and revealing the "discourse of power that creates and sustains the social practices which control the dominated" (McKerrow, 1989, p.92). A critique of freedom, on the other hand, is a state of permanent skepticism based on the understanding that 
"new social relations which emerge from a reaction to critique are themselves simply new forms of power" (p. 96). In other words, freedom from one relation of power begets yet another relation of power, and the critic must be attentive to both. This concept of permanent skepticism is not meant to imply that the critical rhetor must avoid taking a stance as to whether one set of power relations is better than another (McKerrow, 1991). Rather, the critical rhetor should take action based upon the contingent knowledge available at that time, yet maintain a critical eye on the new 'norms' that evolve from this position (McKerrow, 1991).

Both critical rhetoric and CDA have a commitment to praxis and therefore this project should be assessed by what it does or can do in the material world. In arguing for a race-centric approach to CDA, I declared the goal of such an undertaking to be the transformation of social relations between White people and people of color in order to open up possibilities and new ways of being for all people. I believe that a precondition for this transformation is an understanding of how Whiteness serves as a structural principle in all of our social institutions. As a small step in this direction, my intention with the present project was to provide a framework for revealing how Whiteness produces and is reproduced by powerful discursive structures drawn upon in policy making, specifically in race-conscious admissions policies. My hope is that this critical analysis of the affirmative action debate will serve as a discursive resource to policy makers, specifically pro-affirmative action proponents.

As I stated in the rationale for this project, I believe that however flawed affirmative action policies may be, they are a necessary tool for addressing racial inequality in higher education and society as a whole. I also believe that part of the 
problem is the way the problem is talked about and argued within the debate around raceconscious admissions. Therefore, with this project, I hope to illuminate alternative ways to problematize the issues and move the conversation forward. The extent to which this project may be useful in the real world should be the ultimate evaluation of this effort.

\section{Conclusion}

In a widely cited Harvard Review article, Randall Kennedy (1986) argued that the long standing affirmative action debate:

cannot be understood without acknowledging simultaneously the force of the openly stated arguments for and against preferential treatment and the submerged intuitions that disguise themselves with these arguments. To disregard either of these features of the debate is to ignore an essential aspect of the controversy. To appreciate both is to recognize the frustrating complexity of our racial situation" (p. 1328).

The purpose of this project was to explore and shed light on these "submerged institutions" in order to contribute to this ongoing conversation and hopefully work towards building pathways through the complexity of "our racial situation." To this end, I have argued for a race-centric approach to CDA to encourage a body of scholarship that specifically critiques Whiteness as a dominant structural principle and enduring institution that permeates social organizing practices. The particular method developed in this chapter served to explore how Whiteness structured the discursive practice of debating race-conscious admissions policies in the Supreme Court.

Understood as rules and resources, policies are an integral part of organizational

life that serves to enable and constrain organizational actors. From a critical perspective, 
policies can be understood as "institutionalized forms of domination" (Codd, 1988, p. 243) that are often not recognized as such because power is obscured by neutral policy language. The framework for analyzing policy debate and development through a lens of Whiteness developed in this project is intended to be applied to a wide range of policies, debates, and organizational contexts. 


\section{CHAPTER 4: ANALYSIS}

In chapter two, I drew upon Gidden's (1984) Structuration Theory to conceptualize Whiteness as a deep-level structural principle and an enduring institution that organizes the totality of U.S. society. Understood within this framework, Whiteness produces and is reproduced by ideological assumptions, beliefs, and normative rules that emerge through discursive structures and resources that are drawn upon in discursive practices. In the present project, the affirmative action debate as enacted in the Supreme Court is understood as a discursive practice. The language and logics for argumentation in this discursive practice are conceptualized as discursive resources. In drawing upon particular discursive resources that emerged from particular discursive structures, the agency of participants in the debate was both enabled and constrained. At the same time, enacting agency served to shape the meaning of discursive structures that enabled and constrained agency. The forthcoming analysis explores how the discursive practice of debating race-conscious admissions in the Fisher case was produced by, (re)produced, and/or contested the structuring power of Whiteness. This chapter presents the findings from my three-phase analytical process and proceeds as follows.

I begin the chapter by conceptualizing the Grutter ruling as a discursive structure that served to enable and constrain the discursive practice of debating race-conscious admissions in the Fisher case. After describing the concepts that constitute the Grutter structure, I present the findings from each phase of analysis. The first phase focused on identifying and describing the dominant discursive resources engaged in the debate, as well as the gradual narrowing down of these resources through the decision-making process. The second phase of analysis engaged a close textual analysis and ideological 
critique of the Supreme Court's final ruling on the Fisher case. The third and final phase of analysis involved bringing together the findings from the first two phases to answer my research questions:

RQ \#1: How was the deep-level structuring principle of Whiteness producing and reproduced by the discursive practice of debating race-conscious admissions in the Fisher case?

RQ \#2: How are White and non-White subjects constituted within the discursive practices of the Fisher case?

RQ \#3: How might marginalized discursive resources and structural contradictions in the debate serve to de-center the normative power of Whiteness in the affirmative action debate?

\section{Grutter as a Discursive Structure}

Based on the principles as outlined in Bakke (1978), the Grutter decision has served as the constitutional cornerstone of race-conscious admissions for more than a decade (Kennedy, 1986; Lawrence, 2001; Ledesma, 2013; Liu, 1998). In terms of my theoretical framework, the Grutter decision is conceptualized as a discursive structure, or rule-resource set, that enables and constrains the discursive practice of debating raceconscious admissions. In this section, I delineate the rules of this discursive structure in order to contextualize my analysis of the Fisher case.

As explained in chapter two, rules are the legitimized norms that are engaged in and give meaning to social practices (Giddens, 1984, p. 21). Some rules, such as the ones that constitute the Grutter structure, are codified in law or legal structures. These types of rules are enforceable through authoritative power, or domination. Rules also carry power 
through signification and legitimation. Signification refers to the constitutive power that generates meaning in the form of knowledge that agents draw upon in social interaction. Legitimation is the sanctioning power, or normative function, that makes people follow rules. In the context of the Fisher case, the rules that constitute the Grutter structure served as discursive resources that enabled and constrained this discursive practice. In other words, in order for participants to have their arguments about race-conscious admissions understood as relevant and legitimate, they had to draw upon the following rules as discursive logics. At the same time as these rules enabled or legitimized certain arguments, these rules also served to constrain what arguments would be considered valid in this context.

\section{The compelling Interest in student body diversity.}

The first rule produced by the Grutter structure is that race-conscious admissions are justified by the compelling interest in student body diversity. As explained in chapter two, the only constitutionally permissible reason to consider race in a law or policy is that such consideration serves a compelling state or national interest, meaning that the consideration of race is seen as imperative or necessary to further state or national concerns such as national security, constitutional rights, and public safety (Tanenhaus, 2008). The Grutter decision to uphold the University of Michigan Law School's (UM) race-conscious admissions policy (re)produced the rule, first articulated in Bakke (1978), that the compelling interest in the use of race-conscious admissions is to further the goal of attaining student body diversity to produce educational benefits for all students. In order to capture the full sense of the compelling interest in diversity as delineated in 
Grutter, I offer the following extensive quote in which the Court explained its evaluation of the UM's race-conscious admissions policy:

Law School defines its critical mass concept by reference to the substantial, important, and laudable educational benefits that diversity is designed to produce, including cross-racial understanding and the breaking down of racial stereotypes. The Law School's claim is further bolstered by numerous expert studies and reports showing that such diversity promotes learning outcomes and better prepares students for an increasingly diverse work force, for society, and for the legal profession. Major American businesses have made clear that the skills needed in today's increasingly global marketplace can only be developed through exposure to widely diverse people, cultures, ideas, and viewpoints. High-ranking retired officers and civilian military leaders assert that a highly qualified, racially diverse officer corps is essential to national security. Moreover, because universities, and in particular, law schools, represent the training ground for a large number of the Nation's leaders, the path to leadership must be visibly open to talented and qualified individuals of every race and ethnicity. (Grutter v. Bollinger, 2003, p. 308)

The discursive resources (re)produced in this quote include diversity, stereotypes, workforce, global marketplace, national security, and leadership. These discursive resources constitute the dominant diversity rationale, the legitimatized reasons that the Court considered 'compelling' enough to warrant the consideration of race in admissions. As discussed in the literature review, other possible compelling interests, such as remedying past discrimination, are foreclosed within the Grutter structure. Thus, the only 
constitutionally permissible reason to consider race in admissions is to further the goal of attaining a diverse study body for the purpose of educational benefits.

Within the Grutter structure, the meaning of diversity is constrained by Justice Powell's opinion in Bakke. According to Justice Powell, the diversity that furthers the compelling interest in educational benefits is one that "encompasses a far broader array of qualifications and characteristics of which racial or ethnic origin is but a single though important element" (Regents of the University of California v. Allan Bakke, 1978, p. 315). In other words, racial and ethnic diversity alone are not sufficient to achieve the educational benefits that constitute the compelling interest in diversity. Therefore, universities must consider all types of diversity in the application review process. At the same time, it is permissible to have policies that make "special reference to the inclusion of African-American, Hispanic, and Native-American students, who otherwise might not 'be represented in the student body in meaningful numbers"' (Grutter v. Bollinger, 2003, p. 306). As a consequence, the compelling interest in diversity is entwined with another rule: critical mass.

\section{Critical mass.}

The second rule produced by the Grutter decision is that a university must have a “"critical mass' of underrepresented minorities [in order] to further its compelling interest in securing the educational benefits of a diverse student body" (Grutter v. Bollinger, 2003, p. 333). The critical mass rule means that a university must have a "meaningful representation" of minority students to ensure an environment that "encourages underrepresented minority students to participate in the classroom and not feel isolated" (Grutter v. Bollinger, 2003, p. 318). In other words, there must be a sufficient number of 
minority students so that they feel comfortable enough to make the contributions sought in order to achieve the compelling interest in diversity. However, within the Grutter structure, it is "patently unconstitutional" (p. 308) to apply any percentage, quota, or number to defining critical mass. Because quotas are strictly prohibited in defining critical mass, it follows that in the application review process "universities cannot establish quotas for members of certain racial groups or put members of those groups on separate admissions tracks. Nor can universities insulate applicants who belong to certain racial or ethnic groups from the competition for admission" (Grutter v. Bollinger, 2003, p. 336). In other words, there are constraints on the ways in which a university may consider race in admissions in order to attain a critical mass of minority students. This constraint is expressed in the next rule.

\section{Narrowly tailored.}

The third rule in the Grutter structure is that consideration of race in admissions decisions must be narrowly tailored to meet the compelling interest in diversity. The concept of narrowly tailored in race-conscious admissions requires that the consideration of race in the review of applications must be minimal and used only as part of a holistic review process that considers all of an applicant's relevant qualities (Grutter v. Bollinger, 2003). Therefore, to maintain the balance between considering race, but not giving race too much consideration, Grutter provided that admissions plans must "remain flexible enough to ensure that each applicant is evaluated as an individual and not in a way that makes an applicant's race or ethnicity the defining feature of his or her application" (Grutter v. Bollinger, 2003, p. 7). In this way, race may be considered as one among many elements of an application for admissions. Additionally, as structured by Grutter, 
narrow tailoring requires a "serious, good faith consideration of workable race-neutral alternatives that will achieve the diversity the university seeks" (p. 339). In other words, race can only be considered in the pursuit of a critical mass of minority students to achieve the compelling interest in diversity if alternatives that do not explicitly consider race have been unsuccessful in achieving that goal. In this light, the preference for raceneutral policies is embedded within the same structure that allows for the consideration of race.

These three rules that constitute the Grutter discursive structure delineate the legitimized rationales for why and how race can be considered in admissions process. When articulated in the discursive practice of debating race-conscious admissions, these rules served as discursive resources that enabled and constrained the discursive practice of debating the Fisher case. Discursive resources are defined as the logics, assumptions, and values that agents draw upon in order to make their arguments understood as valid, rational, and legitimate in particular discursive practices (Heracleous \& Hendry, 2000), such as debating race-conscious admissions. In discursive practices, drawing upon discursive resources serves to (re)produce and/or transform the discursive structures from which the discursive resources emerge (Heracleous \& Hendry, 2000). The transformative capacity of discursive resources lies in the fact that the meaning of such resources is never fixed. Discourses that circulate meaning are always in competition with each other within hierarchical relations of power (Weedon, 1987). Therefore, the discursive practice of debating race-conscious admissions is understood as a discursive struggle for meaning. As Weedon (1987) argued, "[m]eaning is always political. It is situated within knowledge/power relations which give society its current form" (p. 138). 
Thus, the struggle for meaning in discursive practices both shape and are shaped by the available discourses in circulation at any particular historical moment (Fairclough, 2010; Weedon, 1987; Wodak \& Meyer, 2009). These meanings have "implications for social relations, contesting them, reaffirming them or leaving them in tact (Weedon, 1987, p. 138). My analysis revealed that in arguing for or against race-conscious admissions each side of the debate imbued similar discursive resources with different meanings as they struggled to influence the Supreme Court's interpretation and application of the Grutter structure. My analysis thus moves to the discursive struggle for meaning that emerged in the amicus briefs filed in the Fisher case.

\section{Amicus Briefs: Discursive Resources and the Struggle for Meaning}

Amicus briefs are formalized structured documents presented to the Supreme Court Justices for the purposes of laying out arguments and providing information in support of a particular stance on the issue (Tanenhaus, 2008). The amicus briefs represent the broadest set of discursive resources (re)produced in this discursive practice of debating the constitutionality of race-conscious admissions in the Fisher case. In this section, I explore the discursive struggle between the two sides of the debate to act upon (reproduce and/or transform) the Grutter structure and discuss the ways in which Whiteness seemed to structure some of the underlying assumptions and beliefs.

The amicus briefs filed on behalf of the petitioner (hereafter referred to as the "Fisher briefs"), Abigail Fisher, were submitted and made publicly available a few months prior to the briefs filed on behalf of the respondent (hereafter referred to as the "UT briefs"), the University of Texas. This timing means that those who submitted briefs on behalf of UT had the opportunity to read the Fisher briefs before submitting their own 
briefs. In my chronological reading of texts, I came to realize that several of the UT briefs were drafted as direct responses to arguments made in the Fisher briefs, while others focused more generally on supporting the principles as outlined in the Grutter decision.

The majority of arguments engaged by both sides of the debate focused on the constitutional principles as outlined by the Grutter structure (i.e., compelling interest, narrowly tailored, critical mass, strict scrutiny, etc.). My reading of the amicus briefs revealed a discursive struggle for meaning around particular dominant discursive resources in an effort to shape the Court's understanding and application of the Grutter structure. Discursive resources were often articulated with other discursive resources in order to produce particular meanings. Therefore, in what follows, I describe the dominant points of this discursive struggle and the various discursive resources that were drawn upon in an attempt to impose particular meanings.

\section{Equality versus inequality.}

A dominant site of discursive (and ideological) struggle in arguments for and against race-conscious admissions centered on whether contemporary society is characterized by equality or inequality. Based on an assumption that equality is the norm, the natural state of a meritocracy, the Fisher briefs argued that race-conscious admissions are unfair and discriminatory because they constitute unequal treatment based on race. In contrast, the UT briefs were informed by a belief that social conditions are characterized by inequality and an uneven distribution of power and resources and, therefore, race-conscious admissions policies are needed to address systemic discrimination. In this site of discursive struggle, each side drew upon various discursive 
resources in conjunction with equality and inequality in order to legitimize or delegitimize the use of racial preferences.

The Fisher briefs engaged the discursive resource equality in conjunction with a variety of other discursive resources to argue that race-conscious admissions run counter to the principle of equality. For example, the brief filed by Fisher's lawyer argued that:

[i]f any state action should respect racial equality, it is university admission.

Selecting those who will benefit from the limited places available at universities has enormous consequences for the future of American students and the perceived fairness of government action (Brief for the petitioner, 2012, p. 18)

The underlying point of this argument is that the state should not be involved in creating racial preferences, but rather should "respect" the assumed racial equality that naturally exists. Furthermore, failing to respect the norm of racial equality, as the natural state of the status quo, threatens the ideal of fairness, another discursive resource discussed in the literature review. Another Fisher brief drew upon equality in conjunction with race and fairness contending that "the ideal of racial equality applies to members of a racial majority as it does to members of a racial minority. (Brief of amici curiae California Association of Scholars, Connecticut Association of Scholars, Center for Constitutional Jurisprudence, et. al, in support of petitioner, 2012, p. 31, emphasis added). The implication of this quote that it is unfair to exclude the racial majority in policies or discussions related to racial equality. As expressed in these briefs, racial equality is presumed as the natural state of social life and interference in this issue is unfair.

The Fisher briefs also engaged equality as a discursive resource in conjunction with terms such as equal treatment, equal protection, equal dignity, and equal opportunity 
to argue that race-conscious admissions are antithetical to constitutional and moral principles and ideals. For example, one brief attempted to turn the moral table on the consideration of race by arguing that " $[\mathrm{t}]$ he use of racial labeling by the University of Texas is incompatible with one of the basic premises of the Constitution: the inherent, equal dignity of all persons (Amicus brief of the American Center for Law and Justice in support of petitioner, 2012, p. 2, emphasis added). Another brief contrasted racial preferences with the discursive resources of opportunity and achievement by contending that " $[\mathrm{t}]$ he path to genuine equality of opportunity is not paved with racial and ethnic preferences. It is paved with genuine achievement (Brief of the Texas Association of Scholars as amici curiae in support of petitioner, 2012, p. 36, emphasis added). The taken-for-granted assumption that underlies all the preceding quotes is that equality is the norm, the way things are; and equality only ceases to exist if it is manipulated by raceconscious 'tinkering' (a term used by Justice Thomas in the final ruling). Based on this assumption of equality, higher education is an even playing field based on meritocratic principles by which all persons, regardless of race, succeed (or fail) according to his or her abilities. This logic reflects 'individualism,' a manifestation of the structuring principle of Whiteness, which assumes that success is a result of individual effort, accomplishment, and choices. From the perspective of individualism and meritocracy, any explicit benefit or obstacle to social goods based on race constitutes unfair and immoral discrimination and runs counter to the principle of equality.

In contrast to the Fisher briefs, which assumed equality as the natural state of contemporary social life, the UT briefs were informed by an underlying belief that the status quo produces a "complex system of structures that perpetuate disadvantage, often 
unintentionally and without sign of racial animosity" (Brief of amici curiae Coalition of Black Male Achievement Initiatives in support of respondents, 2012, p. 34). As this brief explains, inequality is inherent in and perpetuated by the current "system of structures" that constitute current social conditions. Thus, race-conscious admissions are needed to address this issue and therefore "judicial intervention to withhold from the states the tools necessary to resolve serious and continuing issues relating to race in America would forestall any resolution of the inequalities in our society" (Brief of the American Association for Affirmative Action as amicus curiae in support of respondents, 2012, p. 14). In this fashion, the UT briefs drew upon the discursive resource inequality to argue that race-conscious admissions are needed as a tool to remedy the current social conditions produced by discrimination against minorities.

The discursive struggle around whether society is characterized by equality versus inequality represents two divergent worldviews and standpoints. As engaged by the Fisher briefs, equality referred to the status quo of social relations, such that raceconscious admissions were unfair and threatened the natural state of equality. The UT briefs attempted to contest this vision of contemporary society by drawing upon inequality.

\section{History.}

Another prominent site of discursive struggle centered on the meaning of history in the context of racial classifications and racial preferences in admissions. The Fisher briefs engaged history as a discursive resource warning against racial classifications because such practices are discriminatory. The UT briefs, on the other hand, argued that history produced contemporary effects, which is why racial preferences are needed to 
remedy discrimination. I will now describe how this discursive struggle around history and discrimination emerged in the texts.

The Fisher briefs drew upon the historic discrimination of African Americans, Jews, and Asians to draw a moral equivalence (Cho, 2009) between racial classifications used to harm and those used to help members of racialized groups. This argument contends that any use of racial classifications, regardless of intent, is abhorrent and "deserve[s] the same opprobrium as segregated classrooms and Jim Crow railway cars" (Brief of Abigail Thernstrom, Stephan Thernstrom, Althea K. Nagai, and Russell Nieli as amici curiae in support of petitioners, 2012, p. 32). The immorality of the use of racial categories was further supported by referring to the use of racial categories in Nazi Germany:

In Germany in the early 20th Century, for example, the national regime composed detailed formulae for determining who would or would not be deemed Jewish... The horrific steps following this categorization led to the deaths of millions of Jews (Amicus brief of the American Center for Law and Justice in support of petitioner, 2012, p. 7).

Given this history, the argument contends that any use of racial classifications is inherently dangerous and must be avoided. Thus, the Fisher briefs drew upon history as a warning against repeating past transgressions. By arguing that racial classifications are something to look back upon and vow to never repeat, the unconscionable history of discrimination was drawn upon to discursively distance the past from the present.

The UT briefs contested this framing of history by arguing that history is not a thing of the past, but rather it is manifest in the lingering effects of "state sponsored and 
private segregation and discrimination in the United States against African Americans, Native Americans, Hispanics and Asian Americans. This segregation and discrimination has, in turn, limited educational and employment opportunities for these groups" (Brief of amicus curiae United Negro College Fund in support of respondents, 2012, p. 7). The UT briefs also drew upon the contextually specific historic discrimination at the University of Texas in arguing for the need to consider race in admissions:

UT excluded blacks from living in the on-campus dormitories designated for whites and specifically forbade all black students from entering the living quarters of white women. UT established separate and inferior residential housing for blacks. UT barred black students from intercollegiate athletics, excluded them from extracurricular activities such as music and theater, and permitted segregated fraternities and sororities. UT even banned black students from using the same bathroom facilities as whites. (Brief of the Advancement Project as amicus curiae in support of respondents and urging affirmance, 2012, p. 15)

The brief argued that this history produced lingering effects that "shape the current campus environment and influence how UT pursues its mission of training leaders to serve the state of Texas" (Brief of the Advancement Project as amicus curiae in support of respondents and urging affirmance, 2012, p. 5). In this fashion, the UT briefs used the past to contextualize the present, arguing that racial classifications are necessary to remedy the current situation produced by historic discrimination of various minority populations.

The Fisher briefs also made a connection between past and present day discrimination in higher education, but in a very different way. Several Fisher briefs 
drew upon the logic of moral equivalence to argue that the historic discrimination of Jews in higher education is the same as present day discrimination faced by Asian Americans due to race-conscious admissions policies. As one brief explained, "[i]n the 1920s, Harvard College and other prominent universities reacted to the perceived 'overrepresentation' of Jews in their student bodies by setting up informal quotas and other restrictive policies that persisted through the 1950s" (Brief for the Asian American Legal Foundation and the Judicial Education Project as amici curiae in support of petitioner, 2012, p. 18). This history of discrimination against Jews in higher education was then drawn upon to argue that "[h]istory repeats itself. Today the 'problem' on some campuses is not just 'too many whites,' but 'too many Asians.' Asians are perceived as the new 'upstarts' at highly competitive universities" (Brief of amici curiae California Association of Scholars, Connecticut Association of Scholars, Center for Constitutional Jurisprudence, et. al, in support of petitioner, 2012, p. 26). The Fisher briefs drew a parallel between previous policies used to exclude Jews from Harvard to the use of raceconscious admissions policies in California "to limit enrollment by Asian students because the more academically qualified Japanese and Chinese ancestry student were being admitted in numbers far beyond their ethnic groups' percentage of California's overall population" (Brief of the Texas Association of Scholars as amici curiae in support of petitioner, 2012). In other words, the Fisher briefs equated historic anti-Semitism in higher education to the impact of race-conscious admissions on Asian Americans.

While the Fisher briefs framed Asian Americans as the academically successful 'new upstarts,' the UT briefs drew upon the historic discrimination of Asian Americans to contest this framing by differentially racializing Asian Americans in a historic context: 
The history of U.S. policy on Asian immigration has vacillated from openness in the late 1800's — when the country needed the pioneering efforts of Asian immigrants - to exclusion during the internment camps of World War II and the anti-Asian immigration acts which largely closed U.S. borders to Asian immigration until the 1950 's... Since then, differences in the migration paths taken by Asian American and Pacific Islander subgroups have led to substantial economic and educational disparities in the Asian American community today. (Brief of the Asian American Legal Defense and Education Fund, Asian/Asian American Faculty and Staff Association of UT, et al., as amici curiae in support of respondents, 2012, p. 27)

In this way, history was drawn upon as discursive resource to argue that Asian Americans are not a homogenous group and, like African Americans, are victims of historic discrimination and marginalization that created and perpetuates contemporary inequality. By foregrounding the impact of U.S. history, the UT briefs attempted to shape the meaning of past and current discrimination to contest the moral equivalence argument engaged by the Fisher briefs.

\section{Harm.}

A third site of discursive struggle in the amicus briefs centered on the discursive resource of harm as both sides drew upon other discursive resources to shape understanding of who is helped and who is harmed by race-conscious admissions policies. Although the Fisher case was based on the assertion that race-conscious admissions are harmful to White and Asian students, as discussed above, another 
dominant line of argument in the Fisher briefs asserted that the beneficiaries of racial preferences in admissions are also harmed. For example, one brief argued that:

[t]here is increasing evidence that the so-called beneficiaries of racial preferences are actually harmed by them. Indeed, the evidence provided by Sander and Taylor suggest that these beneficiaries are producing weak educational outcomes: failure to pass professional competency exams, poor grades, or just plain dropping out. (Amicus curiae brief of the Center for Individual Rights in support of petitioner, 2012, p. 13)

The resulting harm, it is argued, is two-fold. First, failure to achieve academic success harms the individual in terms of livelihood and possibilities for the future. Second, the entire racial group is harmed "by creating a class of beneficiaries who conspicuously fail to achieve those goals when admitted to particular schools, preferential policies reinforce and compound the very stereotype of inferiority that those policies were intended to overcome" (Amicus curiae brief of the Center for Individual Rights in support of petitioner, 2012, p. 14). Even minorities who did not receive racial preferences are harmed because the existence of racial preferences "places an unwarranted badge of inferiority on the thousands of Hispanic and African-American applicants who are admitted to UT each year based on merit and achievement" (Brief for the petitioner, 2012, p. 42). In other words, minority students, regardless of ability, are automatically labeled as unable to meet the 'standards' and therefore are automatically stigmatized. Thus, the Fisher briefs insisted that minority students are harmed by racial preferences that set them up to fail, resulting in the perpetuation of negative stereotypes and stigmatization. 
The UT briefs contested this framing of harm to argue that the most pressing harm is that caused by the perpetuation of stereotypes due to lack of a critical mass of minority students in campus spaces. This logic contends that if there are too few minority students, minority students will feel isolated and become susceptible to psychological harm, such as "stereotype threat" which "manifests itself in anxiety and distraction that interferes with intellectual functioning" (Brief of amicus curiae the American Psychological Association in support of respondents, 2012, p. 3). The impact of harmful stereotypes is also imposed on "non-minority" students who are harmed by the "persistence of implicit bias that interferes with the educational process" (Brief of amicus curiae the American Psychological Association in support of respondents, 2012, p. 10). These implicit biases perpetuate harmful stereotypes that "diminish the growth and selfrealization for students who live their lives based on narrow and incomplete views about other people" (Brief of the Black Student Alliance at UT, the Ex-Students of Texas, Inc., and the NAACP in support of respondents, 2012, p. 11). In other words, while the Fisher briefs argued that race-conscious admissions harms minority students, the UT briefs reversed the meaning of harm as a discursive resource to argue that without such policies White students would be harmed by an education process hindered by bias and stereotypes. In this way, both sides tried to shape the understanding of who is harmed and why.

\section{Emotional cost versus material cost.}

A fourth site of discursive struggle involved cost as discursive resource. The struggle for meaning centered on the cost, or impact, of race-conscious admissions on society. The Fisher briefs drew upon cost in terms of 'cost-benefit' analysis. In this line 
of argument, any possible benefit in terms of increasing minority student population was outweighed by the emotional costs to society. For example, one Fisher brief argued that: $[\mathrm{t}]$ he speculative benefits of a diverse student body must be weighed against the inherent, undeniable, and well-known costs... racial classifications tear at the very fabric of our society, dehumanize us as individuals, and significantly hamper the very students they are designed to protect. (Brief amicus curiae of Pacific Legal Foundation, Center for Equal Opportunity, American Civil Rights Institute, et al., in support of petitioner, 2012, p. 17)

In this cost-benefit analysis, the emotional costs that "tear at the very fabric of our society" are tangible and far outweigh any "speculative benefits" that might be produced by a diverse student body. Several of the Fisher briefs similarly drew upon the language associated with cost in arguing that the increase in minority enrollment due to raceconscious admissions creates only "small gains," "minimal impact," and a "negligible effect." In other words, because race-conscious admissions only minimally increase minority enrollment, the potential contribution to diversity advanced by these policies must also be minimal. Therefore, the cost of race-conscious admissions cannot be worth the harms to White and minority students, as articulated in the previous section on harm as a discursive resource.

While the Fisher briefs' conceptualization of 'costs' focused on the emotional harms inflicted on society and individuals, the UT briefs discursively linked costs with the discursive resource of inequality to articulate a material understanding of 'cost,' one that is extracted upon the broader unit of society, as illustrated in the following two quotes: 
Research shows that racial inequality in primary and secondary education undermines the nation's economic prosperity and its national security. The achievement gap costs the United States hundreds of billions of dollars a year, contributing to the economic equivalent of a permanent national recession (Brief of amicus curiae Teach for America, Inc. in support of respondents, 2012, p. 4)

$[R]$ research findings suggest that social disadvantage in the United States today is largely structural. That is, community-level, place based risk factors, such as limited access to healthcare and healthy, fresh foods and the supermarkets that stock them, are predictive of dramatic health inequalities. All of the residents of a state end up paying for the costs of these disparities. (Brief of amici curiae Coalition of Black Male Achievement Initiatives in support of respondents, 2012, p. 32)

These quotes argued that inequality extracts a financial cost on society at large through government programs needed to address economic and health disparities caused by inequality in education. This material cost of inequality on society shifted the focus from harm to impoverished communities or individuals to a broad social problem that affects everyone. This argument was not widely taken up in the UT briefs and was not mentioned in the oral transcript or final ruling, therefore it is conceptualized as a marginalized discursive resource and will be explored more in depth in answering my third research question. 


\section{Critical mass and quantification.}

The discursive struggle to impose meaning on critical mass as a discursive resource produced by the Grutter structure centered on definitions of and evidence for the concept of critical mass. As previously discussed, the Grutter structure allows that universities may consider race as part of their admissions review process in order to obtain a 'critical mass,' or meaningful representation, of minority students deemed necessary to further the compelling interest in diversity. However, the definition of critical mass is also constrained by the fact that racial quotas or goals were previously delegitimized in case precedent (e.g. Bakke v. Reagents and Gratzv. Bollinger). In other words, the discursive resource critical mass is also a discursive structure that enables and constrains how critical mass can be engaged as a discursive resource. In so doing, the critical mass rule creates a structural contradiction between meaningful representation and prohibited quotas or numeric goals. The Fisher briefs attempted to exploit this contradiction through the discursive resource quantification, while UT briefs attempted to resist quantification and resolve the contradiction through the discursive resource of qualitative evidence.

The Fisher briefs insisted that critical mass could only be defined in quantifiable terms because:

[w]ithout a numerical goal, how does the University determine if a protected minority is 'underrepresented' unless it has already established 'a satisfactory level of representation.' How does the University determine if the required 'critical mass' has been attained, if it does not use a set numerical target? (Brief of 
the Texas Association of Scholars as amici curiae in support of petitioner, 2012, p. 7)

The argument asserts that the only way to define critical mass is in quantifiable terms. Without such quantification, critical mass is "such an amorphous and indefinable concept that no narrowly tailored remedy to achieve it can be identified" (Amicus curiae brief of Mountain States Legal Foundation in support of petitioner, 2012, p. 3). This line of argument sought to delegitimize the concept of critical mass because it was "arbitrary," "ambiguous," and "amorphous." Thus, the Fisher briefs argued that the use of critical mass to justify race-conscious admissions is suspect because "its use can be supported in every instance by manipulation of the racial groups for which a 'critical mass' is sought or the level at which 'critical mass' is applied" (Brief of the Cato Institute as amicus curiae in support of the petitioner, 2012, p. 4). Therefore, in order to shape the meaning of the discursive resource critical mass, the Fisher briefs drew upon the discursive resource of quantification to argue that critical mass could only be defined in numerical terms, even though applying any quotas, goals, or percentages in race-conscious admissions is unconstitutional.

The UT briefs contested the discursive constraint of quantification and struggled to shape the definition of critical mass in qualitative terms, as illustrated in the following two exemplars:

It is not appropriate to reduce critical mass to a simple target number. The optimal level of student body diversity depends upon numerous considerations and varies by institution. Colleges and universities should be given breathing space to determine and to tailor, based on their relevant expertise, the appropriate 
critical mass of students for their campuses in order to guard against the dangers of underrepresentation and to secure the many benefits that flow from diversity. (Brief of amicus curiae the American Psychological Association in support of respondents, 2012, p. 22).

\section{***}

There is no quota, target, or predetermined percentage of undergraduate enrollment that automatically produces these benefits; nor could there be, as this Court has directed repeatedly. For this reason, critical mass cannot be defined by simple numerical calculations alone. Rather, critical mass depends on the quality, as much as the quantity, of individual students' cross-racial interactions, as well as the context and community in which the particular university is situated. (Brief of the Black Student Alliance at UT, the Ex-Students of Texas, Inc., and the NAACP in support of respondents, 2012, p. 8).

In these examples, the UT briefs resisted the attempts to constrain critical mass to an objective, quantifiable concept by asserting a contextual, qualitative meaning. This debate around what 'counts' as evidence reflects an ongoing ideological and epistemological struggle in a system that privileges objectivity and rationality over subjectivity and emotionality. This discursive struggle around quantitative vs. qualitative definitions and evidence in conjunction with critical mass also dominated the oral arguments, as will be discussed in the next section. There was only one instance in which the UT briefs challenged the discursive structure of critical mass by suggesting that the term be eliminated altogether: 
[P]erhaps it is time to retire the term 'critical mass' from the lexicon. Comparing minorities to a fissionable lump of uranium is probably not the most fortunate nomenclature, especially if one wants to reduce racial tensions. 'Significant number' or 'substantial group' may be less explosive terms than 'critical mass.'

(Brief of amicus curiae David Boyle in support of respondents, 2012, p. 40)

While the majority of UT briefs focused on defining and defending the term critical mass, this quote reflects the only instance of contesting the term. Therefore, I initially considered this resistance to be a marginalized or non-dominant argument. However, the problematic nature of this term was also raised by Justice Scalia in the oral arguments, indicating that critical mass as part of the Grutter discursive structure may be losing some legitimacy, as will be discussed in chapter five.

\section{Diversity and race.}

The contested meanings of the discursive resources diversity and race dominated the discursive practice of debating the Fisher case, as will be illustrated throughout the remainder of this analysis. The Grutter structure legitimized particular dominant meanings of these discursive resources that enabled and constrained the debate. According to Grutter, diversity of student body is important because of the educational benefits that constitute a compelling state interest. Within this discursive structure, race is conceptualized as one aspect of diversity that may legitimately be considered in the application process in order to obtain these benefits. My analysis revealed that the UT briefs drew upon and reproduced the dominant meaning system around diversity and race as structured by Grutter. The Fisher briefs, on the other hand, both drew upon and attempted to transform the Grutter structure, by asserting meanings of diversity and race 
that delegitimized the consideration of race as part of the compelling interest in diversity. Within this discursive struggle, each side of the debate engaged various discursive resources to legitimize and delegitimize particular meanings of diversity and race, as will now be discussed.

\section{The business case for diversity.}

The legitimized rationale for diversity produced by Grutter can be understood as the 'business case' for diversity. The business case for diversity is based on a marketdriven rationale that focuses on the needs of employers to bolster support for diversity initiatives (Litvin, 2006; Mease, 2012; Perriton, 2009). The business case is epitomized in the following quote:

Because small businesses have more limited resources to recruit, train, and manage a diverse workforce, small businesses often depend heavily on public institutions like the University of Texas at Austin to provide not only the knowledge and skills that small business leaders need to excel, but also access to the business and social networks that are critical to succeeding in business. (Brief for amici curiae Small Business Owners and Associations in support of respondents, 2012, p. 4)

As an argument for the continued use of race-conscious admissions, this quote asserts the role of the university as a training ground to produce qualified employees with valuable networks who can meet the needs of businesses. The needs of business as a primary rationale for diversity is further exemplified in the following quote:

The importance of diversity to success in business is supported by multiple studies showing that a diverse workforce provides significant business benefits. 
Specifically, increasing racial diversity in the workplace increases sales revenue, increases the number of customers, increases market share, and, ultimately, increases profits. Increased racial diversity leads to increased employee productivity and performance, decreased lawsuits, increased market opportunities, increased recruitment, increased creativity, and a healthier business image. (Brief of the American Association for Affirmative Action as amicus curiae in support of respondents, 2012, p. 16)

The above quote foregrounds the market-driven interests (e.g., increased profits, productivity, market opportunities) that constitute the compelling interest in diversity as legitimized within the business case rationale. The majority of the UT briefs engaged discursive resources associated with the business case for diversity through the consistent repetition of terms such as global, competitive, markets, employers, employment, leadership, and success. These discursive resources are produced by and reproduce the discursive structure or underlying ideological assumptions of the 'right to profit' discursive structure. As discussed in chapter two, the 'right to profit' structure is a manifestation of the structuring principle of Whiteness that produces 'the profit motive' as a dominant discursive resource that legitimizes social practices (Okun, 2009). Thus, the business case for diversity draws upon the discursive logic of the profit motive to enhance the legitimacy of the compelling interest in diversity.

The UT briefs also (re)produced the discursive resource of race in relation to diversity within this 'right to profit' meaning system. Drawing upon the business case rationale for the consideration of race, the UT briefs discursively constructed race as a commodity with instrumental value as illustrated in these typical examples: 
The University's policy has increased the enrollment of well-qualified African American and Latino students who help the University leverage the benefits of diversity in its classrooms and on campus (Brief of American Social Science Researchers as amici curiae in support of respondents, 2012, p. 10)

The only means of obtaining a properly qualified group of employees is through diversity in institutions of higher education, which are allowed to recruit and instruct the best qualified minority candidates and create an environment in which all students can meaningfully expand their horizons (Brief for amici curiae Fortune-100 and other leading American businesses in support of respondents, 2012, p. 2)

\section{$* * *$}

[T] here is, as yet, no race-neutral method that can replace race as a factor that provides insight into the applicant's experiences and potential contributions to diversity (Brief of amici curiae the American Jewish Committee, Central Conference of American Rabbis, and Union for Reform Judaism in support of respondents, 2012, p. 28)

In each of these examples, race is conceptualized as an essential part of the diversity equation that "help[s] the University leverage the benefits of diversity," "create[s] and environment" for expanding horizons, and provides insights into "potential contributions" to a diverse learning environment. By linking race to diversity and diversity to productive outcomes, race was legitimized as a valuable commodity that serves instrumental goals. 
Neither side of the debate contested the business case for diversity as a compelling state interest, which illustrates the discursive power produced by the Grutter structure. Even (most of) the Fisher briefs acknowledged the importance of diversity in terms of educational benefits as proposed by Grutter. Rather than contesting the compelling interest in diversity, the Fisher briefs attempted to delegitimize race in relation to diversity in order to transform the Grutter structure.

\section{Legitimate versus illegitimate diversity.}

The Fisher briefs tried to shape the meaning of diversity through discursive resources that attempted to delegitimize race as a relevant aspect of diversity. According to the Fisher briefs, the legitimate conceptualization of diversity that serves a compelling interest in educational benefits is an amalgamation of a variety of individual factors including "socio-economic status, geography, as well as diversity of skills, interests, and experiences" (Brief for amici curiae current and former federal civil rights officials in support of petitioner, 2012, p. 7). These various individual traits constitute what the Fisher briefs referred to as real, genuine, organic, and naturally occurring diversity. In contrast, diversity that includes race as a factor was labeled artificial, manufactured, and racial pork-barreling. The main argument being that policies promoting racial diversity serve only to locate people within "misleading" racial groups, which undermines "true diversity" (Brief of the Asian American Legal Defense and Education Fund, Asian/Asian American Faculty and Staff Association of UT, et al., as amici curiae in support of respondents, 2012, p. 4). For example:

Attempts to force racial diversity necessarily act to the detriment of genuine individual diversity. The very act of classifying students by 'race' in the first 
place creates artificial groupings that mask the myriad differences within those classifications, and detracts focus from the individual. (Brief of amici curiae California Association of Scholars, Connecticut Association of Scholars, Center for Constitutional Jurisprudence, et. al, in support of petitioner, 2012, p. 3) Thus, individual experience rather than experience as part of a racial group constitutes "genuine" diversity, which is threatened by "artificial" categories such as race. This quote imposes a meaning of diversity that reproduces the structuring principle of Whiteness by drawing upon the underlying discursive structure of individualism, as discussed in chapter two. Within this belief system, the locus of control (over one's life) is understood to lie within individuals, irrespective of group or collective identities. The following quote further draws upon individualism to turn the moral table on raceconscious admissions through arguments such as:

Far from promoting genuine diversity - which is a function of individual qualities, abilities, experience and interests - using racial demographics as the yardstick for diversity merely masks racial stereotyping and appropriates the language of diversity for the far less noble goal of proportional racial representation. (Brief for the Asian American Legal Foundation and the Judicial Education Project as amici curiae in support of petitioner, 2012, p. 24)

In this quote, "genuine diversity" is constructed as a variety of individual traits, excluding race; while the consideration of race as part of diversity is "less noble." This same brief further argued for the moral high ground by contending that race-conscious admissions are a "perversion of the otherwise worthwhile goal of 'diversity" (p. 25). Thus, this 
quote both reproduced and attempted to transform the compelling interest in diversity rule as part of the Grutter structure by contesting race as a meaningful aspect of diversity. Another way that the Fisher briefs attempted to delegitimize race in connection to diversity was to draw upon the discursive resource of biological science to deny that race exists as a meaningful category experience. For example, one brief argued:

Human race and ethnicity are inherently ambiguous social constructs that have no validity in science. Invoking race and ethnicity to promote diversity relies on racial and ethnic stereotyping of individuals' viewpoints, backgrounds, and experiences. (Brief of amici curiae Judicial Watch, Inc. and Allied Educational Foundation in support of petitioner, 2012, p. 2)

By defining race as a social construction lacking scientific validity, this quote appropriated social constructionist understandings of race in order to delegitimize race as meaningful category of experience. As discussed in my literature review, social constructionist theories of race contend that race does not carry inherent meaning, but rather race is the product of socially constructed, historically contingent, power-laden social practices (Frankenberg, 1993; Haney-López, 2006; Horton, 2005; Omi \& Winant, 1986). The above quote drew upon this argument to contend that since race is nothing but a social construct, any consideration of race amounts to stereotyping. Another brief drew upon this same logic by arguing that:

Racial beliefs constitute myths about the diversity in the human species and about the abilities and behavior of people homogenized into "racial" categories. The myths fused behavior and physical features together in the public mind, impeding comprehension of both biological variations and cultural behavior, implying that 
both are genetically determined. Racial myths bear no relationship to the reality of human capabilities or behavior. (Brief of amici curiae Judicial Watch, Inc. and Allied Educational Foundation in support of petitioner, 2012, p. 7)

Similar to the preceding quote, this argument appropriated the logics that were once used to contest racist laws and practices that discriminated against Black people in order to argue that race has no basis in human experience. The following quote provided yet another example of engaging science as a discursive resource to delegitimize race:

Clear-cut categories do not exist. The particular traits which have generally been chosen to characterize races have been criticized as having little biological significance. It has been found that differences between individuals of the same race are often greater than the differences between the 'average' individuals of different races. (Amicus brief of the American Center for Law and Justice in support of petitioner, 2012, p. 5)

Thus, by focusing attention on the individual as the meaningful site of experience, the importance of race as a collective or group experience of discrimination is obscured. According to the preceding quotes, race is nothing more than a myth, an unscientific proposition, and an artificial grouping used to replace individual identity with collective stereotypes. By these accounts, the concept of race is an assault on individualism and antithetical to diversity. These quotes attempted to turn the moral table on raceconsciousness by defining race as a social construction with no basis in biological science. The rhetorical force of racial denial is derived from the White ideology of individualism, which centers the individual as the locus of experience and action, while 
obscuring the collective experience of historic and contemporary discrimination based on race.

As this section of analysis revealed, the heart of the debate around race-conscious admissions are the contested meanings of diversity and race. Although both sides drew upon and (re)produced the compelling interesting in diversity, the meaning of diversity and what types of diversity should be legitimately considered in admissions was a central site of discursive struggle in the debate, and remained so throughout all stages of this discursive practice.

\section{Section summary.}

My analysis of the amicus briefs revealed a discursive struggle for meaning to shape the Court's understanding of discrimination, history, harm, costs, critical mass, diversity, and race as discursive resources in the context of race-conscious admissions. For the most part, the debate engaged the same the dominant pro- and anti-affirmative action arguments that have framed the debate over the past decades, as outlined in chapter two. Unsurprisingly, the debate continues to center on the contested meanings of diversity and race. However, what emerged as new from this analysis was the discursive attack and destabilization of the discursive resource critical mass as provided by the Grutter structure. In the following section, I discuss how the contested meanings of diversity, race, and critical mass continued to dominate this discursive practice in the oral arguments.

\section{Transcript of the Oral Arguments}

The oral arguments took place on October 10, 2012 and lasted for one hour and twenty minutes. The transcript of the oral argument was 83 pages long, plus 15 pages of 
indexed words. Participants in the oral argument included Mr. Rein (Fisher's lawyer), Mr. Garre (UT's lawyer), General Verrilli (friend of the court, supporting UT), Chief Justice Roberts, and Justices Scalia, Sotomayor, Beyer, Kennedy, Alito, and Ginsberg ${ }^{1}$. During the oral arguments, the lawyers responded to questions asked by the Justices. In this sense, the Justices structured this phase of this discursive practice by enabling and constraining particular discursive resources.

The oral arguments represent the first filtering down of discursive resources from the amicus briefs. The contested meanings of critical mass, diversity, and race dominated the discursive struggle in this phase of the process, while history, harms, and discrimination were marginalized or excluded. The marginalization and exclusion of discursive resources was evidenced by the appearance or absences of key words from the index. For example, the word 'discrimination' was mentioned only one time in oral arguments; 'harm' was not mentioned at all, but the related word 'stereotype' did appear two times in the transcript. The word history was also mentioned twice. Although these discursive resources were heavily engaged in the amicus briefs, the absence of these words in oral transcript indicates that these discursive resources were 'filtered out' of this stage of the debate. In the oral arguments, the discursive struggled centered almost exclusively around the contested meanings of the discursive resources critical mass, diversity, and race.

\footnotetext{
${ }^{1}$ Justice Thomas did not appear in the transcript, so it is unclear if he was present during the oral arguments.
} 


\section{Critical mass.}

Critical mass emerged as a central site of discursive struggle in the oral arguments. According to the word index, the phrase critical mass was used 82 times, which illustrates the term's dominance in the text. As explained in the previous section, the discursive resource critical mass creates a contradiction within the discursive structure of Grutter. Within this rule-resource set, the constitutionality of race-conscious admissions depends on being able to show that the use of race is narrowly tailored to meet the compelling interest in diversity. At the same time, the Grutter structure provided that a critical mass of minority students was necessary to achieve that compelling interest. In other words, a university must have enough minority students to reap the benefits of diversity, but must use very restrictive methods to obtain critical mass in terms of explicitly considering race. Additionally, racial quotas are strictly prohibited, based on Bakke (1978) and Gratz (2003). And yet, the dominance of the discursive resource of quantification to shape the discursive resource of critical mass was illustrated by the fact that the words percent, percentage, and number were together used a total of 108 times, according to the index. Similar to arguments in the Fisher briefs, some of the Justices tried to impose a numerical definition of critical mass in questioning UT's lawyer:

CHIEF JUSTICE ROBERTS: What is that number? What is the critical mass of African Americans and Hispanics at the university that you are working toward? (Fisher v. University of Texas at Austin (oral arguments), 2013, p. 39)

$$
\text { *** }
$$


JUSTICE ALITO: How many -- how many non-top 10 percent members of the two minorities at issue here are admitted in each class? (Fisher v. University of Texas at Austin (oral arguments), 2013, p. 36)

JUSTICE SCALIA: And how do they decide? You know, it's -- they want not just a critical mass in the school at large, but class by class? How do they figure out that particular classes don't have enough? (Fisher v. University of Texas at Austin (oral arguments), 2013, p. 34)

The fact that three different Justices attempted to force UT's lawyer, Mr. Garre, to articulate critical mass in numeric terms illustrates the (re)production of the discursive resource 'quantification' as engaged in the Fisher briefs to delegitimize critical mass as part of the Grutter structure. Fisher's lawyer, Mr. Rein, attempted to exploit the contradiction produced by the Grutter structure by arguing that defining critical mass is important because "you can't tailor to the unknown. If you have no range of evaluation, if you have no understanding of what critical mass means, you can't tailor to it" (Fisher v. University of Texas at Austin (oral arguments), 2013, p. 19). In other words, Mr. Rein insisted that critical mass must be defined in numeric terms, even though it is not constitutionally permissible to do so. Justice Sotomayor turned the rhetorical table on Mr. Rein and asked how he would define that number:

JUSTICE SOTOMAYOR: So what are you telling us is the standard of critical mass? At what point does district court or a university know that it doesn't have to do any more to equalize the desegregation that has happened in that particular state over decades, that it's now going to be stuck at a fixed number and it has to 
change its rules. What's that fixed number? (Fisher $v$. University of Texas at Austin (oral arguments), 2013, p. 17)

By drawing upon past discrimination as a discursive resource, Justice Sotomayor contested the meaning of critical mass and challenged the contradiction imposed by quantification. The underlying meaning of her questioning was "How many people of color is enough to make up for the past?" A question, of course, that no one would want to be forced to answer. Therefore, Mr. Rein continued to avoid quantifying critical mass: MR. REIN: Well, Justice Sotomayor, I think it's very important to distinguish between the operative use of that range. In other words, that's where we are, and we're going to use race until we get there, every year, in consideration of each application, which was a problem --(Fisher $v$. University of Texas at Austin (oral arguments), 2013, p. 18)

The underlying assumption of this argument is that once a particular target has been reached, there will no longer be a justification for racial remedies. Therefore, there must be a specified, identifiable end point. This logic is based on a forward looking rationale that ignores the historic context that Justice Sotomayor referred to in the previous quote. To challenge Mr. Rein's end point argument, Justice Sotomayor drew upon the Grutter rule-resource set:

JUSTICE SOTOMAYOR: Boy, it sounds awfully like a quota to me, that Grutter said you should not be doing, that you shouldn't be setting goals, that you shouldn't be setting quotas. You should be setting an individualized assessment of the applicants (Fisher v. University of Texas at Austin (oral arguments), 2013, p. 
By drawing upon the rules imposed by the Grutter structure, Justice Sotomayor's questions and retorts to Mr. Rein served to constrain his exploitation of the structural contradiction produced by the critical mass rule. The only other instance in which discrimination and racism were engaged as a discursive resource occurred as Mr. Varelli answered Chief Justice Roberts request:

CHIEF JUSTICE ROBERTS: Okay. I'm hearing a lot about what [critical mass is] not. I'd like to know what it is because our responsibility is to decide whether this use of race is narrowly tailored to achieving, under this University's view, critical mass. (Fisher v. University of Texas at Austin (oral arguments), 2013, p. 70)

MR. VARELLI: I think the way the Court would go about making that independent judgment is to look at the kind of information that the university considered. That could be information about the composition of the class. It could be information about classroom diversity. It could be information about retention and graduation rates. It can be information about -- that's specific to the university's context in history. Is it a university that has had a history of racial incidents and trouble or not? A series of factors...(Fisher v. University of Texas at Austin (oral arguments), 2013, p. 70)

In this quote, Mr. Varelli subtly drew upon historic discrimination and current racial tensions at UT to decouple the concept of critical mass from demographic representation. The list of criteria that he referred to (information about classroom diversity, graduation and retention rates, racial problems on campus) were all part of UT's dossier in defending its use of race-conscious admissions and defining critical mass. However, Mr. Rein 
dismissed UT's evidence arguing that they "just used words" and failed to define a “working target” (Fisher v. University of Texas at Austin (oral arguments), 2013, p. 13).

Thus, Mr. Rein attempted to delegitimize the evidence UT used to demonstrate that it had not yet reached a critical mass of minority students.

After extensive questioning around critical mass throughout the oral argument, Justice Scalia finally suggested that "[we] should probably stop calling it critical mass then, because mass, you know, assumes numbers, either in size or a certain weight" (Fisher v. University of Texas at Austin (oral arguments), 2013, p. 70). This critique of the term critical mass was also brought up once in the UT briefs and seemed to point to a destabilization of this rule of Grutter structure. But then, the discursive opening was closed when Justice Scalia jokingly suggested to "call it a cloud or something like that" (Fisher v. University of Texas at Austin (oral arguments), 2013, p. 71). The implication of his joking tone was that his suggestion to reconsider the problematic term critical mass in ways that might resolve the structural contradiction was not to be taken seriously. Thus, through the oral arguments, the term critical mass remained a dominant and contested discursive resource. As will now be discussed, my analysis revealed that the concept of critical mass was intertwined with diversity and race.

\section{Diversity and race.}

The meaning of diversity in relation to race was contested and challenged throughout the oral arguments and emerged as another dominant site of discursive struggle. The term diversity was mentioned 36 times in the transcript, while the word race was mentioned 91 times, which illustrates the centrality of these discursive resources. Additionally, specific groups were mentioned: African American 25 times, 
Hispanic 26 times, Asian 13 times, minorities 52 times, and White 3 times. The relative absence of specifically saying the word 'White' will be addressed in the final phase of analysis. Just as in the amicus briefs, the discursive structure of diversity as a compelling interest was not challenged in the oral arguments. In fact, in the oral argument, Fisher's lawyer specifically pointed out that in presenting their case "we had said, very carefully, we were not trying to change the Court's disposition of the issue in Grutter" (Fisher v. University of Texas at Austin (oral arguments), 2013, p. 8). Rather, the discursive struggle centered around the meanings of diversity and race and how these concepts should be operationalized in admissions policies.

In order to justify UT's consideration of race, Mr. Garre had to explain why raceneutral policies did not meet the UT's need to garner a diverse student body. He argued that the race-neutral plan guarantying admission to the top $10 \%$ of graduates at Texas' racially segregated high schools produced "diversity that looks okay on paper, but it doesn't guarantee you diversity that produces educational benefits on campus" (Fisher v. University of Texas at Austin (oral arguments), 2013, p. 41). Instead, Mr. Garre argued, the type of diversity that generates educational benefits comes from "representatives and different viewpoints from individuals within the same -- the same racial group, just as you would from individuals outside of that" (Fisher v. University of Texas at Austin (oral arguments), 2013, p. 42). The logic behind Mr. Garre's argument is that if you only admit minorities who grew up in the same areas and went to the same schools as each other, you would not be able to explicitly look for "the kind of candidate that's going to come on campus, help to break down racial barriers, work across racial lines, dispel stereotypes" (Fisher v. University of Texas at Austin (oral arguments), 2013, p. 42). In 
other words, Mr. Garre was arguing for intra-racial diversity, meaning minorities from the same racial group, but from varying socio-economic and geographic backgrounds. This argument attempted to decouple the discursive resources of diversity and race from the discursive resource of socio-economic class in order to contest the idea that raceneutral policies are sufficient to achieve the compelling interest in diversity. Mr. Garre's attempt to shape the meaning of diversity away from socio-economic class was challenged by Justices Alito and Kennedy.

Justices Alito's line of questioning and commentary sought to discursively link diversity and social class. Justice Alito argued, "I thought that the whole purpose of affirmative action was to help students who come from underprivileged backgrounds, but you make a very different argument that I don't think I've ever seen before" (Fisher $v$. University of Texas at Austin (oral arguments), 2013, p. 43). It is uncertain whether this comment is sincere, because the concept of intra-racial diversity was actually raised a few times in the UT briefs. Justice Alito continued this discursive linking of race and class by questioning whether minority applicants who come from privileged backgrounds "deserve a leg-up against, let's say, an Asian or a white applicant whose parents are absolutely average in terms of education and income" (Fisher v. University of Texas at Austin (oral arguments), 2013, p. 44). This argument about whether minorities from economically privileged backgrounds deserve a preference serves to decouple race from power by asserting a view that racism and discrimination are only manifest in socioeconomic conditions, rather than in the daily lived experiences of racial minorities. Furthermore, the question of whether minorities deserve racial preferences draws upon the discursive resource of innocence and fairness, as discussed in chapter two, in which 
Black beneficiaries of affirmative action are discursively framed as the "undeserving Black taker" (Ross, 1990, p. 310) in contrast to innocent White victims.

Justice Kennedy further drew upon this discursive linkage between race and socio-economic status in the context of the Grutter structure to create another discursive trap for Mr. Garre. According to the Grutter decision, race can only be considered as part of a "holistic review of each applicant's file, giving serious consideration to all the ways an applicant might contribute to a diverse educational environment" (Grutter v. Bollinger, 2003, p. 337). In the following exchange, Justice Kennedy attempted to force Mr. Garre to admit that race was not just one factor, but was in fact the predominant consideration in UT's plan:

MR. GARRE: Because, Your Honor, our point is, is that we want minorities from different backgrounds. We go out of our way to recruit minorities from disadvantaged backgrounds.

JUSTICE KENNEDY: So what you're saying is that what counts is race above all?

MR. GARRE: No, Your Honor, what counts is different experiences -JUSTICE KENNEDY: Well, that's the necessary -- that's the necessary response to Justice Alito's question.

MR. GARRE: Well, Your Honor, what we want is different experiences that are going to -- that are going to come on campus -

JUSTICE KENNEDY: You want underprivileged of a certain race and privileged of a certain race. So that's race. 
MR. GARRE: No, Your Honors, it's -- it's not race. It's just the opposite. I mean, in the LUAC decision, for example, this Court said that failing to take into account differences among members of the same race does a disservice -JUSTICE KENNEDY: But the -- but the reason you're reaching for the privileged is so that members of that race who are privileged can be representative, and that's race.

In this exchange, Mr. Garre again attempted to decouple race from class by arguing that race has an impact on an individual's life experience, whether the applicant is economically privileged or not; therefore, both race and class should be considered as two different factors. By arguing that "race counts above all" in the applicant selection process, Justice Kennedy forced discursive closure around Mr. Garre's rationale in an attempt to delegitimize UT's consideration of race in the context of the Grutter structure, which prohibits using race as a defining feature of the application scoring process.

Both Justices Alito and Kennedy attempted to delegitimize UT's consideration of race by discursively linking race and class. According to Justice Alito's questioning, only economically disadvantaged minorities deserved a "leg up" over White people in the admissions process. In other words, race should only be a consideration when it is not too unfair to White people. While Justice Alito's discourse privileged class over race in the race/class connection, Justice Kennedy seemed to conflate the two concepts by discrediting Mr. Garre's argument that race and class are distinct and meaningful categories of experience in terms of the compelling interest in diversity structure.

The other dominant discursive struggle around race centered on what legitimately counts as membership to a racial group. In this series of exchanges between Chief Justice 
Roberts and Mr. Garre, the Chief Justice contested the legitimacy of racial categories and then questioned the legitimacy of racial self-identification:

CHIEF JUSTICE ROBERTS: Counsel, before -- I need to figure out exactly what these numbers mean. Should someone who is one-quarter Hispanic check the Hispanic box or some different box? (Fisher v. University of Texas at Austin (oral arguments), 2013, p. 32)

MR. GARRE: Your Honor, there is a multiracial box. Students check boxes based on their own determination. (Fisher v. University of Texas at Austin (oral arguments), 2013, p. 32)

CHIEF JUSTICE ROBERTS: Well, I suppose a person who is one-quarter percent Hispanic, his own determination, would be, I'm one-quarter percent Hispanic. (Fisher v. University of Texas at Austin (oral arguments), 2013, p. 32) CHIEF JUSTICE ROBERTS: They would check that box. What about oneeighth? (Fisher v. University of Texas at Austin (oral arguments), 2013, p. 33) MR. GARRE: Your Honor, that was -- they would make that self-determination, Your Honor. If -- if anyone, in any part of the application, violated some honor code then that could come out. (Fisher v. University of Texas at Austin (oral arguments), 2013, p. 33)

CHIEF JUSTICE ROBERTS: Would it violate the honor code for someone who is one-eighth Hispanic and says, I identify as Hispanic, to check the Hispanic box? (Fisher v. University of Texas at Austin (oral arguments), 2013, p. 33)

The Chief Justice's line of questioning is based on a biological conceptualization of race. His discursive logic is reminiscent of the "one drop of blood rule," as discussed in the 
literature review, which served to constitute Whiteness by demarcating non-White subjects as those who had one drop (or more) of African blood. The 'one drop of blood' rule was originally applied to delineate racial categories in order to restrict certain rights and privileges to White people. The Chief Justice drew upon this same biological concept of race to destabilize such categories in order to constrain non-White subjects' claim to racial preferences in the admissions process. The implied question underlying the Chief Justice's discursive logic was how much racial/ethnic blood is enough to warrant a preference that is restricted from White people. Then, the Chief Justice further destabilized the legitimacy of racial categorizations by voicing suspicion about the process of self-identification, when he asked "You don't check, in any way, the racial identification?" (Fisher v. University of Texas at Austin (oral arguments), 2013, p. 34). This question infers that the Chief Justice not only believes that racial categories suspect, but so is the process of self-identification. This suspicion presumes that there is an objective measure of racial identity and individuals should not be trusted to make that determination. By constraining racial identity to a biological definition and casting suspicion on racial self-identification, Chief Justice Roberts' line of questioning served to delegitimize the discursive resources of race and racial identity in race-conscious admissions arguments.

\section{Section summary.}

In the oral arguments, the Justices exerted agency to impose and/or contest the meanings of particular discursive resources. For the most part, discursive resources associated with history, discrimination, and harm were excluded from this phase of the discursive practice. Instead, the Justices focused the oral arguments around the contested 
meanings of critical mass, diversity, and race. As revealed through the various excerpts from the transcript highlighted in this section, several of the Justices attempted to impose meanings that delegitimized critical mass, diversity, and race as interrelated discursive resources within the context of the Grutter structure. The quantification of critical mass, the discursive linking of race and class, and the discourse of suspicion around racial classifications and self-identification were engaged as rhetorical logics to weaken the discursive power of these discursive resources in arguments favoring race-conscious admissions. As a consequence, the Justices also strengthened these discursive resources for arguments against race-conscious admissions. In the Court's final ruling, the Justices further exerted agency to shape the meaning and legitimacy of these discursive resources.

\section{The Court's Final Ruling}

Unlike the amicus briefs and oral arguments, the Court's final ruling does not represent a site of discursive struggle, but rather it is a site of discursive domination. As argued in the rationale for this project, Supreme Court rulings and opinions are imbued with authoritative power that enhances the discursive power of the discursive resources and structures produced in these texts. Therefore, for this phase of analysis, I conducted a close textual analysis and ideological critique in order to explore the dominant meaning system (re)produced in this final stage of this particular decision making process in the Fisher case.

The Supreme Court's ruling on the Fisher case was handed down on June 24, 2013, almost eight months after the oral arguments. In the end, the Court did not rule on the question of whether UT's admissions policy violated the Equal Protection Clause. Instead, the Supreme Court ruled that the lower court's review of the case did not meet 
the standard of strict scrutiny, as required in cases regarding the use of race, and sent the case back to be reviewed and ruled on again. In other words, the question of UT's use of race in its admissions programs remains open. Although the final ruling in the Fisher case upheld the constitutionality of race-conscious admissions, it also (re)produced discursive resources and structures that may serve to destabilize the Grutter structure in future legal challenges to race-conscious admissions.

In addition to the majority opinion, three Justices wrote opinions: two concurring and one dissenting. Justices offer concurring opinions when they agree with the majority ruling, but have additional or differing reasons than those expressed in the majority opinion (Tanenhaus, 2008). A dissenting opinion disagrees with the majority's interpretation of the law or facts of the case and/ or the application of the relevant legal principles (Tanenhaus, 2008). Justice Scalia wrote a three sentence concurring opinion stating that he would like to be asked to rule on whether or not diversity is a compelling interest, which was not the question put before the Court in the Fisher case. Justice Thomas' 20 page concurring opinion explicitly stated that he would like to overrule Grutter. Justice Ginsberg wrote the only dissenting opinion, only four pages long, in which she explained why she disagreed that the case needed to be sent back for further review by the lower court. Dissenting and concurring opinions do not set legal precedent nor impact how the lower courts will apply the ruling. However, they are important because they remain in the official record and can be drawn upon as persuasive logic in deciding similar cases (Tanenhaus, 2008).

In terms of my theoretical framework, the majority, consenting, and dissenting opinions produced by the Justices in the Fisher ruling (re)produce discursive structures 
and resources. When discursive resources imbued with the authority and power of the Court are consistently drawn upon and reproduced across time and space in situated discursive practices, they may eventually become discursive structures. For example, the Grutter structure is constituted in part by discursive resources produced by Justice Powell's opinion in Bakke. In the Grutter ruling, the Justices endowed the discursive resource 'diversity' with signification (a particular meaning), legitimation (a normative use), and domination (a legal standing), thus transforming the discursive resource into a discursive structure (i.e., the compelling interest in diversity), or rule-resource set, that served to structure the Fisher case. At the same time, discursive resources (re)produced through Justices' opinions can alter or transform existing discursive structures. In the following analysis, I discuss the ideological work that the Justices' opinions produced in the discursive practice of debating of race-conscious admissions that may yet serve to transform or dismantle the Grutter structure.

\section{Critical mass and quantification.}

The Court's final ruling in the Fisher case served to (re)produce a legitimized meaning of critical mass as connected to the discursive resource quantification. In the final ruling, Justice Kennedy concluded that the lower court had failed to "assess whether the University has offered sufficient evidence that would prove that its admissions program is narrowly tailored to obtain the educational benefits of diversity" (Fisher v. University of Texas at Austin, 2013, p. 13). This conclusion is centered on the question of what legitimately constitutes evidence in regards to critical mass.

In both the amicus briefs and the oral arguments, the discursive struggle emerged around how to define critical mass in order to prove that race-conscious admissions 
policies are necessary to achieve the compelling interest in diversity or that this goal has not yet been reached. This discursive struggle around what counts as evidence reflects a broader ideological debate around epistemological assumptions related to Truth versus truth, objectivity versus subjectivity, and rationality versus emotionality. The fact that the contested meaning of the discursive resource evidence (in conjunction with quantification) emerged as central to the Supreme Court's rationale for vacating the lower court's decision indicates that critical mass will be an important site of discursive struggle in the discursive field of the affirmative action debate in higher education.

Although Justice Kennedy was the only Justice to draw upon the discursive resources of critical mass and evidence; as author of the majority opinion, his words carry substantial weight on the discursive field. Justice Kennedy's ideological stance on evidence was not voiced explicitly in the text. However, given his dissenting opinion in the Grutter ruling, which was read as background for this analysis, his position was evident in reading between the lines of his reasoning. Justice Kennedy began his text by describing and contrasting UT's first two admissions plans, pre and post Hopwood. In Hopwood, the Fifth Circuit court of appeals determined that race-conscious admissions were not justifiable remedies for past or present discrimination, a hostile school climate, nor the interest in diversity (Hopwood v. State of Texas, 1996). Prior to Hopwood, UT considered two factors in admissions: race and academic performance. In response to Hopwood, Justice Kennedy explained that UT developed a new plan called the "Personal Achievement Index" that "stopped considering race" and instead measured an applicant's "leadership and work experiences, awards, extra-curricular activities, community service" together with "other special circumstances" such as "growing up in a single 
family home, speaking a language other than English at home, significant family

responsibilities assumed by the applicant, and the general socioeconomic condition of the student's family" (Fisher v. University of Texas at Austin, 2013, p. 2). Justice Kennedy compared these first two plans as follows:

[In] the last year under the post-Hopwood AI/PAI system that did not consider race, the entering class was 4.5\% African American and 16.9\% Hispanic. This is in contrast with the 1996 pre-Hopwood and Top Ten Percent regime, when race was explicitly considered, and the University's entering freshman class was $4.1 \%$ African-American and $14.5 \%$ Hispanic.

Justice Kennedy concluded from these small increases that the post-Hopwood plan "resulted in a more racially diverse environment at the University" as compared to when "race was explicitly considered" (Fisher v. University of Texas at Austin, 2013, p. 3). In other words, the numbers objectively showed that minority enrollment had increased under the admissions plan that did not explicitly consider race, but instead used "other special circumstances" as a proxy for race. The increased number of minorities was then equated to a "more racially diverse environment," thus constituting diversity as demographic representation.

After providing the background on the previous two policies, Justice Kennedy then turned to the current admissions policy in which UT "reverted to explicit consideration of race" (Fisher v. University of Texas at Austin, 2013, p. 3) after the Grutter ruling. Justice Kennedy explained that UT changed its admissions policy to explicitly consider race based on research that: 
[r]elied in substantial part on a study of a subset of undergraduate classes containing between 5 and 24 students. It showed that few of these classes had significant enrollment by members of racial minorities. In addition the Proposal relied on what it called 'anecdotal' reports from students regarding their 'interaction in the classroom.' The Proposal concluded that the University lacked a 'critical mass' of minority students and that to remedy the deficiency it was necessary to give explicit consideration to race in the undergraduate admissions program. (Fisher v. University of Texas at Austin, 2013, p. 4)

Justice Kennedy's framing of UT's evidence as based on a "subset" of small classes and "anecdotal reports" about "classroom interaction" seems to imply that such evidence lacks legitimacy as compared to the statistical data that he referenced earlier in his description of UT's pre and post Hopwood plans. In other words, an increase in minority enrollment was sufficient proof of a more "racially diverse environment," but evidence based on what minority students had to say about their experience in the university was not.

Although the final ruling did not explicitly articulate the type of evidence needed to meet the standard of strict review of its race-conscious admissions, Justice Kennedy's opinion seemed to (re)produce and legitimize a particular meaning system around the discursive resource evidence. Constraining the meaning of evidence to an objective and quantifiable form of knowledge serves to (re)produce Whiteness by marginalizing the knowledge produced from the lived experiences of people of color. 


\section{Diversity and race.}

The contested meaning of diversity and race was a central site of struggle throughout the amicus briefs, the oral arguments, and in the final ruling. Each of the Justices produced different rhetorical effects on these discursive resources by shaping the meanings of and relationships between diversity and race in the context of the Grutter structure. In this section, I will discuss the ideological underpinnings of Justices Kennedy, Scalia, and Thomas' texts. Later in this analysis, I will discuss how Justice Ginsberg's opinion attempted to contest these ideological assumptions.

\section{Race-neutral diversity.}

Justice Kennedy drew upon race-neutral universalism to (re)produce a meaning system around diversity that rhetorically distanced it from race. As discussed in the literature review, race-neutral universalism, a discursive structure produced by post-racial ideology, is a call for laws and policies that avoid explicit race-consciousness (Cho, 2009). The rhetoric of race-neutral universalism casts race-conscious remedies as “benefiting primarily those with 'special interests' versus all Americans" (Cho, 2009, p. 1602). Justice Kennedy's discourse drew upon race-neutral universalism to constrain the meaning of diversity within the Grutter structure. First, he reminded readers that redressing past discrimination does not constitute a compelling state interest, but the attainment of a diverse student body is constitutionally permissible because it "serves values beyond race alone, including enhanced classroom dialogue and the lessening of racial isolation and stereotypes" (Fisher v. University of Texas at Austin, 2013, p. 6). In other words, the consideration of race is only legitimate if it serves a "purpose beyond race," which can be understood as a purpose that does not just serve racial minorities, 
such as the educational benefits that flow from a diverse student body. It follows that an interest 'beyond race' cannot be met through racial and ethnic diversity alone. Rather, according to Bakke (1978), diversity must encompass "a far broader array of qualifications and characteristics of which racial or ethnic origin is but a single though important element" (Fisher v. University of Texas at Austin, 2013, p. 2). Therefore, to maintain the balance between considering race, but not giving race too much consideration, the Grutter ruling provided that admissions plans must "remain flexible enough to ensure that each applicant is evaluated as an individual and not in a way that makes an applicant's race or ethnicity the defining feature of his or her application" (Fisher v. University of Texas at Austin, 2013, p. 2). In his assessment of UT's current admissions policy, Justice Kennedy concluded that although UT does not assign a numerical value to race, "it is undisputed that race is a meaningful factor" (Fisher v. University of Texas at Austin, 2013, p. 4). Given his line of questioning in the oral arguments, it seems clear that he suspects that UT considers race beyond what is acceptable. Therefore, he admonished that the "reviewing court must ultimately be satisfied that no workable race-neutral alternative would produce the educational benefits of diversity"(Fisher v. University of Texas at Austin, 2013, p. 11). In other words, informed by race neutral universalism, the consideration of race is always highly suspect and the best way to ensure that racial minorities do not receive special treatment is though policies that do not consider race.

In Justice Kennedy's post-racial view of the world, race ceases to be a meaningful factor in admissions if race is not explicitly considered. Justice Kennedy seems to assume that admissions policies are rendered race-neutral by removing non-White racial 
identities from the equation. This assumption serves to naturalize Whiteness by obscuring White racial identity in admissions processes and centering the problem on this issue of non-White identities.

\section{Destabilizing diversity.}

The opinions produce by Justices Kennedy, Scalia, and Thomas all serve to destabilize the discursive resource of diversity within the Grutter structure. Justices Kennedy and Scalia both provided small discursive openings to challenge the constitutionality of diversity in relation to race. Justice Thomas' approach was to directly attack the legitimacy of the concept of diversity. I will now explain how each of the Justices' texts produced discursive effects that served to destabilize diversity as a discursive resource.

As previously explained, the Fisher case was not an explicit challenge to diversity as a compelling interest as part of the Grutter structure. However, in the following quote about the lower courts' decisions in the Fisher case, Justice Kennedy both upholds Grutter as well as contests it:

[t]he District Court and Court of Appeals were correct in finding that Grutter calls for deference to the University's conclusion...that a diverse student body would serve its educational goals. There is disagreement about whether Grutter was consistent with the principles of equal protection in approving this compelling interest in diversity. But the parties here do not ask the Court to revisit that aspect of Grutter's holding (Fisher v. University of Texas at Austin, 2013, p. 9). 
Justice Kennedy is referring to, and implicitly reproducing, the "disagreement" expressed in the dissenting opinions offered in the Grutter ruling. Justice Scalia was slightly more direct in contesting diversity as part of the Grutter structure. In his one paragraph opinion, Justice Scalia explained that "[t]he petitioner in this case did not ask us to overrule Grutter's holding that a 'compelling interest' in the educational benefits of diversity can justify racial preferences in university admissions. I therefore join the Court's opinion in full (Fisher v. University of Texas at Austin (Scalia, concurring), 2013, p. 1). In other words, given the opportunity, Scalia would delegitimize diversity as a discursive resource connected to race. Although Justice Scalia's text is sparse, it carries significant weight as a discursive resource on the discursive field of affirmative action because of his agentic power as a Supreme Court Justice. Justices Kennedy and Scalia both drew upon constitutional discursive resources to destabilize the discursive structure of the compelling interest in diversity by creating a discursive opening for future challenges. By contesting diversity as it relates to race in admissions policies, both Justices drew upon and reproduced the normativity of race-neutral universalism.

Justice Thomas' text also made reference to constitutional discursive resources, but his discursive logic drew upon the discursive logic of moral equivalence rather than race-neutral universalism. As discussed in the literature review, moral equivalence is a rhetorical strategy that draws upon the historic abuse of racial categorizations to argue that any consideration of race, whether used to harm or help people of color, is inherently wrong (Cho, 2009). Moral equivalence is based on the belief that racialized practices, such as the consideration of race in policies and laws that served to subordinate 
minorities during the Jim Crow era, are morally equivalent to the racialized practices born from the Civil Rights era as a remedy to this historic discrimination (Cho, 2009). Justice Thomas' line of argument drew a moral equivalence between diversity and segregation by contending that " $[t]$ here is no principled distinction between the University's assertion that diversity yields educational benefits and the segregationists' assertion that segregation yields those same benefits" (Fisher v. University of Texas at Austin (Thomas, concurring), 2013, p. 12). To illustrate this argument, Justice Thomas outlined three examples drawing connections between pro-diversity and pro-segregation justifications. First, Justice Thomas drew a parallel between the argument that diversity in a student body is necessary to prepare students to become leaders in a diverse society to the argument used by segregationists who insisted that segregated schools provide Black students with "greater opportunity for full participation and for the development of leadership" (Fisher v. University of Texas at Austin (Thomas, concurring), 2013, p. 9). Secondly, Justice Thomas maintained that just as diversity is said to improve racial relations, the segregationists argued that forcing the races to mix would "inflame racial resentment" and therefore segregated schools were needed to "maintain the public peace, harmony, and welfare" (p. 10). And third, Justice Thomas pointed out that while "[UT] admits that racial discrimination in admissions is not ideal, it asserts that it is a temporary necessity because of the enduring race-consciousness of our society" (p. 11); so too did the segregationists argue that “...segregation may not be the ethical or political ideal. At the same time we recognize the practical considerations that may prevent realization of the ideal" (p. 11). By drawing these parallels between arguments used to support diversity to those used to support segregation, Justice Thomas sought to delegitimize the 
discursive structure of diversity as a compelling interest to justify the consideration of race in admissions.

Justice Thomas further advanced moral equivalence arguments to delegitimize diversity by arguing that "[t]he worst forms of racial discrimination in this Nation have always been accompanied by straight-faced representations that discrimination helps minorities" (p. 14). He went on to explain that "[s]laveholders argued that slavery was a 'positive good' that civilized blacks and elevated them in every dimension in life" (p. 14). Similarly, segregation was argued to be not only benign, but beneficial to black students by "protecting them from racist white students and teachers" (p. 15). In this way, Justice Thomas engaged moral equivalence to turn the paternalistic arguments used to enslave and segregate Black people towards the policies designed to remedy the effects of this history. On the surface, Justice Thomas' rhetoric might be seen as challenging Whiteness by shining a light on historic abuses. However, by delegitimizing racial remedies for past discrimination, his arguments served to protect and reproduce the vested interests of the White power structure. In the next section, I discuss how Justice Thomas also (re)produced Whiteness through the discursive resource of harm.

\section{Harm and White normativity.}

In this section, I discuss how Justice Thomas' engaged the discursive resource of harm (to minority students) in ways that served to produce and reproduce White normativity. Whiteness is normative in that it sets the standard through which others are judged, so that non-White subjects are constituted in relation or opposition to Whiteness (Delgado \& Stefancic, 2012). The normative function of Whiteness (re)produced by the 
discursive resource of harm is illustrated in the following quote from Justice Thomas' opinion:

The University admits minorities who otherwise would have attended less selective colleges where they would have been more evenly matched. But, as a result of mismatching, many black and Hispanics who likely would have excelled at less elite schools are placed in a position where underperformance is all but inevitable because they are less academically prepared than the white and Asian students with whom they must compete. (Fisher v. University of Texas at Austin (Thomas, concurring), 2013, p. 18)

In this quote, White and Asian students are constituted as the 'norm' at elite institutions; they set the (ostensibly neutral) standards that "black and Hispanic" inevitably fail to achieve. By this logic, the problem is the underperformance of the minority students as compared to White and Asian students, rather than the White normative standards that produce barriers to achievement. Because Whiteness is normative at selective schools and non-Whiteness is not, Justice Thomas argued that minority students are automatically stamped with a "badge of inferiority" (Fisher v. University of Texas at Austin (Thomas, concurring), 2013, p. 19) under affirmative action policies. This badge of inferiority stigmatizes all students of color regardless of ability to perform academically because "no one can distinguish those students [who would have gotten in without racial preferences] from the ones whose race played a role in their admission" (p. 20). This stigma argument is based on the White normative assumption that race does not play a role in the admissions of White students; that race is somehow decoupled from White applicants, yet inextricably linked to non-White applicants. Furthermore, as a discursive resource, the 
stigma argument focuses on the object of the stigma (the students of color) and shifts the gaze away from Whiteness as the source of that stigma. In other words, the logic of the stigmatizing harm of racial preferences obscures the White normativity that marks 'others' as deficient.

\section{Contesting race-neutral universalism.}

In the sole dissenting opinion in the Fisher ruling, Justice Ginsberg contested the logic of race-neutral universalism. In reference to the case as laid out by Fisher's lawyer, Justice Ginsberg argued that:

[Fisher] urges that Texas' Top Ten Percent Law and race-blind holistic review of each application achieve significant diversity, so the University must be content with those alternatives. I have said before and reiterate here that only an ostrich could regard the supposedly neutral alternatives as race unconscious. (Fisher $v$. University of Texas at Austin (Ginsberg, dissenting), 2013, p. 2)

In this quote, Justice Ginsberg changed the term 'race-neutral' to 'race-blind,' a rhetorical move that challenges the White normative assumption that if non-White subjects are not explicitly considered, then race is no longer a factor in the process. She exposed the fallacy of race-neutral logic by arguing that Texas' Top Ten Percent plan was “adopted with racially segregated neighborhoods and schools front and center stage" therefore "[it] is race consciousness, not blindness to race, that drives such plans"(Fisher $v$. University of Texas at Austin (Ginsberg, dissenting), 2013, p. 2). In other words, the ostensibly race-neutral strategy of increasing minority enrollment by admitting the top ten percent of students from a racially segregated school system amounts to "deliberate obfuscation" (p.2) of the issue of race. Justice Ginsberg further contested race-neutral universalism 
and post-racial ideology by explicitly stating her position that "government actors, including state universities, need not be blind to the lingering effects of 'an overtly discriminatory past,' the legacy of 'centuries of law-sanctioned inequality."'(Fisher $v$. University of Texas at Austin (Ginsberg, dissenting), 2013, p. 2). In this way, Justice Ginsberg drew upon and (re)produced the discursive resources of history and discrimination to legitimize the explicit consideration of race in admissions and contest race-neutral universalism.

\section{Section summary.}

The importance of the final ruling in the Fisher case is not the impact of the decision on race-conscious admissions, but rather this ruling is important for what it (re)produced ideologically within the discursive field of affirmative action. The Fisher ruling, as well as previous affirmative action decisions, structures the discursive practice of affirmative action policy-making by (re)producing legitimized discursive resources that may be drawn upon to advocate for or against particular policies. The Supreme Court's ruling on the question of UT's race-conscious admissions policy served to both (re)produce and destabilize the Grutter structure. On one hand, the ruling in the Fisher case did not technically alter the discursive structure of the Grutter decision, thus reproducing its dominance on the discursive field. On the other hand, this analysis revealed that the discursive power of some of the Justices did serve to create discursive openings for such challenges to the Grutter structure.

My structurational analysis revealed that the discursive resources (re)produced by the majority of the Supreme Court Justices in the oral arguments and in the final ruling drew upon the same meaning system as (re)produced in the Fisher briefs. Although 
Justices Sotomayor and Ginsberg did engage the discursive resources of discrimination and history based on the same ideological grounding as the UT briefs, the majority of Justices (re)produced and enhanced the legitimacy of the ideological positioning that underlies the Fisher briefs. Thus, although the Grutter structure was (re)produced, so too was a meaning system that may eventually dismantle this rule-resource set that legitimizes race-conscious admissions.

\section{Research Questions}

Supreme Court cases and decisions shape and perpetuate ways of thinking and talking about policy issues and those subject to those policies (Bacchi, 1999; Benjamin Baez, 1999; Brown-Nagin, 2005; Schneyer, 1993). In this light, the discursive practice of debating affirmative action in the Supreme Court (re)produces knowledge about race and how it should be understood and enacted in the context of higher education. This knowledge/power regime is a product of relations of power that serves to enable and constrain this discursive struggle for meaning. As explicated in the literature review, this project and my analysis are informed by the assumption that Whiteness, as an underlying structural principle in U.S. society, (re)produces hierarchical knowledge/power relations in ways that are often invisible and produce both discursive and material effects; often in the form of privileges for White people and obstacles to people of color. Therefore, my research questions are focused on revealing and critiquing the ways that Whiteness structured and was reproduced by the meanings of race and diversity in debate around race-conscious admissions in the Fisher case, as well as foregrounding marginalized perspectives that contradict White dominance: 
RQ \#1: How was the deep-level structuring principle of Whiteness producing and reproduced by the discursive practice of debating race-conscious admissions in the Fisher case?

RQ \#2: How are White and non-White subjects constituted within the discursive practices of the Fisher case?

RQ \#3: How might marginalized discursive resources and structural contradictions in the debate serve to de-center the normative power of Whiteness in the affirmative action debate?

To answer these questions, I took a critical ideological approach in order to "reveal the vested interests produced by a particular rhetorical framework for understanding social order" (Crenshaw, 1997, p. 255). My analysis is informed by the race-centric approach to critical discourse analysis as outlined in chapter three, as well as the analytical concepts delineated in my literature review.

\section{(Re)producing Whiteness through White Interests}

As explained in the literature review, Whiteness functions ideologically as a set of dominant underlying beliefs, values, and assumptions that constitute meaning (signification) and norms (legitimation) through its privileged structural position (domination). As a structuring principle, Whiteness emerges and is (re)produced through discursive structures that enable and constrain discursive practices. Therefore, my first research question asked:

RQ \#1: How was the deep-level structuring principle of Whiteness producing and reproduced by the discursive practice of debating race-conscious admissions in the Fisher case? 
To answer this question, I drew upon Critical Race Theory (CRT), which helped me understand how White dominance is (re)produced in a discursive structure that ostensibly serves the interests of people of color. As articulated in Critical Race Theory (CRT), the concept of interest convergence contends that "racial equality and equity for people of color will be pursued and advanced when they converge with the interests, needs, expectations, and ideologies of Whites" (Milner, 2008, p. 332). Therefore, policies, laws, and practices that seemingly advance people of color must also be understood as promoting White self-interest, namely the status quo of power relations (Bell, 1979). Understood through the lens of interest convergence, my analysis revealed how the Grutter structure served to enable and constrain this discursive practice in ways that served to center White interests, defined as rationales or goals that (re)produce White dominance.

\section{The compelling interest in diversity.}

One way that White interests were centered in the Fisher debate was through the discursive structure and resource of diversity as a compelling interest. Within the Grutter structure, the compelling interest in diversity is articulated as an educational benefit to all students so that they can meet market-place demands and the productive needs of society. Diversity as a compelling interest is primarily based on the business case for diversity, which asserts that diversity on campus is needed to "ensure that students receive the best possible education and graduate with the skills and experiences necessary to succeed as citizens, workers, and leaders" and to serve the needs of "employers who, in order to remain competitive, must hire qualified workers reflecting the increasingly diverse communities and markets in which their businesses now operate" (Brief of the American 
Association for Affirmative Action as amicus curiae in support of respondents, 2012, p.

2). The market-driven rationale that underlies the compelling interest in diversity serves to center White interests by (a) commodifying people of color as a means to an end in the educational process, (b) promoting a forward-looking agenda that ignores the lingering effects of historic discrimination, and (c) maintaining the status quo of power relations. As the dominant legitimized rationale for the use of race-conscious admissions within the Grutter structure, the compelling interest in diversity was drawn upon to legitimize arguments made in the UT briefs.

Almost all of the 72 UT briefs drew upon and (re)produced the discursive structure of a compelling interest in diversity. For example, one typical UT brief emphasized that increasing the diversity of the student body not only benefits minority students, but "[n]onminority students are equally primed to reap the benefits of diversity. Social scientists widely agree that students' interpersonal interaction with peers is one of the most powerful educational resources in higher education (Brief of amicus curiae the American Psychological Association in support of respondents, 2012, p. 20). In claiming that that the benefits of diversity equally apply to "nonminority students," this argument assures that White interests are served rather than subverted by the presence of minority students. Another UT brief similarly argued that:

Experiencing diverse classrooms and a healthy racial climate is as important for white students as for minority students. If there are no Latino or African American students in their classrooms or fields of study, white students have little opportunity for cross-racial interactions. (Brief of American Social Science Researchers as amici curiae in support of respondents, 2012, p. 9) 
In contrast to the previous quote which assured that White interests would be "equally" met by the presence of minority students, this quote completely centered White interests by constituting the presence of Latino and African students as a means to an end to serve White interests. Even arguments that asserted minority interests by drawing upon justiceoriented discursive resources were hedged by discursive resources that promote White interests, such as in the following example:

Diversity in the profession shows that the path to leadership is open to all citizens and demonstrates that the justice system serves the public in a fair and inclusive manner. Moreover, such diversity improves the quality of legal services and judicial decisions, and is necessary for successful competition in the global marketplace. (Brief of the American Bar Association as amicus curiae in support of respondents and urging affirmance, 2012, p. 9)

While the first sentence in the quote draws upon discursive resources such as fairness and inclusion, the second sentence served to re-center White interests as manifest by the business case for diversity (i.e., successful competition in the global marketplace). Interest convergence emerged in the UT briefs in another more subtle way: One study of the career choices of University of Michigan Law school graduates reported that graduates who were African American, Latino, and Native American were more likely to begin their careers in public service, and those who entered private practice tended to do more pro bono work, than their white counterparts. (Brief of the American Bar Association as amicus curiae in support of respondents and urging affirmance, 2012, p. 18) 
This argument valorizes minority graduates for doing the less desirable, low or no paying work that White people are less inclined to do. Thus, in this example, White interests were centered through the subjugation of minority subjects.

The majority of the Fisher briefs also (re)produced the compelling interest in diversity, but they did so in ways that contested the argument that race-conscious policies serve dominant interests. Direct attacks on the compelling interest in diversity were constrained by the Grutter structure because the question before the Court was not whether or not the principles of Grutter are constitutional, but whether or not UT's raceconscious admissions policy was constructed within the bounds of Grutter. Therefore, rather than attack the compelling interest in diversity, the Fisher briefs attempted to reshape the legitimized meaning of diversity by discursively decoupling race from diversity. As discussed in the first phase of analysis, the Fisher briefs drew upon discursive resources such as real, genuine, organic, or naturally occurring to argue that diversity was an amalgamation of individual experiences, factors, and qualities, whereas diversity based on race and ethnicity was artificial, manufactured, and misleading. By constraining the meaning of diversity, the Fisher briefs centered White interests, yet contested interest convergence, by delegitimizing race as an aspect of diversity and as a meaningful aspect of experience.

\section{Critical mass.}

White interests were further centered through the rule of critical mass. According to Grutter, admissions policies may allow for the explicit consideration of race in admissions in order to achieve a critical mass of minority students that furthers the compelling interest in diversity. By implication, there is a particular stopping point at 
which there will be enough minorities to attain the desired educational benefits. According to one of the UT briefs, "[e]ven small increases in diversity may have significant effects on certain aspects of the educational experience, such as promoting gains in creativity and civic engagement for all students (Brief of amicus curiae the American Psychological Association in support of respondents, 2012, p. 20). In other words, the interests of White students can be met with only a few minority students. According to one of the Fisher briefs, a critical mass of minority students has already been surpassed "[g]iven that a majority of students at UT today are already minorities, clearly UT has already more than attained the critical mass necessary to achieve the educational benefits of diversity" (Amicus curiae brief of the American Civil Rights Union in support of petitioner, 2012, p. 9). Once the courts have arrived at this same conclusion, the justification for race-conscious admissions ends. This point was made clear in the oral arguments as several of the Justices and Fisher's lawyer struggled to impose quantifiable limitations on critical mass. The critical mass structure entails that once it has been determined that there are enough non-White bodies to meet the interests of the White students and the demands of the market-place, the admissions process must cease to consider race in admissions. In this way, the critical mass structure centers White interests by building in the legal mechanism to return to the previous system that systematically excluded minority students, the very reason that race-conscious policies were needed in the first place.

As structured by Grutter and (re)produced in the Fisher case, the compelling interest in diversity and the critical mass rule serve to both enable and constrain the use of race-conscious admissions. On the one hand, the compelling interest in diversity serves 
to legitimize the consideration of a particular, de-historicized conceptualization of race.

On the other hand, this legitimacy is contingent upon and constrained by White interests. Once these interests have been met, the critical mass rule provides the mechanism for ending the consideration of racial preferences for non-White students. So, while the critical mass discursive resource was produced in Grutter to enable agency of affirmative action policy makers, my analysis revealed that through the discursive structure, or underlying logic, of quantification, critical mass may be transforming into a discursive resource that will instead constrict agency in the enactment of admissions policies.

\section{The Constitution of Racialized Subjects}

In order to understand how the discursive practice of debating race-conscious admissions (re)produces a meaning system that constitutes racialized identities and locates subjects within asymmetrical relations of power, this project asked:

RQ \#2: How are White and non-White subjects constituted within the discursive practices of the Fisher case?

My analysis revealed that Whiteness structured the constitution of racialized subjects through the discursive structures, or underlying logics, of binary thinking, White normativity, and unmarking Whiteness. In the debate around race-conscious admissions, these discursive structures served to produce particular understandings of racialized subjects in which non-White subjects were hierarchically subordinated and White subjects were made both normative and invisible.

\section{Binary thinking.}

As discussed in the literature review, binary thinking is a discursive structure that emerges from the structuring principle of Whiteness. In the constitution of subject 
positions, the amicus briefs (re)produced Whiteness by drawing upon binary logic to hierarchically locate White subjects in the dominant position and non-White subjects in the subjugated position. My textual analysis revealed that White and non-White subjects were constituted in hierarchically ordered binary opposition to each other in the following three forms: Black/White, Black \& Hispanic/White, and Black \& Hispanic/White \& Asian. In the Fisher briefs, these binary pairs were discursively linked to admissions and academic performance in ways that delegitimized Black and Hispanic students in the context of higher education. As will be discussed, both the Fisher briefs and the UT briefs drew upon binary thinking to (re)produce White normativity.

\section{Admissions and White innocence.}

In connection to admissions, the Fisher briefs implicitly drew upon the discursive resources of merit and fairness to assert that White and Asians students were unfairly victimized by racial preferences that favored Black and Hispanic students. Non-White and White subjects were constituted in binary pairs marked by terms that implied a reverse and illegitimate hierarchy. The terms preferred, favored, underrepresented were used to describe Blacks and Hispanic subjects; while White and Asian subjects were marked by the opposite terms---non-preferred, disfavored, and overrepresented. For example, one of the Fisher briefs argued that "UT uses race in admissions to favor African-Americans and Hispanics, but to disfavor Asian-Americans, who it considers overrepresented among UT students even though the UT student body includes fewer Asian-Americans than Hispanics" (Amicus curiae brief of the American Civil Rights Union in support of petitioner, 2012, p. 3). White students, like Abigail Fisher, are also disfavored when denied admission based on "[t]he undisputed reason...that she is white, 
a member of the Caucasian race or classification, while those favored with admission despite lesser academic qualifications were of different racial classifications" (Amicus curiae brief of the American Civil Rights Union in support of petitioner, 2012, p. 10). These examples illustrate how the Fisher briefs positioned White subjects in an 'unnatural' subjugated hierarchical position in the context of admissions by drawing upon the rhetoric of innocence (Ross, 1990). The rhetoric of White innocence serves as a discursive resource to constitute the White subject as an innocent victim of unfair admissions practices and the Black subject as the "undeserving black taker" (Ross, 1990, p. 310) who illegitimately benefits from special treatment at a cost to White students, despite "lesser academic qualifications." In this preferred/non-preferred binary, the rhetoric of innocence was manifest through the discursive resource of fairness to delegitimize racial preferences in admissions. As structured by Whiteness, unfairness is defined by the harm caused to White students. At the same time, the harm caused to nonWhite subjects through systems of privilege that produced the need for race conscious admissions is obscured and normalized.

\section{Academic performance and White normativity.}

In discourses about academic performance, both the Fisher and the UT briefs reinforced hierarchical binary subject positions through the discursive structure of White normativity. As previously discussed in the analysis of Justice Thomas' opinion, White normativity refers to Whiteness as the standard through which others are judged, so that non-White subjects are constituted in relation or opposition to Whiteness (Delgado \& Stefancic, 2012). White normativity emerged in discussions about academic performance in ways that served to re-center Whiteness as the norm or standard from which Black and 
Latino students were unfavorably compared. For example, in comparing dropout rates, one brief argued that the "[lowering of academic standards to admit African-American students] leads to African-American students failing or dropping out of school at much higher rates than white students" (Brief amicus curiae of Pacific Legal Foundation, Center for Equal Opportunity, American Civil Rights Institute, et al., in support of petitioner, 2012, p. 23). In this argument, the dropout rate of White students is normalized and the dropout rate of African American is deviant in comparison. No explanation is given for the White students dropping out, but the African American dropout rate is attributed to racial preferences.

In discussions about academics, Asian subjects were often discursively linked or paired with White students. For example, one Fisher brief argued that racial preferences create a "disincentive to hard work" that serves to "diminish the need for college-bound black and Latino high school youth to work as diligently as their white and Asian classmates"(Brief of Abigail Thernstrom, Stephan Thernstrom, Althea K. Nagai, and Russell Nieli as amici curiae in support of petitioners, 2012, p. 28). One UT brief argued that the problem of underperformance of minorities as compared to White and Asian students is due to "[p]sychological factors such as "stereotype threat" that "lead nonAsian minorities to underperform as compared to Whites and Asians with similar cognitive and academic abilities" (Brief of experimental psychologists as amici curiae in support of respondents, 2012, p. 1). In these exemplars, the Black/ White and Black \& Latino/White \& Asian binaries were engaged to constitute White academic superiority and non-White inferiority. Although Asian subjects are not White, the consistent discursive linking of 'White and Asian' and the term 'non-Asian minority' can be 
understood as White appropriation of hardworking, academically successful Asian identity, the 'model minority' as an exception to other minorities.

Another way that Whiteness was made normative in the discourse about race and academics was by marking minority exceptionalism. In both the UT and the Fisher briefs, minority students were often marked by the qualifier qualified minorities, while the qualification of White students was assumed. One of the UT briefs argued that "[ $\mathrm{t}] \mathrm{he}$ minority student excelling in geometry, or the sciences, for example, challenges in a direct and forceful manner the stereotypes" (Brief of amici curiae the American Jewish Committee, Central Conference of American Rabbis, and Union for Reform Judaism in support of respondents, 2012, p. 16). By highlighting 'the minority student' who happens to excel in math or science, such statements reinforce the very stereotypes that they claim to want to dispel. Other exceptional minorities are those "who did not need any preference at all" and yet are "unfairly stigmatized"(Amicus curiae brief of the Center for Individual Rights in support of petitioner, 2012, p. 14). The following quote further differentiates between "minority students" and "better qualified minority students" and suggests that both types of minority students might be better off in class with fewer minorities because:

[A] classroom with fewer minority students might result in minority students performing at higher levels by inducing them to study (by necessity) with better prepared non-affirmative action peers. Affirmative action might particularly impact the better-qualified minority students who could switch from studying with better-performing classmates to worse performing classmates. (Brief of 
Scholars of Economics and Statistics as amici curiae in support of petitioner, 2012, p. 16).

In this quote, minority students are constituted as needing to be induced to study and 'worse performing,' while their unmarked White counterparts are constituted by the terms 'better prepared' and 'non-affirmative action.' Marking some minority students as 'qualified' or 'better prepared' naturalizes the assumption that minority students are normally not qualified or prepared, while the unmarked White student in this binary coupling is normalized as the standard.

In the amicus briefs, binary thinking was drawn upon as a discursive structure, or underlying logic, to locate racialized subjects in hierarchically ordered opposition. White and Asian subjects were constituted as innocent victims of unfair admissions practices as well as the standard or norm of academic performance, while non-White subjects were constituted as illegitimate beneficiaries of racial preferences and academic inferiors. In this way, the structuring power of Whiteness was (re)produced through marking White subjects in contrast to non-White subjects.

\section{Whiteness as invisible and universal.}

As discussed in chapter two, Whiteness emerges and is obscured in discursive practices through rhetorical strategies that serve to render Whiteness both invisible and

universal (Frankenberg, 1993; Nakayama \& Krizek, 1995). In some texts, White subjects were rendered invisible through unmarking or excluding the word White, while in other texts, White subjects were constituted as the universal norm.

In the oral arguments and in the majority ruling, White subjects were relatively unmarked as compared to minority subjects. In the transcript of the oral argument, the 
word 'White' was mentioned only 3 times as compared to 116 references to non-White subjects. Similarly, in the majority ruling, the word White did not appear a single time in Justice Kennedy's text and only 19 times in the entire document, as compared to the 65 references to non-White subjects. Leaving White subjects unmarked, while marking 'others' in the discursive practice of debating race-conscious admissions, served to render White subjects invisible in the problematization of the admissions review policy. The invisibility of Whiteness in the context of the review process reifies the underlying assumption that being White has nothing to do with an applicant's academic and personal profile. By this logic, Whiteness is 'race neutral' and only by explicitly considering race (in the application review process) does race become a factor. Through this discursive invisibility, the structural power of Whiteness was (re)produced in the construction of the policy problem and practice by maintaining the focus on minority students as the locus of the problem.

Another way that Whiteness was (re)produced was by constituting White subjectivity as universal. For example, one of the Fisher briefs claimed that "[t]he evidence that most Americans do not support discrimination in [higher education] is exceedingly persuasive. The majority are unpersuaded by the diversity rationale—or any other rationale — for race-preferential admissions (Brief of amici curiae California Association of Scholars, Connecticut Association of Scholars, Center for Constitutional Jurisprudence, et. al, in support of petitioner, 2012, p. 10). In this quote, the terms "most Americans" and "majority" imply White subjects who do not support the diversity rationale or racial preferences. Another Fisher brief argued that the purpose of raceconscious admissions was to "increase the number of minority students on campus and 
ultimately to promote their integration into high prestige careers and mainstream society" (Amicus brief of Gail Heriot, Peter \& Todd Gaziano, Members of the U.S. Commission on Civil Rights in support of the petitioner, 2012, p. 4). The words 'prestige' and 'mainstream' infer White spaces and culture; social locations to which Others seek integration. In these examples, the terms 'most Americans,' 'majority,' 'prestige,' and 'mainstream' were engaged as proxies for White subjects and served to (re)produce Whiteness as the universal, yet invisible, norm.

This analysis revealed how Whiteness served to structure the constitution of racialized subjects in the discursive practice of debating race-conscious admissions through the discursive structures of binary thinking, White innocence and fairness, White normativity, and unmarking Whiteness. In drawing upon these discursive structures, the discourse produced in the amicus briefs served to constitute non-White subjects in a hierarchically subjugated position and to (re)produce White superiority, invisibility, and dominance. In this way, these discursive structures both emerged from and served to (re)produce the underlying structural principle of Whiteness.

\section{Contesting Whiteness}

Thus far, my analysis has focused on the ways that Whiteness produced and was (re)produced by the discursive practice of debating race conscious admissions in the Fisher case. However, as delineated in my theoretical framework, discursive structures, such as those that (re)produce Whiteness, are not determinative of discursive practices; rather, discursive structures and practices exist in a mutually constitutive relationship. In other words, human agency is not fully constrained by discursive structures and, in turn, 
discursive structures are susceptible to change through discursive practices. Therefore, my third research question asked:

RQ \#3: How might marginalized discursive resources and structural contradictions in the debate serve to de-center the normative power of Whiteness in the affirmative action debate?

To answer this question, I foreground marginalized discursive resources that challenged the dominant and legitimized meaning system produced by the Grutter discursive structure. To this end, I drew upon Critical Race Theory (CRT) to guide my analysis. A central principle of CRT involves destabilizing dominant visions of reality by highlighting the stories and counter-stories told by people of color (Delgado \& Stefancic, 2012; López, 2003). By highlighting these marginalized accounts, CRT practice seeks to "demystify the notion of a racially neutral society and tell another story of a highly racialized social order"(López, 2003, p. 85). Therefore, I turned my analysis to the six amicus briefs produced by Black interest groups in order to explore how the logics and rationales that they drew upon may serve to challenge the structural principle of Whiteness. To be clear, Whiteness was contested through discursive resources in other briefs, as well as by Justices Sotomayor and Ginsberg. However, I felt it was particularly salient to my critical agenda to highlight the voices of Black people as they enacted agency to influence the discursive structures that (re)produce them as Black subjects in the discursive and material world of higher education.

\section{An alternative compelling interest.}

One way that the Black briefs contested Whiteness was by articulating alternatives to the compelling interest in diversity. As previously explained, the Grutter 
structure not only legitimized one particular compelling interest (in diversity), it also delegitimized the consideration of race for remedial purposes. Two of the briefs submitted by Black organizations contested the discursive closure around a remedial compelling interest ${ }^{2}$.

The brief submitted by the National Association for the Advancement of Colored People (NAACP) was one of the only briefs that did not (re)produce the diversity rationale. Instead, the NAACP brief drew upon the discursive resources of constitutionality and historic discrimination to contradict Justice Powell's arguments against the legitimacy of the goal of remedying past discrimination. The NAACP brief referenced several previous cases involving remedial policies in government employment and contracting to assert that the goal of "lessening or eliminating remaining vestiges of de jure segregation in the Texas higher educational system” (2012, p. 24) has already been affirmed as constitutional in previous case law. Furthermore, the NAACP argued that:

UT's admissions program provides a modest remedy for the lingering injury which black Texans have suffered from slavery, a century or more of de jure educational segregation, and several decades more of malign state neglect in a de facto segregated university system. Accordingly, UT's admissions program serves one of the most compelling of state interests: undoing the scarring damage of state -imposed and encouraged discrimination in higher education. (Brief for

\footnotetext{
${ }^{2}$ It is worth noting that only one other of the 72 UT briefs also challenged the limitation of the compelling interest imposed by Grutter.
} 
amici curiae National Association for the Advancement of Colored People, et al. in support of respondents, 2012, p. 31)

This quote drew upon the discursive resource of "state-imposed" historic discrimination to assert that the use of racial preferences in admissions is only a "modest remedy" compared to all that people of color have suffered and continue to suffer at the hands of a White power structure. Moreover, this argument claims a moral high ground for racebased remedies by arguing that "undoing the scarring damage" is not only a legitimate compelling interest, but it is "one of the most" (emphasis added) compelling interests. In contrast to the compelling interest in diversity, which looks forward toward the goal of educational benefits, this argument attempts to hold the White power structure accountable for centuries of state-sponsored discrimination in education.

The brief filed on behalf of the Coalition of Black Male Achievement Initiatives (CBMAI) also challenged the idea of what legitimately constitutes a compelling state interest. In contrast to the NAACP brief, the CBMAI brief did not challenge the discursive structure that precludes the constitutionality of racial preferences as a remedy to past discrimination. Instead, the brief advanced an argument that focused on present social conditions. According to the CBMAI brief, the present social condition is one marked by devastating disparities in which:

[s]ome neighborhoods are the sites of high performing schools, safe streets, robust job centers, strong healthcare facilities, well-resourced libraries, and stable and affordable housing. These are the neighborhoods in which children thrive, where the incomes and wealth of the next generation tend to build upon and surpass that of their parents. In sharp contrast, other neighborhoods are the sites of failing 
schools, scarce job opportunities, high crime rates, distant healthcare facilities, vacant property, and poor and unstable housing. In these neighborhoods generations of young Americans and their families languish, and the odds of children moving up the economic ladder are significantly reduced. (p. 29)

Notably, in this quote, these social disparities are not marked as 'White' and 'Black,' but rather as the untenable conditions of inequality in a shared society. In contrast to the previously discussed binary framing of racialized subjects, the CBMAI brief constituted African Americans as 'Americans' and 'residents.' In other words, this brief does not locate African Americans in a social position of other, but rather as we. Rather than reproducing the compelling interest in diversity, this brief argued that "[s]tates have a compelling interest in reducing conditions that impair the equal opportunity for advancement of a cognizable group of their residents. Failure to improve these conditions imperils the well-being of all residents." (Brief of amici curiae Coalition of Black Male Achievement Initiatives in support of respondents, 2012, p. 2). In contrast to other UT briefs, which drew upon diversity to create interest convergence, this quote can be understood as an attempt to create interest convergence with White interests around addressing a shared problem. To be clear, the CBMAI brief did not argue against diversity as an educational benefit, but rather than foreground the diversity rationale, it centered its argument in support of race-conscious admissions on the shared interest in addressing the untenable racial disparities that are harmful to society overall.

The NAACP and CBMAI both briefs drew upon the discursive resources of constitutionality, history, and discrimination to legitimize a compelling interest with a remedial goal and assert discursive resistance to the constraint imposed by the Grutter 
discursive structure. In attempting to act upon or transform the Grutter structure, these briefs enacted agency against the structuring principle of Whiteness by asserting Black interests in the formulation of race-conscious admissions policy. As will be discussed in chapter five, an alternative to the compelling interest in diversity to support the continued use of race-conscious admissions may be especially important to the discursive practice of debating race-conscious admissions given that the discursive power of the diversity rationale seems to be weakening in the wake of the Fisher case.

\section{Asserting black agency.}

Another way the Black briefs contested Whiteness was by asserting black agency to contest the discursive resource of harm. As previously discussed, one of the dominant arguments engaged by the Fisher briefs, as well as in Justice Thomas' opinion in the final ruling, is that race-conscious admissions policies are harmful to minority students. The discursive resource of harm contends that racial preferences do a disservice to Black students by granting them access to elite institutions where they cannot effectively compete against their "better prepared" White counterparts and therefore underperform; thus reinforcing negative stereotypes and stigma. Therefore, the harm argument contends that Black students, who would otherwise not be accepted to elite schools without racial preferences, would be better served in less elite institutions where they might be more academically competitive. The brief submitted by the National Black Law Students Association (NBLSA) contested this discursive resource by asserting that the harm argument inappropriately assumes that minority students are incapable of making informed judgments about the potential costs and benefits of attending flagship universities and top-tier graduate schools. The NBLSA brief argued that Black students 
have access to the same information about LSAT scores and rankings as everyone else, so they fully understand their own position within those contexts, as well as the benefits of graduating from an elite institution. Therefore, the NBLSA brief asserted that:

[T] he choice to stretch and challenge ourselves academically at top-tier law schools in exchange for the academic opportunities and the potential of increased career opportunities is a valuable one that race-conscious admission programs have made possible. The ability to make these choices for ourselves should not be taken away. Like all law students, NBLSA students must be allowed to continue weighing potential benefits and risks, and have our decisions respected. (Brief for the National Black Law Students Association as amicus curiae in support of respondents, 2012, p. 8)

In contesting the discursive resource of harm, this argument articulates and demands Black agency, which can be understood as a discursive resource to contest White normative power. For example, in the previous section on the constitution of racialized subjects, I explored how Black and Hispanic students were discursively constructed in subjugated positions to White students. The above quote, in contrast, creates an agentic subjectivity for Black students, a subjectivity that contests the idea that their presence on campus is a gift granted by race-conscious admissions, but rather constitutes their presence as a choice that they have an equal right to make. In the Fisher briefs, the discursive resource of harm was engaged to constrain Black agency and thus (re)produce the structuring principle of Whiteness. The NBLSA brief contested the discursive resource of harm by constituting Black students as agentic subjects in the field of higher education as opposed to passive beneficiaries of benevolent policies. 


\section{De-centering White interests.}

In this section, I explore how some of the briefs submitted by Black interest groups advanced historical and material arguments that centered Black interests, rather than (re)produce the discursive resources that foreground White interests. I define Black interests as those that de-center Whiteness by drawing upon discursive logics that do not (re)produce White dominance, invisibility, or normativity. My analysis of the briefs submitted by Black interest groups revealed two rhetorical strategies that de-centered Whiteness: re-centering the historic context and denaturalizing Whiteness.

Re-centering the historic context. As previously discussed, the diversity rationale is a forward-looking rhetoric that decouples diversity from history and race and instead advances a vision for the future. To contest the historical amnesia advanced by the diversity rationale, the briefs submitted by Black interest groups drew upon the discursive resource of historic discrimination to contextualize the compelling interest in diversity. For example, the brief submitted by the United Negro College Fund argued that:

It is impossible to evaluate colleges and universities' compelling interest in student body diversity without recognizing the primary reasons that diversity does not occur naturally. There has been a long history of state-sponsored and private segregation and discrimination in the United States against African Americans, Native Americans, Hispanics and Asian Americans. This segregation and discrimination has, in turn, limited educational and employment opportunities for these groups. (Brief of amicus curiae United Negro College Fund in support of respondents, 2012, p. 8). 
This historically contextualized reframing of the need for race-conscious admissions to achieve a diverse student body de-centers White interests by offering an alternative view to the forward-looking diversity rationale and re-centering this historic context perpetrated by White dominance. Similarly, another brief argued that "[o]pening pathways to leadership and opportunity is particularly critical for African-American students because they were excluded from the University for much of its history — first by law and then in effect" (Brief of the Black Student Alliance at UT, the Ex-Students of Texas, Inc., and the NAACP in support of respondents, 2012, p. 18). Again, drawing upon history, this brief asserted the need to remedy the contemporary effects of the tarnished history specific to the University of Texas, thus illuminating a story normally obscured by the diversity rationale.

Denaturalizing Whiteness. The underlying logic of the Grutter discursive structure is that universities must have a critical mass of minority students in order for (predominantly White) students to reap the promised benefits of a diverse student body. As a counter-story to this line of thinking, the brief submitted by the family of civil rights icon Herman Sweatt argued that in Texas' highly segregated school system, more than $85 \%$ of Black students attend schools that are 50-100\% minority enrollment, which means that "[t]he typical black student would see a white face in only a quarter of her schoolmates" (Brief of the family of Heman Sweatt as amicus curiae in support of respondents, 2012, p. 28). Therefore, it is not until coming to college that many Black students have any interaction with White peers (Brief of the family of Heman Sweatt as amicus curiae in support of respondents, 2012). This argument flips the 'benefit to Whites' rationale by foregrounding the need of Black students to encounter the 
strangeness of the 'other.' This argument denaturalizes Whiteness, marks it as 'other,' and re-centers Black interests.

Another way that Whiteness was denaturalized to assert Black interests was by countering the argument that race-neutral policies in fact do not provide racial preferences. In this extensive quote, the NAACP brief articulates the de facto White privilege that is (re)produced through admissions policies that do not consider race:

What Petitioner seeks is to deny African Americans and other racial minorities an admissions system that is 'designed to consider each applicant as an individual.' Under her position, every applicant would be 'holistically' considered except African Americans and other racial minorities, whose personal essays would have to be censored (or self-censored) to remove any mention of experience with race. Important achievements by these students would thereby be deemed meaningless and worthless. UT would have to treat extraordinary applicants as though they were commonplace. For example, UT would have to pretend that the first African American member of a traditionally all-white organization, who tore down barriers and rose to become president of the organization, had not done anything of historical significance. Even if an applicant had triumphed over direct, personalized, de facto racism, UT would be barred from considering that triumph. (Brief for amici curiae National Association for the Advancement of Colored People, et al. in support of respondents, 2012, p. 34)

By contrasting supposedly equal achievements (i.e. being a member of an all White organization), this quote delegitimized the idea that Whiteness is absent from race-neutral admissions policies. Furthermore, by highlighting the resilience of Black students who 
overcome racial barriers, this brief constituted a Black-centered sense of achievement and merit. The NAACP brief ended by drawing upon and contesting two discursive resources that are typically engaged in anti-affirmative action arguments. First, the NAACP brief argued that if admissions policies ceased to consider race "[White] students, for whom race presented no obstacle, would effectively have an unfair advantage" (p. 34). This argument de-centers White interests that are obscured when the discursive resource 'fairness' is drawn upon in anti-affirmative action arguments to contend that racial preferences are unfair to applicants from non-preferred racial categories. Then, the NAACP brief asserted that "[m]any racial minority applicants have pulled themselves up by their bootstraps, and the Court should reject Petitioner's attempt to take away their boots" (p. 34). As explained in chapter two, the 'boot strap theory' is a discursive logic produced by Whiteness, which asserts that in a meritocracy all individuals have the opportunity to pull themselves up by their bootstraps if they work hard enough and have enough talent. While the discursive resource of the bootstrap theory typically obscures the obstacles that racial minorities face on the supposedly even playing field, this quote engaged this discursive resource to argue that race-conscious policies are an integral part of the bootstrap theory for Black students.

In this section, I have highlighted a few of the ways that Black voices asserted agency while acting within a discursive practice structured by Whiteness. By resisting the discursive closure that constrains the compelling interest in diversity structure, asserting Black agency, and foregrounding Black interests in arguments for raceconscious admissions, these briefs produced a counter-story that contested Whiteness and created discursive resources that may yet serve to transform the Grutter structure. 


\section{Conclusion}

The purpose of this race-centric CDA was to explore and reveal how Whiteness produced and was (re)produced in the discursive practice of debating race-conscious admissions in the Fisher case. In summary, my analysis revealed that dominant arguments produced by both liberal and conservative ideological positions in the debate around race-conscious admissions engaged the concepts of race and diversity in ways that were produced by and (re)produced Whiteness. Both sides of the debate discursively decoupled race from power, but in different ways and for different reasons. The UT briefs sought to maintain the legitimacy of diversity as a discursive structure by drawing upon arguments that promote interest convergence through the compelling interest in diversity as structured by Grutter. The Fisher briefs, on the other hand, sought to constrain the meaning of diversity by delegitimizing race as a category of relevant experience to the compelling interest in diversity. Even as the discursive structure of diversity was (re)produced and legitimized throughout this process, its rhetorical strength as a ruleresource set was also weakened as discussed in my analysis of the oral arguments and the Court's final ruling.

My analysis of the oral arguments and the Court's final ruling revealed that the majority of Justices drew upon and (re)produced the discursive resources as engaged by the Fisher briefs. In other words, through the structurational process of debating raceconscious admissions, the meaning system that was ultimately (re)produced in this discursive practice was aligned with the ideological positioning of the anti-affirmative action advocates. My analysis of the final ruling revealed how Justice Kennedy and Justice Thomas' discourse (re)produced the structural principle of Whiteness through 
race-neutral universalism, unmarking Whiteness, White normativity, and moral equivalence. Although Justices Ginsberg contested Whiteness by attempting to delegitimize the race-neutral discursive resource, her dissenting opinion does not carry the same legitimized, normative power as the majority ruling. In other words, her opinion may yet serve as a resource for discursive resistance, but perhaps not a very strong one in the discursive practice of debating race-conscious admissions.

My analysis also highlighted how Black voices contested Whiteness and thus produced discursive resources that may serve to inform this ongoing discursive practice. In the final chapter, I will explore the practical implications of these findings, as well as how my analysis paves the way for continuing research on this topic. 


\section{CHAPTER 5: DISCUSSION}

This project was guided by several ambitious goals. First, I sought to problematize the decades-long debate around race-conscious admissions in higher education in order to illuminate ways to move this stagnant conversation forward. Second, I aspired to extend the use of Structuration Theory for the purposes of critical organizational communication scholarship by enhancing its explanatory power through post-structuralist theories of discourse, power, and ideology. Finally, I hoped to encourage and contribute to a line of inquiry in organizational communication scholarship that explores and denaturalizes the ways that Whiteness functions to maintain its structural dominance and (re)produce systems of racial inequality. Based on these goals, the purpose of this Critical Discourse Analysis (CDA) project was to reveal and critique how Whiteness structured and was (re)produced through the discursive practice of debating race-conscious admissions in the Fisher case. In order to explore the extent to which I succeeded in meeting my goals, I first summarize and discuss the results of my analysis, followed by a discussion of my methodological, theoretical, and practical contributions. I end the chapter with a discussion of this project's limitations and how these limitations point to areas of future research.

\section{Summary of Results}

This project engaged a three-phase CDA to analyze the texts produced in the discursive practice of debating the Fisher case in the Supreme Court. My analytical lens was focused on the production, reproduction, and transformation of discursive structures and resources that emerge from the underlying structural principle of Whiteness. The 
first phase of my analysis revealed a discursive struggle for meaning as each side of the debate engaged various discursive resources to shape the Court's view of race-conscious admissions. The second phase involved a close textual analysis of the Court's final ruling in order to surface the underlying ideological meaning system that was (re)produced at this final stage of the decision making process. The third phase brought together the analysis of the first two phases in order to answer my three research questions about the discursive effects of this discursive practice. I will now summarize the findings from each stage of this analysis.

\section{Phase one.}

My first phase of analysis involved identifying the discursive resources engaged in the chronologically ordered texts. My analysis of the amicus briefs revealed that each side of the debate attempted to shape the Court's understanding of discrimination, history, harm, costs, critical mass, diversity, and race as discursive resources in the context of race-conscious admissions. Although both sides drew upon the same discursive resources, they imbued those resources with different meanings and for different purposes. For example, the Fisher briefs drew upon 'history' as a discursive resource to argue that racial classifications are inherently dangerous as evidenced by history. Thus, the Fisher briefs attempted to discursively distance the past from the present. The UT briefs, on the other hand, drew upon history in relation to the present day lingering effects of the past in order to contextualize the need for affirmative action policies. Overall, the analysis of the amicus briefs provided a broad overview of the dominant points of discursive struggle around discursive resources engaged in the discursive practice of debating race-conscious admissions. 
For the most part, this discursive struggle for meaning in the amicus briefs drew upon and reproduced the same arguments that have constituted this debate over the past several decades. However, my analysis of the briefs did reveal a new emerging discursive battle over the meaning of critical mass and the way it can/should be operationalized in practice. The discursive struggle over the meaning of critical mass also emerged in the oral arguments, which indicates the growing dominance of this issue, as will be discussed further in the findings for phase three.

\section{Phase two.}

The second phase of my analysis involved a close textual analysis and ideological critique informed by Critical Race Theory (CRT) and the analytical tool box developed in my literature review. These analytical concepts helped me explore the ideological underpinnings of the discursive resources that Justices drew upon in the majority, concurring, and dissenting opinions. My ideological reading of the final ruling revealed that the conservative Justices drew upon discursive structures, or underlying logics, of race-neutral universalism, moral equivalence, and White normativity. These discursive structures, as identified in the literature review, are manifestations of the structural principle of Whiteness. In drawing upon this meaning system, the conservative Justices produced discursive openings that destabilized the legitimacy of three dominant discursive resources as engaged by the UT briefs: (a) qualitative meanings of critical mass, (b) race as a part of diversity, and (c) diversity as a compelling interest. The final ruling (re)produced a meaning system around these interrelated discursive resources that drew upon and reinforced arguments made in the Fisher briefs and by Fisher's lawyer in the oral arguments. 


\section{Phase three.}

In phase three, I brought together my analysis of the first two phases to answer the following research questions: (a) how was the deep-level structuring principle of Whiteness producing and reproduced by the discursive practice of debating raceconscious admissions in the Fisher case? (b) how are White and non-White subjects constituted within the discursive practices of the Fisher case? and (c) how might marginalized discursive resources and structural contradictions in the debate serve to decenter the normative power of Whiteness in the affirmative action debate? I will now summarize the major findings for each of these questions.

\section{(Re)producing Whiteness.}

My analysis revealed that the Grutter structure constitutes and is constituted by a set of rules and discursive resources that served to structure the Fisher debate in ways that were produced by and (re)produced White dominance. The first rule that was produced by and served to reproduce Whiteness was the compelling interest in diversity as the justification for considering race in admissions. Within this rule, the consideration of race in admissions policies is primarily legitimized by the business case for diversity. My analysis revealed that both sides of the debate drew upon and reproduced this rule that diversity serves this market-driven compelling interest. However, each side engaged diversity as a discursive resource in different ways and for different purposes. On one side, the UT briefs engaged the business case for diversity to legitimize the consideration of race-conscious admissions. On the other side, the Fisher briefs attempted to transform the meaning of diversity in order to delegitimize race as part of that discursive resource. My analysis suggests that although these two sides are fighting for different outcomes 
regarding affirmative action policy, both of these strategic uses of the business case for diversity (re)produce White dominance. While it is not surprising that the antiaffirmative action stance against race-conscious admissions (re)produces Whiteness, it is of critical importance to understand how pro-affirmative action advocates also participated in the reproduction of Whiteness.

Structured by the market/profit driven logic of the business case, pro-affirmative action advocates argue for use of race-conscious admissions to enhance diversity, constructed as a necessity to meet employers' demands in a diverse society and to maintain America's competitiveness in the global market-place. In drawing upon and (re)producing this legitimized purpose of affirmative action policies, the UT briefs centered on White interests by shifting the focus from the lingering effects of historic discrimination to promoting the forward-looking agenda of the business case. Furthermore, in drawing upon the business case to justify the consideration of race, the UT briefs commodified people of color as important resources in the educational process in order to help all students attain the skills thought to be important to these marketdriven endeavors. Although several of the UT briefs did draw upon history and discrimination to contextualize the need for race-conscious admissions, the compelling interest in these race-conscious policies was almost always articulated as the benefits (to all students) that minority students contribute to the education process. Thus, my analysis suggests that in relying upon the business case for diversity, advocates for raceconscious admissions may inadvertently be perpetuating the status quo of power relations by centering on White interests and marginalizing issues of racial inequality and discrimination. 
Another rule of the Grutter structure that further (re)produced White interests was the concept of critical mass. The critical mass rule served to protect White dominance by providing the stopping point to the consideration of race; which, according to the Grutter structure, is defined as the point at which there are enough minorities to demonstrate the compelling interest in diversity. In other words, White people only have to tolerate racial preferences in order that they themselves might benefit and when those benefits are realized, racial preferences will stop. Furthermore, the Grutter structure creates a structural contradiction around the meaning of critical mass by delegitimizing quantification (i.e. quotas, goals, racial balancing), yet also legitimizing the idea that there must be 'enough' minorities to achieve the compelling interest in diversity. This structural contradiction provided a discursive opening to contest UT's evidence in support of its need to consider race in admissions. In other words, in future debates around race-conscious admissions, the critical mass rule as part of the Grutter structure may also serve to transform or even dismantle this structure, as will be further discussed in the practical application section.

\section{The constitution of racialized subjects.}

In answering my second research question, I found that the discursive practice of talking about racialized subjects in the context of higher education served to (re)produce Whiteness by (a) constituting racialized subjects in hierarchically ordered binary pairs and (b) maintaining White invisibility and universality. Binary thinking, a discursive structure produced by the underlying structuring principle of Whiteness (Okun, 2010), was drawn upon to (re)produce racialized subject positions such that White (and sometimes Asian) students were constructed in a hierarchically superior position in 
relation to Black and Latino students. For example, both the Fisher and the UT briefs drew upon and (re)produced binary thinking in conjunction with White normativity in the context of academic performance in ways that served to re-center Whiteness as the norm or standard from which Black and Latino students were unfavorably compared. The briefs also normalized White academic achievement and denaturalized minority student achievement by marking those minorities who do perform as well as White students as 'qualified minorities.' Thus, binary thinking converged with White normativity to naturalize White subjects as academically superior. Whiteness was also made normative by unmarking (or excluding) the word White and through language that constituted Whiteness as the universal norm. My analysis revealed that White subjects were barely mentioned in the oral arguments and the majority opinion. In other words, the debate around racial preferences centered on non-White racial preferences, thus rendering White subjects invisible in the construction of the policy problem.

\section{Contesting Whiteness.}

Perhaps the most important findings of this project emerged through my analysis of the briefs produced by Black organizations. According to Critical Race Theory (CRT), a critical part of denaturalizing and destabilizing Whiteness is illuminating marginalized accounts of the racialized order. Therefore, to answer my third research question I focused on briefs written by Black agents in this discursive practice. However, the decision to analyze these briefs separately from the others was not made in advance of my analysis. In other words, I did start my analysis with the assumption that arguments produced by Black organizations would differ significantly from other UT briefs. Rather, in analyzing the whole body of amicus briefs, I came to realize that each 
side of the debate primarily drew upon a dominant set of arguments, and the primary exceptions to these dominant lines of argument were found in the amicus briefs produced by Black organizations (hereafter referred to as Black briefs for simplicity). Even the two briefs proffered by Latino organizations relied upon the diversity rationale and (re)produced commodification of minority students. This finding was aligned with Jäger and Maier's (2009) observation that although discourse positions may differ around particular issues, such as for or against race-conscious admissions, "within a dominant discourse, discourse positions are fairly homogenous, which itself is already an effect of dominant discourse" (p.50). Therefore, I came to understand that the Black briefs represented an important site of discursive resistance to ideological dominance. Indeed, my analysis revealed that these Black agents contested White dominance by (a) producing discursive resources to legitimize a compelling interest for race-conscious admissions outside of the diversity rationale, (b) asserting Black agency, and (c) decentering White interests. Together, the Black briefs contested the dominant narrative around race-conscious admissions policies as constructed from a White-centric perspective and provided a different lens through which to construct the policy problem and proposed solutions. To clarify, I am not asserting that there is a monolithic Black perspective, nor am I suggesting that the Black briefs were the only points of discursive resistance to Whiteness. What my analysis did reveal is that within the discursive practice of debating race-conscious admissions, the Black briefs drew upon logics, rationales, and arguments that contested Whiteness in ways that were distinctly different from other briefs. Furthermore, I am suggesting that this perspective is important within a debate about a policy that was originally produced to address the racial inequality 
created by slavery, segregation, and other state-sanctioned actions directed at Black people.

As I stated in chapter one, I strongly believe that affirmative action initiatives are essential to the growth and sustainability of our increasingly diverse society. However, my analysis aligns with previous critical legal studies research that suggests that affirmative policy rationales in their current discursive formation may actually reproduce rather than subvert the racialized social order (Baez, 1999; Delgado, 1991; Lawrence, 2001). Therefore, in the practical application section of the chapter, I apply these findings to suggest new ways to think about, talk about, and argue for race-conscious admissions policies. First, however, I discuss my project's methodological and theoretical contributions.

\section{Methodological Contributions}

My project contributed to the methodology of critical discourse analysis (CDA) by explicating a theoretically rich race-centric approach to CDA. My approach built upon and enhanced the newly emerging method called critical race discourse analysis (e.g., Acholonu, 2013; Briscoe \& Khalifa, 2013; Ledesma, 2013). Specifically, I integrated structurational concepts into my methodological approach, which provided an analytical framework for exploring (a) the mutually constitutive relationship between

discursive structures and resources, (b) how Whiteness produced and was reproduced by the discursive practice of debating affirmative action policy, and (c) how this particular instantiation of the discursive practice of debating law/policy is discursively linked to past and future discursive practices around the same issue. This race-centric approach 
proved to be a fruitful method for understanding and revealing how Whiteness structured and was reproduced by the discursive practice of debating the Fisher case.

My three-phase analysis process allowed me to explore the broad discursive field enacted in the debate, as well as the deep-level ideological work ultimately producing of and (re)produced through this process. When I designed this project, I expected that there would be a narrowing down of the discursive resources engaged throughout this decision-making process. In other words, I expected that some discursive resources would be taken up and others would be excluded or marginalized in the oral arguments and in the Court's final ruling. To some extent, this narrowing down did occur. However, the second phase of my analysis, which focused on the ideological underpinnings of the final ruling, revealed that the more meaningful narrowing down was not around the discursive resources themselves, but rather the narrowing that occurred around the ideological meaning system drawn upon to (re)produce particular meanings of these discursive resources. Specifically, my analysis of the final ruling revealed that the conservative Justices drew upon discursive structures, or underlying logics, that were produced by and served to reproduce the structural principle of Whiteness. This finding suggests that in order to understand and reveal the discursive ideological processes at work in policy debates, researchers should analyze both the broader discursive field as well as the final product of a policy debate. My three-phase analytical approach proved to be a fruitful method for such an analysis. As such, I encourage future scholarship that adapts and extends this approach to the analysis of any contested law or policy. 


\section{Theoretical Contributions}

Critical, post-modern, and post-structuralist feminist scholars have developed a rich body of theory and research that illuminates how gender organizes and is organized by institutionalized discursive practices that privilege patriarchal, masculine forms of knowledge/power relations (e.g. Acker, 1990; Ashcraft \& Mumby, 2004; Lazar, 2007; Weedon, 1987). A post-structuralist feminist critique of social relations explicates how patriarchal ideology produces and is reproduced by gendered discourses that locate male and female subjects in a hierarchically ordered binary opposition that subjugates women in relation to men (Weedon, 1987). Inspired by this feminist critique of patriarchal power, the present project explicated a theoretical and analytical framework for understanding how the ideological power of Whiteness produces and is reproduced by institutionalized discursive practices. By weaving together concepts from Structuration Theory (Giddens, 1984), communication theories of institutions (Lammers \& Barbour, 2006; Phillips, Lawrence, \& Hardy, 2004), and critical and feminist post-structuralist theories of discourse, power, and ideology (Fairclough, 2010; Mumby, 1987; Weedon, 1987), I contributed to a discourse-centered theory of Whiteness and enhanced ST's potential for critical scholarship. My framework provided an analytical lens through which to explore how Whiteness functioned as an underlying structural principle that emerged in discursive resources and structures that maintained White invisibility, universality, and dominance in the discursive practice of debated race-conscious admissions policies. By revealing and critiquing how Whiteness was invisibly produced, reproduced, and contested in this discursive practice, I opened agentic possibilities for 
new ways of understanding the discursive and material construction of affirmative action policy, as will be discussed further in the practical applications section.

A second theoretical contribution of this project was the extension of the concept of discursive resources. In organizational communication research, this concept has primarily been applied to surface the underlying discourses submerged in individuals' accounts or stories about their identities and work (e.g., Kuhn \& Nelson, 2002; Kuhn, 2009; Wieland, 2010). In this project, I extended the use of discursive resources to analyze an ideological debate. I enhanced the explanatory value of this concept by locating discursive resources within a systemic discursive framework that accounts for the mutually constitutive relationship between discursive resources and discursive structures embedded in ideological systems of meaning that structure the totality of society (structural principles). My theoretical framework proved to be a useful tool for analyzing the discursive production of public policy within the legal arena, an area of research that has yet to be taken up in organizational communication research.

In contrast to other organizational communication research that focuses on the enactment of policies (e.g., Buzzanell \& Liu, 2005; Clair, 1993; Kirby \& Krone, 2002; Meisenbach et al., 2008), my project built upon Browning and Beyer’s (1998) research focused on the development of industry standards by agents who are removed in time and space from the people and sites that will later be subject to these standards. By analyzing the structurational decision-making process in the U.S.'s highest Court, my project opened a line of research that holds promise for organizational communication scholars interested in the production of policies that broadly impact the organizing of social life. This macro-level organizing does not easily lend itself to scholarly research because it is 
rather abstract as compared to organizing in specific situated contexts and sometimes requires learning practice-specific vocabulary, such as constitutional terminology. I believe that my project has demonstrated that organizational communication theories and methodologies can and should be fruitfully applied to exploring this complex and diffuse level of organizing that serves to enable and constrain localized organizing practices. In what follows, I discuss how this project contributed to the existing scholarship on affirmative action.

\section{Contributions to Affirmative Action Scholarship}

My project makes four main contributions to existing scholarship on affirmative action. First, my analysis contributed to a small body of literature that critiques liberal arguments for affirmative action (e.g., Bell, 2003; Delgado, 1991; Katznelson, 2006; Lawrence, 2001; Yount, 1993). Second, my findings both support and alter Cho's (2009) critique of post-racial ideology. Third, I extended research on the constitution of racialized subjects in policy discourse. And finally, I highlighted a Black standpoint in the affirmative action debate. I will now discuss each of the contributions.

As delineated in my literature review and methodological approach, this project intentionally maintained a critical gaze on the arguments proffered in favor of affirmative action. As Lazar (2007) argued in her conceptualization of a feminist critical discourse analysis, it is important to maintain a critical gaze on liberal arguments that seemingly advance an agenda of equality, but may, in fact, maintain current structures of domination. My analysis suggests that in relying upon the business case for diversity to reproduce the Grutter structure, advocates for race-conscious admissions may inadvertently be perpetuating the status quo of power relations by centering on White 
interests and marginalizing arguments around racial inequality and discrimination. This finding supports and is supported by the critiques of the business case for diversity as discussed in the literature review (e.g., Litvin, 2006; Zanoni, Janssens, Benschop, \& Nkomo, 2010). My findings are also aligned with Yount's (1993) conclusion that the problematization of affirmative action within the conservative/liberal debate (re)produces the existent knowledge/power regime around the meanings of and rationales for affirmative action policies. Moreover, Yount (1993) argued that liberal arguments for affirmative action act in collusion with conservative ones because liberal affirmative action solutions "only contest the mechanisms, and not the more encompassing structure they all accommodate" (p. 211). In terms of my project, the "encompassing structure" was the knowledge/power regime produced by Grutter, particularly around the discursive resources of diversity and race. My analysis revealed that while participants in the debate argued about the "mechanism" of race-conscious admissions, both sides of the debate drew upon a set of rules and resources produced by, and that served to reproduce, the structuring principle of Whiteness.

My second contribution was to the theorization of post-racial ideology in affirmative action discourse. Cho's (2009) post-racialism framework delineated four strategies or rhetorical logics derived from post-racial ideology: racial progress, raceneutral universalism, moral equivalence, and a distancing move. Interestingly, the only one of these strategies not found in my analysis was racial progress. In other words, neither side of the debate seems to be claiming that society has made great strides in overcoming racial divisions. Some critical race scholars claimed that the election and reelection of an African American to the U.S. presidency produced the rise of post-racial 
discourse in U.S. society (e.g., Cho, 2009; Ford Dowe, 2010; Wise, 2010). While the rise of racial progress discourse may have been true immediately following those elections, my analysis suggests that this discursive logic may no longer hold sway. Rather than racial progress, I found that anti-affirmative action advocates drew upon a discursive structure, or underlying logic, of racial denial. For example, some of the Fisher briefs drew upon social constructionist theories of race to contend that race is not a real category of experience, but merely a group stereotype used to label individuals. This argument draws upon individualism to deny that race constructs a meaningful category of group experience. Historically, the structural; principle of Whiteness produced and was reproduced by the discursive structure and resource of race (Haney-López, 2006; Harris, 1998). White subjects were produced through legislation that demarcated boundaries around rights and privileges reserved for White people. Now it seems that the structural principle of Whiteness is producing new discursive structures and resources that attempt to dismantle and delegitimize race as a discursive resource engaged by pro-affirmative action advocates to assert advantage or privilege to minorities.

The third contribution this project makes to the affirmative action literature is the explication of how the debate around race conscious admissions constituted and reproduced racialized subjects. My analysis supports and extends Iverson's (2010) conclusion that the knowledge produced in university diversity policies served to constitute the subject positions of minority students as 'outsiders' who are both deficient as compared to the dominant norm as well as useful to meeting instrumental goals. My findings support her claims, but also foreground how White subjects were produced and reproduced by the structural principle of Whiteness. In other words, while Iverson's 
work focused mainly on how minority students were constituted in diversity policies, my analysis revealed how binary thinking, White normativity, and unmarking Whiteness constituted White subjects in a hierarchically superior position. In this way, my analysis served to remove the cloak of invisibility by marking White subjects in the affirmative action discourse.

My final contribution to affirmative action scholarship is the explication of an alternative standpoint within the dominant liberal/conservative debate. By analyzing and articulating a Black standpoint or counter-narrative in the affirmative action debate, this project highlighted a set of discursive resources and strategies that were foreclosed in the discursive practice of debating race-conscious admissions. While not all the arguments produced in the Black briefs were different from the rest of the UT briefs, my analysis revealed a distinctly Black standpoint in the debate that contested the discursive closure around the compelling interest rule, asserted Black agency as a discursive resource in the debate, and de-centered White interests. This finding demonstrated that a critique of the invisibility and universality of Whiteness is enhanced by foregrounding a distinctly nonWhite perspective. Furthermore, these findings highlight an important site of discursive resistance to Whiteness that seems to be subsumed within the dominant liberal side of the affirmative action debate. Thus, future research that focuses on the discursive struggle within public policy or legal debates would be greatly enriched by integrating feminist standpoint (e.g., Buzzanell, 1994; Dougherty, 1999) and Black feminist standpoint theory (Allen, 1996; Collins, 1986) into the analytical framework.

In summary, this project served to further problematize the affirmative action debate within the existing body of research. The above contributions hint at both 
practical implications for the current debate as well as lines of future research, as will be discussed in the following sections.

\section{Practical Implications}

By marking Whiteness as an organizing principle in the affirmative action debate, this project opened agentic possibilities for revitalizing this decades-old debate and moving it beyond the dominant lines of argument in which the debate is currently mired. In practice, the Supreme Court's final ruling in the Fisher case left the Grutter structure and the legality of race-conscious admissions intact. In effect, however, the decision left the door open to future challenges and signaled that the Court majority is willing and eager to revisit the constitutionality of race-conscious admissions (Stowes, 2013). In fact, those efforts are already underway. The Project on Fair Representation, the organization that funded Abigail Fisher's case, has already launched a campaign seeking plaintiffs for potential lawsuits challenging the race-conscious admissions policies at Harvard University, the University of North Carolina at Chapel Hill, and the University of Wisconsin at Madison (Hoover, 2014). Proponents of affirmative action fear that universities will switch to ostensibly race-neutral admissions policies in order to insulate themselves from costly legal challenges (Schmidt, 2013; Stowes, 2013). In light of these threats and fears, I offer three key insights that might be helpful to affirmative action advocates (e.g. campus administrators, lawyers, and advocating organizations) as they strategize ways to maintain the legality of race-conscious admissions.

\section{Confront Critical Mass}

My first suggestion is that administrators seeking to defend their race-conscious admissions policies should bolster their efforts to shape the meaning of critical mass and 
to collect evidence that correlates with that meaning. My analysis revealed that the discursive struggle around the ambiguous concept of critical mass centered on how to legally and legitimately define critical mass and how to prove that this 'stopping point' has or has not been reached. In the Fisher case, the anti-affirmative action position sought to delegitimize the qualitative and holistic meaning of and evidence for critical mass proffered by UT. The Fisher briefs and the several of the Justices attempted to constrain the meaning of critical mass by insisting that only objective way to know if a critical mass goal had been reach was through quantitative measures, which is legally impermissible within the Grutter structure. Additionally, anti-affirmative action rhetoric engaged in the Fisher case attempted to delegitimize the types of evidence that UT offered in support of its race-conscious programs, such as surveys and interviews. Given that these arguments were not only prevalent in the Fisher briefs, but also emerged in the oral arguments and to some extent in the majority opinion, it seems likely that the battle over critical mass may be central to future legal challenges. Therefore, I offer three recommendations to counter these attacks.

My first recommendation is to stop reproducing the term critical mass. My theoretical framework asserts that discursive structures and resources only exist to the extent that they are continuously reproduced in discursive practices. Pro-affirmative action advocates might justify retiring the phrase critical mass by drawing upon Justice Scalia's 'critical cloud' comment about the problematic nature of the term critical mass. Future amicus briefs might replace critical mass with the phrase meaningful representation, which was also used in the Grutter ruling, but has not been reproduced in later discourse to the extent that the critical mass terminology has been used thus far. 
A second strategy is attempt to delegitimize the critical mass concept altogether because although it is now engaged to justify the use of race-conscious admissions, at some point it may also be used to call for an end to such policies. In other words, critical mass implies that a stopping point to the consideration of race should and will be determined. Affirmative action advocates should develop other arguments about when the consideration of race in admissions might no longer be necessary, such as when admissions policies no longer provide advantage to White students or when racial disparities have been diminished.

And third, administrators could challenge the positivist conceptualizations of critical mass and evidence by engaging rigorous qualitative and quantitative methodologies to monitor and assess the campus climate for diversity, the impact of diversity on learning outcomes, and the perceptions of potential applicants in relation to diversity on campus. By developing and being able to explain rigorous standards of qualitative research, university administrators will be better positioned to counter arguments that assert that critical mass can only be demonstrated in quantitative terms. Further, well-designed and executed research about diversity on campus would not only help in the context of legal challenges, but would also help assess whether and how raceconscious admissions efforts actually lead to the professed goals.

\section{Rethink the Compelling Interest in Diversity.}

My second recommendation to affirmative action advocates is to rethink reliance on the compelling interest in diversity as a resource to legitimize race-conscious admissions. Despite the fact that diversity as a compelling interest is a dominant and legitimized discursive resource, my analysis revealed that it is also malleable concept that 
can be transformed to argue against such policies. The Fisher briefs and the Court's final ruling created various discursive openings to challenge and reshape the meaning of diversity in the context of educational benefits. In response, I suggest that affirmative action advocates rethink the reliance on this discursive resource. Not only does diversity's discursive power seem to be weakening as a justification for race-conscious admissions in the Supreme Court, but also the diversity rationale, as circumscribed by the business case, serves to (re)produce the racial hierarchy by reproducing Whiteness through profit-driven logic, commodifying non-White students, and decoupling race from historic and systemic discrimination. Instead, I suggest that pro-affirmative action legal teams build constitutionally sound arguments around the alternative compelling interests that were proffered by the Black briefs; namely, the compelling interest in remedying past discrimination and/or in addressing the present social condition of unsustainable inequality. Through the (re)production of arguments that support a compelling interest in addressing the unsustainable racial disparities that mar society, it may be possible to disrupt, deconstruct, and dismantle the rhetorical force of Justice Powell's proclamation that societal discrimination does not constitute a compelling interest.

\section{Historicize Affirmative Action}

My final recommendation to help bolster arguments in support of race-conscious admissions is to articulate a more meaningful account of affirmative action history. Although many of the UT briefs drew upon the discursive resources of history and discrimination to contextualize the need for race-conscious admissions policies, none of the briefs specifically addressed the ways that White people have been advantaged by racial preferences provided through public policies. Ira Katznelson (2005) argued in his 
book, When Affirmative Action was White: An Untold Story of Racial Inequality in Twentieth-Century America, that affirmative action advocates have weakened the case for affirmative action by failing to recognize and articulate how "fundamental public policies [such] as Social Security, the Wagner Act, military segregation and the GI Bill [were] racially skewed by design, and how their powerful negative effects have compounded in the past two generations" (p. 160). In effect, these policies constituted a decades-long program of White affirmative action that served to create the White middle class and leave generations of Black families far behind the starting line (Kratznelson, 2005). This history has been missing from the affirmative action debate, thus serving to maintain White invisibility in the discussion about affirmative action justifications. By drawing attention to the ways that these public policies resulted in a "massive transfer of privileges to white Americans," (p. 160) the conversation around racial preferences in admissions might be framed more equitably. In other words, affirmative action arguments tend to focus on the lingering effects of institutional and state-sanctioned discrimination on people of color. Shifting focus to the lingering effects of privilege and systemic advantage that government programs produced for White people serves to denaturalize the invisibility of Whiteness in the policy debate and may provide new and improved constitutional justifications for race-conscious admissions.

\section{Limitations and Future Directions}

This project was limited to a critical discourse analysis of the documents produced in the Fisher v. UT case as argued in the Supreme Court in order to explore how Whiteness produced and was reproduced by this particular discursive practice in this particular socio-historic moment. In what follows, I discuss how these choices of 
analytical lens, method, context, and data set imposed several limitations, yet also opened various directions for future research.

By engaging Whiteness as my analytical lens, my analysis excluded some discursive structures and resources that might fruitfully be explored through other theoretical frameworks. For example, there was a line of argument around states' rights, academic freedom, and the role of federal government. Although this seemed like an important area of discursive struggle, it did not lend itself to an analysis of Whiteness. Therefore, political scientists and political communication scholars might explore the affirmative action debate informed by political theories to understand how decisions around race-conscious admissions are bound up in broader discussions about rights and power. Education scholars might also analyze the same texts through theoretical frameworks that explore the meanings of education entwined in capitalist discourses within this debate.

The second important limitation of this project was created in answering my third research question, which focused on the Black briefs. Although other sections of my analysis discussed how Latinos and Asians were discursively constructed within this debate, my focus on Black agency as the point of resistance to Whiteness in this discursive practice may have served to further marginalize non-Black minority groups. Future research should explore how agency was enacted by Latino, Asian American, Native American, and other non-dominant identity groups within the debate.

The third limitation was that my project focused only on one site of discursive practice in regards to the Fisher case. Therefore, future research should explore the debate around the Fisher case as enacted in other discourse strands, or bodies of texts, 
related to this case. For example, discourse tracing (LeGreco \& Tracy, 2009) could be used to analyze of a wide variety of texts related to the Fisher case such as newspaper articles, online discussion boards, official statements, policy texts, and marketing materials aimed at prospective students. This type of project would provide insight into the ways that discursive resources emerge as institutionalized practices and/or are contested within the broader discursive field.

A fourth limitation was that my project contributed only to understanding a particular moment in the long standing affirmative action debate. Therefore, to further advance the knowledge of the structurational process of law and policy making, it is important to continue to analyze the discursive practice of debating race-conscious admissions in the legal context in order to understand if/how the Grutter structure is reproduced and/or transformed. For example, the new ruling that will be produced by the lower Court will either affirm or invalidate its original finding in favor of UT. Either way, this decision will (re)produce important discursive resources on the discursive field of the legal context. Additionally, as previously discussed, there may be more lawsuits contesting race-conscious admissions on the horizon, which provides a fruitful avenue for exploring structurational processes overtime within this particular discursive practice.

The fifth limitation of my project was that it focused only on the affirmative action debate in the context of higher education. As part of the broader legal debate around affirmative action, court decisions on race-conscious admissions also impact affirmative action practices in both the public and private sectors (Baez, 1999; Goodwin, 2013; Jaschik, 2013; Leiter \& Leiter, 2011). Therefore, future research should explore if/how the meaning system around affirmative action policy and practice shifts or 
changes outside of higher education in response to the Fisher case. For example, while my analysis revealed how each side of the debate attempted to impose particular meanings of diversity in relation to race in a discursive practice structured by Grutter, future research might explore if/how this discursive struggle emerges outside of the legal debate in other contexts. A potentially fruitful way to explore the ways that diversity is engaged as a discursive resource in organizational contexts is through language convergence/meaning divergence (LC/MD) theory, a newly emerging organizational communication theory. LC/MD provides a theoretical framework for exploring how the engagement of certain discursive resources might create the illusion of shared meaning, thus obscuring underlying tensions produced by divergent visions of reality (Dougherty, Kramer, Klatzke, \& Rogers, 2009). In this light, LC/MD might be particularly useful for exploring the ways that individuals in differentially structured subject positions define and understand the meaning of diversity in specific organizational contexts.

Finally, this project only explored one of the myriad of ways that Whiteness organizes social life. Whiteness is an overarching, yet underlying, structuring principle and institution that organizes the whole of society (e.g., housing, employment, education, health care, etc.). Informed and inspired by feminist theories of organizing that denaturalize patriarchal organizing practices (e.g., Ashcraft \& Mumby, 2004; Buzzanell \& Liu, 2005; Dougherty, 2001; Mumby \& Putman, 1992), the analytical lens developed in this project should be further developed to explore and reveal the ways that organizing practices are also structured by, and serve to (re)produce, Whiteness. A research agenda centered on Whiteness and race is critical to advancing organizational communication 
scholarship in an increasingly diverse and global society, both for the health of the discipline and for the health of the organizations in which we operate.

\section{Conclusion}

Given the growing and unsustainable problem of socio-economic racial inequality in the U.S., it is of critical importance that admissions policies and practices facilitate access to higher education for students of color. However, access to education alone will not resolve the issue of racial inequality. I believe that fostering racial equality requires revealing, confronting, and contesting the underlying ideologies and discursive practices that (re)produce White normativity, universality, and invisibility. By surfacing Whiteness to our collective discursive consciousness, society, educators, policy makers, and scholars can be begin to interrupt the systemic (re)production of White privilege, dismantle the racial hierarchy, and develop more just and equitable organizing practices. Therefore, in order to make a small contribution to this monumental task, my hope with this project was to bring to light and destabilize entrenched, taken-for-granted assumptions about affirmative action, diversity, and race. 


\section{Appendix}

\begin{tabular}{|c|c|}
\hline 2 BRIEFS FOR NEITHER PARTY & \\
\hline Equal Employment Advisory Council & 25 pages \\
\hline Richard Sander and Stuart Taylor Jr. & 35 pages \\
\hline TOTAL PAGES & 60 \\
\hline 17 BRIEFS FOR PETITIONER (Fisher) & \\
\hline Abigail Thernstrom, Stephan Thernstrom, Althea K. Nagai, and Russell Nieli & 40 pages \\
\hline American Center for Law and Justice & 17 pages \\
\hline American Civil Rights Union & 25 pages \\
\hline Asian American Legal Foundation and the Judicial Education Project & 46 pages \\
\hline $\begin{array}{l}\text { California Association of Scholars, Connecticut Association of Scholars, } \\
\text { Center for Constitutional Jurisprudence, Reason Foundation, Individual Rights } \\
\text { Foundation, and American Civil Rights Foundation }\end{array}$ & 44 pages \\
\hline CATO Institute & 41 pages \\
\hline Center for Individual Rights & 20 pages \\
\hline Current and Former Civil Rights Officials & 32 pages \\
\hline $\begin{array}{l}\text { Gail Heriot, Peter Kirsanow \& Todd Gaziano, Members of the United States } \\
\text { Commission on Civil Rights }\end{array}$ & 44 pages \\
\hline $\begin{array}{l}\text { Honorable Allen B. West, Member of Congress and Lieutenant Colonel, } \\
\text { United States Army (Ret.) }\end{array}$ & 33 pages \\
\hline $\begin{array}{l}\text { Judicial Watch, Inc., and Allied Educational Foundation in Support of } \\
\text { Petitioner }\end{array}$ & 31 pages \\
\hline $\begin{array}{l}\text { Louis D. Brandeis Center for Human Rights Under Law, the 80-20 National } \\
\text { Asian American Educational Foundation, et al }\end{array}$ & 48 pages \\
\hline Mountain States Legal Foundation in Support of Petitioner & 29 pages \\
\hline $\begin{array}{l}\text { Pacific Legal Foundation, Center for Equal Opportunity, the American Civil } \\
\text { Rights Institute, the National Association of Scholars, and Project } 21\end{array}$ & 52 pages \\
\hline Scholars of Economics and Statistics & 50 pages \\
\hline Southeastern Legal Foundation & 35 pages \\
\hline Texas Association of Scholars & 50 pages \\
\hline TOTAL PAGES & 637 \\
\hline 73 BRIEFS FOR RESPONDANT (University of Texas) & \\
\hline $\begin{array}{l}28 \text { Undergraduate and Graduate Student Organizations Within the University } \\
\text { of California in Support of Respondents }\end{array}$ & 59 pages \\
\hline 38 Current Members of the Texas State Senate and House of Representatives & 42 pages \\
\hline Advancement Project in Support of Respondents and Urging Affirmance & 58 pages \\
\hline American Association for Affirmative Action & 53 pages \\
\hline American Bar Association & 42 pages \\
\hline American Civil Liberties Union & 29 pages \\
\hline American Social Science Researchers & 80 pages \\
\hline American Council on Education and 39 Other Higher Education Organizations & 59 pages \\
\hline American Educational Research Association, et al., & 57 pages \\
\hline
\end{tabular}




\begin{tabular}{|c|c|}
\hline $\begin{array}{l}\text { American Jewish Committee, Central Conference of American Rabbis and } \\
\text { Union for Reform Judaism }\end{array}$ & 41 pages \\
\hline American Psychological Association & 56 pages \\
\hline $\begin{array}{l}\text { Amherst, Allegheny, Barnard, Bates, Bowdoin, Bryn Mawr, Carleton, Colby, } \\
\text { Connecticut, Davidson, Dickinson, Franklin \& Marshall, Grinnell, Hamilton, } \\
\text { Hampshire, Haverford, Lafayette, Macalester, Middlebury, Mount Holyoke, } \\
\text { Oberlin, Pomona, Reed, Sarah Lawrence, Simmons, Smith, St. Olaf, } \\
\text { Swarthmore, Trinity, Union, Vassar, Wellesley, and Williams Colleges, } \\
\text { Bucknell, Colgate, Wesleyan and Tufts Universities }\end{array}$ & 43 pages \\
\hline Anti-Defamation League & 24 pages \\
\hline Appalachian State University and 35 Fellow Colleges and Universities & 65 pages \\
\hline $\begin{array}{l}\text { Asian American Legal Defense and Education Fund, Asian/Asian American } \\
\text { Faculty and Staff Association of the University of Texas at Austin, Asian Desi } \\
\text { Pacific Islander American Collective of the University of Texas at Austin, } \\
\text { other Asian American and Pacific Islander Education and Youth-Serving } \\
\text { Organizations, and Higher Education Officials }\end{array}$ & 60 pages \\
\hline Association of American Law Schools & 47 pages \\
\hline Association of American Medical Colleges et al. & 52 pages \\
\hline Association of the Bar of the City of New York & 26 pages \\
\hline $\begin{array}{l}\text { Black Student Alliance at the University of Texas at Austin, the Black Ex- } \\
\text { Students of Texas, Inc., and the NAACP Legal Defense and Educational Fund, } \\
\text { Inc. }\end{array}$ & 42 pages \\
\hline Boston Bar Association & 41 pages \\
\hline $\begin{array}{l}\text { Brennan Center for Justice at NYU School of Law and the League of Women } \\
\text { Voters of the United States }\end{array}$ & 47 pages \\
\hline $\begin{array}{l}\text { Brown University, University of Chicago, Columbia University, Cornell } \\
\text { University, Dartmouth College, Duke University, Harvard University, Johns } \\
\text { Hopkins University, Massachusetts Institute of Technology, University of } \\
\text { Pennsylvania, Princeton University, Stanford University, Vanderbilt } \\
\text { University, and Yale University }\end{array}$ & 39 pages \\
\hline State of California & 23 pages \\
\hline $\begin{array}{l}\text { California Institute of Technology, Carnegie Mellon University, Case Western } \\
\text { University, Emory University, George Washington University, Northwestern } \\
\text { University, Rice University, Tulane University, University of Rochester, and } \\
\text { Washington University }\end{array}$ & 42 pages \\
\hline $\begin{array}{l}\text { Coalition of Bar Associations of Color (National Bar Association, Hispanic } \\
\text { National Bar Association, National Asian Pacific American Bar Association, } \\
\text { and National Native American Bar Association) }\end{array}$ & 44 pages \\
\hline Coalition of Black Male Achievement Initiatives & 72 pages \\
\hline $\begin{array}{l}\text { Coalition to Defend Affirmative Action, Integration and Immigrant Rights and } \\
\text { Fight for Equality by Any Means Necessary (BAMN), and United for Equality } \\
\text { and the Affirmative Action Legal Defense Fund (UEAALDF) }\end{array}$ & 23 pages \\
\hline College Board and the National School Boards Association, et al. & 60 pages \\
\hline Constitutional Law Scholars and Constitutional Accountability Center & 33 pages \\
\hline $\begin{array}{l}\text { Council for Minority Affairs at the University of Houston, Society of Hispanic } \\
\text { Professional Engineers at the University of Texas-Austin, University }\end{array}$ & 41 pages \\
\hline
\end{tabular}




\begin{tabular}{|c|c|}
\hline $\begin{array}{l}\text { Leadership Institute, and Texas College Students for Diversity Alejandra } \\
\text { Aguilar, et al. }\end{array}$ & \\
\hline David Boyle & 53 pages \\
\hline Dean Robert Post and Dean Martha Minow & 37 pages \\
\hline Distinguished Alumni of the University of Texas at Austin & 40 pages \\
\hline Dr. Robert Putnam & 22 pages \\
\hline Emory Outlaw and the Emory Latin American Law Students Association & 24 pages \\
\hline Empirical Scholars & 38 pages \\
\hline Experimental Psychologist & 45 pages \\
\hline The Family of Heman Sweatt & 50 pages \\
\hline $\begin{array}{l}\text { Fordham University, Boston College, DePaul University, Georgetown } \\
\text { University, College of the Holy Cross, Marquette University, University of } \\
\text { Notre Dame, and the University of San Francisco }\end{array}$ & 37 pages \\
\hline $\begin{array}{l}\text { Former Commissioners and General Counsel of the Federal Communications } \\
\text { Commission and the Minority Media and Telecommunications Council }\end{array}$ & 45 pages \\
\hline Former Student Body Presidents of University of Texas at Austin & 34 pages \\
\hline Fortune 100 and other Leading American $\mathrm{Bu}$ & 27 pages \\
\hline Harvard Graduate School of Education Students for Diversity & 30 pages \\
\hline Howard University School of Law Civil Rights Clinic & 43 pages \\
\hline Houston Community College System & 28 pages \\
\hline Human Rights Advocates, et al. & 39 pages \\
\hline $\begin{array}{l}\text { Lt. Gen. Julius W. Becton, Jr., Gen. John P. Abizaid, Adm. Dennis C. Blair, } \\
\text { Gen. Bryan Doug Brown, Lt. Gen. Daniel W. Christman, Gen. Wesley K. } \\
\text { Clark, Adm. Archie Clemins, Gen. Ronald R. Fogleman, et al. }\end{array}$ & 54 pages \\
\hline Kimberly West-Faulcon & 40 pages \\
\hline Law School Admissions Council & 38 pages \\
\hline Lawyers Committee for Civil Rights Under Law & 50 pages \\
\hline $\begin{array}{l}\text { Leading Public Research Universities the University of Delaware, the Board of } \\
\text { Trustees of the University of Illinois, Indiana University, the University of } \\
\text { Kansas, the University of Michigan, Michigan State University, the University } \\
\text { of Nebraska-Lincoln, the Ohio State University, the Pennsylvania State } \\
\text { University, and Purdue University }\end{array}$ & 38 pages \\
\hline Members of the Asian American Center for Advancing Justice, et al., & 74 pages \\
\hline $\begin{array}{l}\text { National Association for the Advancement of Colored People, Texas State } \\
\text { Conference of NAACP Branches and Barbara Baderaldave }\end{array}$ & 43 pages \\
\hline $\begin{array}{l}\text { National Association of Basketball Coaches, Women's Basketball Coaches } \\
\text { Association, Black Coaches \& Administrators, Beth Burns, Johnny Dawkins, } \\
\text { Jamie Dixon, Paul Hewitt, Ben Howland, Tom Izzo, Phil Martelli, Joanne P. } \\
\text { Mccallie, Mike Montgomery, Sue Semrau, Orlando “Tubby" Smith, Charli } \\
\text { Turner Thorne, Coquese Washington and Additional Individuals }\end{array}$ & 33 pages \\
\hline National Black Law Students Association & 50 pages \\
\hline National Education Association, et al. & 54 pages \\
\hline National Latino Organizations & 60 pages \\
\hline $\begin{array}{l}\text { National League of Cities, Campus Compact, Imagining America, Anchor } \\
\text { Institutions Task Force, Transformative Leadership Working Group, Center for }\end{array}$ & 55 pages \\
\hline
\end{tabular}




\begin{tabular}{|l|r|}
\hline $\begin{array}{l}\text { Democracy and Citizenship, Chancellor Nancy Cantor, Superintendent Sharon } \\
\text { Contreras, President Freeman Hrabowski, President Scott Cowen, CEO Nolan } \\
\text { Rollins, Chancellor James Dworkin, Superintendent Glade Montgomery, } \\
\text { President Thomas Rochon, Superintendent Luvelle Brown, President James T. } \\
\text { Harris, Superintendent Cheryl Cunningham }\end{array}$ & \\
\hline National Women's Law Center & \\
\hline $\begin{array}{l}\text { The States of New York, Connecticut, Hawaii, Illinois, Iowa, Maryland, } \\
\text { Massachusetts, Mississippi, Montana, New Mexico, North Carolina, Vermont, } \\
\text { Washington, West Virginia, The District Of Columbia, and the Territory of the } \\
\text { U.S. Virgin Islands }\end{array}$ & 30 pages \\
\hline The New York State Bar Association & 29 pages \\
\hline President and Chancellors of the University of California & 47 pages \\
\hline Religious Organizations and Campus Ministries, et al. & 37 pages \\
\hline $\begin{array}{l}\text { Ruben Hinojosa, Member of Congress; Charles A. Gonzalez, Member of } \\
\text { Congress; and 64 Other Members of Congress }\end{array}$ & 29 pages \\
\hline The Small Business Owners Association & 40 pages \\
\hline Social and Organizational Psychologists & 54 pages \\
\hline Society of American Law Teachers & 35 pages \\
\hline Teach for America, Inc., & 12 pages \\
\hline United Negro College Fund & 58 pages \\
\hline The United States & 42 pages \\
\hline The United States Students Association & 25 pages \\
\hline The University of North Carolina at Chapel Hill & 47 pages \\
\hline $\begin{array}{l}\text { U.S. Senators Harry Reid, Tom Harkin, Richard J. Durbin, Charles E. } \\
\text { Schumer, Patty Murray, Carl Levin, John F. Kerry, Barbara A. Mikulski, } \\
\text { Dianne Feinstein, Barbara Boxer, Jack Reed, Mary L. Landrieu, Frank R. } \\
\text { Lautenberg, Benjamin L. Cardin, Bernard Sanders, Christopher A. Coons, and } \\
\text { Richard Blumenthal }\end{array}$ & 35 pages \\
\hline & \\
\hline GRAND TOTAL 3856 & \\
\hline
\end{tabular}




\section{References}

Acholonu, I. (2013). The "Gutting” of Grutter: White Racial Innocence and Postracialism in the Abigail Fisher v. University of Texas Austin Oral Arguments. Journal of Curriculum Theorizing, 29(2), 206-219.

Acker, J. (1990). Hierarchies, jobs, bodies: A theory of gendered organizations. Gender and Society, 4(2), 139-158. Retrieved from http://www.jstor.org/stable/189609

Acker, J. (2006). Inequality Regimes Gender, Class, and Race in Organizations. Gender \& Society, 20(4), 441-464. doi:10.1177/0891243206289499

Allen, B. J. (1995). "Diversity" and Organizational Communication. Journal of Applied Communication Research, 23(2), 143-155. doi:10.1080/00909889509365420

Allen, B. J. (1996). Feminist standpoint theory: A black woman's (re) view of organizational socialization. Communication Studies, 47(4), 257-271.

Alon, S., \& Tienda, M. (2007). Diversity, opportunity, and the shifting meritocracy in higher education. American Sociological Review, 72(4), 487-511.

Alvesson, M., \& Deetz, S. A. (2006). Critical theory and postmodernism approaches to organizational studies. In S. R. Clegg, C. Hardy, T. B. Lawrence, \& W. R. Nord (Eds.), The Sage handbook of organization studies (pp. 255-283). Thousand Oaks, CA: Sage.

Alvesson, M., \& Willmott, H. (1992). On the idea of emancipation in management and organization studies. Academy of Management Review, 432-464. doi:10.5465/AMR.1992.4281977 
Amicus brief of Gail Heriot, Peter \& Todd Gaziano, Members of the U.S. Commission on Civil Rights in support of the petitioner. (2012). Fisher v. University of Texas. No. 11-345.

Amicus brief of the American Center for Law and Justice in support of petitioner. (2012). Fisher v. University of Texas, No. 11-345 (2012).

Amicus curiae brief of Mountain States Legal Foundation in support of petitioner. (2012). Fisher v. University of Texas. No. 11-345.

Amicus curiae brief of the American Civil Rights Union in support of petitioner. (2012). Fisher v. University of Texas. No. 11-345.

Amicus curiae brief of the Center for Individual Rights in support of petitioner. (2012). Fisher v. University of Texas. No. 11-345.

Ashcraft, K. L., \& Allen, B. J. (2003). The racial foundation of organizational communication. Communication Theory, 13(1), 5-38. doi:10.1111/j.14682885.2003.tb00280.

Ashcraft, K. L., \& Mumby, D. K. (2004). Reworking gender: a feminist communicology of organization. Thousand Oaks, CA: Sage.

Bacchi, C. L. (1999). Women, policy, and politics : the construction of policy problems. London; Thousand Oaks, CA: Sage.

Baez, B. (1999). Supreme Court and Affirmative Action: Narratives about Race and Justice, The. St. Louis University Public Law Review, 18, 413.

Baez, B. (2000). Agency, structure, and power: An inquiry into racism and resistance for education. Studies in Philosophy and Education, 19(4), 329-348. doi:10.1023/A:1005241732091 
Baez, B. (2000). Diversity and its contradictions. Academe, 86(5), 43.

Barley, S. R., \& Tolbert, P. S. (1997). Institutionalization and structuration: Studying the links between action and institution. Organization Studies, 18(1), 93-117. doi:10.1177/017084069701800106

Barron, J. A., \& Dienes, C. T. (2005). Constitutional law in a nutshell (6th ed.). St. Paul, MN: Thomson/West Group.

Bell, D. A. (2003). Diversity's Distractions. Columbia Law Review, 103(6), 1622-1633. doi: $10.2307 / 3593396$

Bell, D. A. (1979). Brown v. Board of Education and the interest-convergence dilemma. Harvard Law Review, 93, 518.

Biskupic, J. (2012, December 4). Special Report: Behind U.S. race cases, a little-known recruiter. Reuters. Retrieved August 28, 2013, from http://www.reuters.com/article/2012/12/04/us-usa-court-casemakeridUSBRE8B30V220121204

Blommaert, J., \& Verschueren, J. (1998). Debating diversity: Analysing the discourse of tolerance. London; New York: Routledge.

Blumrosen, A. W. (1995). Draft report on reverse discrimination commissioned by Labor Department: How courts are handling reverse discrimination cases. Washington, D.C.: Bureau of National Affairs.

Bollinger, L. C. (2013, June 24). A long, slow drift from racial justice. New York Times. Retrieved July 10, 2013, from http://www.nytimes.com/2013/06/25/opinion/along-slow-drift-from-racial-justice.html?_r=0 
Bollinger, L. C., \& Steele, C. M. (2012, October 9). Affirmative action in higher education: A Supreme Court challenge. Los Angeles Times. Retrieved March 5, 2014, from http://articles.latimes.com/2012/oct/09/opinion/la-oe-bollinger-fishertexas-race-20121009

Bonilla-Silva, E. (2001). White supremacy and racism in the post-civil rights era. Boulder, CO: L. Rienner.

Boswell, T. E. (1986). A split labor market analysis of discrimination against Chinese immigrants, 1850-1882. American Sociological Review, 352-371.

Bowen, W. G., \& Bok, D. (1998). The shape of the river: Long-term consequences of considering race in college and university admissions. Princeton: Princeton University Press.

Brekhus, W. (1998). A sociology of the unmarked: redirecting our focus. Sociological Theory, 16(1), 34-51. doi:10.1111/0735-2751.00041

Brief amicus curiae of Pacific Legal Foundation, Center for Equal Opportunity, American Civil Rights Institute, et al., in support of petitioner. (2012). Fisher v. University of Texas. No. 11-345.

Brief for amici curiae current and former federal civil rights officials in support of petitioner. (2012). Fisher v. University of Texas, No. 11-345.

Brief for amici curiae Fortune-100 and other leading American businesses in support of respondents. (2012). Fisher v. University of Texas. No. 11-345.

Brief for amici curiae National Association for the Advancement of Colored People, et al. in support of respondents. (2012). Fisher v. University of Texas. No. 11-345. 
Brief for amici curiae Small Business Owners and Associations in support of respondents. (2012). Fisher v. University of Texas. No. 11-345.

Brief for the Asian American Legal Foundation and the Judicial Education Project as amici curiae in support of petitioner. (2012). Fisher v. University of Texas, No. $11-345$.

Brief for the National Black Law Students Association as amicus curiae in support of respondents. (2012). Fisher v. University of Texas. No. 11-345.

Brief for the petitioner. (2012). Fisher v. University of Texas. No. 11-345.

Brief of Abigail Thernstrom, Stephan Thernstrom, Althea K. Nagai, and Russell Nieli as amici curiae in support of petitioners. (2012). Fisher v. University of Texas. No. 11-345.

Brief of American Social Science Researchers as amici curiae in support of respondents. (2012). Fisher v. University of Texas. No. 11-345.

Brief of amici curiae California Association of Scholars, Connecticut Association of Scholars, Center for Constitutional Jurisprudence, et. al, in support of petitioner. (2012). Fisher v. University of Texas, No. 11-345.

Brief of amici curiae Coalition of Black Male Achievement Initiatives in support of respondents. (2012). Fisher v. University of Texas. No. 11-345.

Brief of amici curiae Judicial Watch, Inc. and Allied Educational Foundation in support of petitioner. (2012). Fisher v. University of Texas, No. 11-345.

Brief of amici curiae the American Jewish Committee, Central Conference of American Rabbis, and Union for Reform Judaism in support of respondents. (2012). Fisher v. University of Texas. No. 11-345. 
Brief of amicus curiae David Boyle in support of respondents. (2012). Fisher v.

University of Texas. No. 11-345.

Brief of amicus curiae Teach for America, Inc. in support of respondents. (2012). Fisher v. University of Texas, No. 11-345.

Brief of amicus curiae the American Psychological Association in support of respondents. (2012). Fisher v. University of Texas. No. 11-345.

Brief of amicus curiae United Negro College Fund in support of respondents. (2012). Fisher v. University of Texas, No. 11-345.

Brief of experimental psychologists as amici curiae in support of respondents. (2012). Fisher v. University of Texas. No. 11-345.

Brief of Scholars of Economics and Statistics as amici curiae in support of petitioner. (2012). Fisher v. University of Texas. No. 11-345.

Brief of the Advancement Project as amicus curiae in support of respondents and urging affirmance. (2012). Fisher v. University of Texas, No. 11-345.

Brief of the American Association for Affirmative Action as amicus curiae in support of respondents. (2012). Fisher v. University of Texas. No. 11-345.

Brief of the American Bar Association as amicus curiae in support of respondents and urging affirmance. (2012). Fisher v. University of Texas. No. 11-345.

Brief of the Asian American Legal Defense and Education Fund, Asian/Asian American Faculty and Staff Association of UT, et al., as amici curiae in support of respondents. (2012). Fisher v. University of Texas, No. 11-345. 
Brief of the Black Student Alliance at UT, the Ex-Students of Texas, Inc., and the NAACP in support of respondents. (2012). Fisher v. University of Texas. No. 11345.

Brief of the Cato Institute as amicus curiae in support of the petitioner. (2012). Fisher v. University of Texas. No. 11-345.

Brief of the family of Heman Sweatt as amicus curiae in support of respondents. (2012). Fisher v. University of Texas. No. 11-345.

Brief of the Texas Association of Scholars as amici curiae in support of petitioner. (2012). Fisher v. University of Texas. No. 11-345.

Briscoe, F. M., \& Khalifa, M. A. (2013). “That racism thing”: a critical race discourse analysis of a conflict over the proposed closure of a black high school. Race Ethnicity and Education, (ahead-of-print), 1-25.

Broadfoot, K., Deetz, S., \& Anderson, D. (2004). Multi-levelled, multi-method approaches in organizational discourse. In D. Grant, C. Hardy, C. Oswick, \& L. L. Putman (Eds.), Sage handbook of organizational discourse (pp. 193 - 211). London: Sage.

Browning, L. D., \& Beyer, J. M. (1998). The structuring of shared voluntary standards in the US semiconductor industry: Communicating to reach agreement. Communications Monographs, 65(3), 220-243. doi:10.1080/03637759809376449

Brown-Nagin, T. (2005). Elites, social movements, and the law: The case of affirmative action. Columbia Law Review, 1436-1528. 
Butler, J. A., \& Modaff, D. P. (2008). When work is home: Agency, structure, and contradictions. Management Communication Quarterly, 22(2), 232-257. doi:10.1177/0893318908323151

Butler, S. (2012). Cracking the codes: The system of racial inequity. Oakland, CA: World Trust Educational Services. Retrieved from http://crackingthecodes.org/

Buzzanell, P. M. (1994). Gaining a voice: Feminist organizational communication theorizing. Management Communication Quarterly, 7(4), 339. Retrieved from http://proxy.mul.missouri.edu/login?url=http://search.proquest.com/docview/2328 55311 ?accountid=14576

Buzzanell, P. M., \& Liu, M. (2005). Struggling with maternity leave policies and practices: a poststructuralist feminist analysis of gendered organizing. Journal of Applied Communication Research, 33(1), 1-25.

doi:10.1080/0090988042000318495

Canary, H. E. (2010). Constructing policy knowledge: Contradictions, communication, and knowledge frames. Communication Monographs, 77(2), 181 - 206. doi:10.1080/03637751003758185

Canary, H. E. (2010). Structurating activity theory: An integrative approach to policy knowledge. Communication Theory, 20(1), 21-49.

Caputo, J. D., \& Yount, M. (1993). Foucault and the critique of institutions. University Park, PA: Pennsylvania State University Press.

Carnevale, A. P., \& Strohl, J. (2013). Separate and unequal: How higher education reinforces the intergenerational reproduction of white racial privilege. (p. 61). 
Washington, D.C.: Georgtown Public Policy Institute. Retrieved from http://cew.georgetown.edu/separateandunequal/

Chang, M. J. (2005). Reconsidering the Diversity Rationale. Liberal Education, 91(1), 613.

Chemerinsky, E. (2013, August 6). What's next for affirmative action? ABA Journal. Retrieved March 5, 2014, from http://www.abajournal.com/news/article/chemerinsky_whats_next_for_affirmativ e_action/

Cho, S. (2009). Post-Racialism. Iowa Law Review, 94(5), 1589-1649.

Clair, R. P. (1993). The bureaucratization, commodification, and privatization of sexual harassment through institutional discourse: A study of the big ten universities. Management Communication Quarterly, 7(2), 123-157.

Codd, J. A. (1988). The construction and deconstruction of educational policy documents. Journal of Education Policy, 3(3), 235-247. doi:10.1080/0268093880030303

Collins, P. H. (1986). Learning from the outsider within: The sociological significance of black feminist thought. Social Problems, 33(6), 14-32.

Cose, E. (1997). Color-blind: seeing beyond race in a race-obsessed world. New York: HarperCollins Publishers.

Crenshaw, C. (1997). Resisting whiteness' rhetorical silence. Western Journal of Communication, 61(3), 253-278. doi:10.1080/10570319709374577 
Cummings, A. D. P. (2005). Grutter v. Bollinger, Clarence Thomas, Affirmative Action and the treachery of originalism: The sun don't shine here in this part of town. Harvard BlackLetter Law Journal, 21, 1-74.

Daniels, N., Kennedy, B., \& Kawachi, I. (2007). Justice is good for our health. In R. Bayer \& D. Beauchamp (Eds.), Public health ethics : theory, policy, and practice (pp. 205-275). New York: Oxford University Press.

DeCuir, J. T., \& Dixson, A. D. (2004). "So when It comes out, they aren't that surprised that It Is there": Using Critical Race Theory as a tool of analysis of race and racism in education. Educational Researcher, 33(5), 26-31.

Deetz, S. (2005). Critical theory. In S. May \& D. K. Mumby (Eds.), Engaging organizational communication theory \& research: multiple perspectives (pp. 85 111). Thousand Oaks, CA: Sage Publications.

Delgado, R. (1991). Affirmative action as a majoritarian device: Or, do you really want to be a role model? Michigan Law Review, 1222-1231.

Delgado, R., \& Stefancic, J. (2012). Critical race theory: An introduction (2nd ed.). New York: NYU Press.

Devins, N. (1991). Rhetoric of Equality, The. Vanderbilt Law Review, 44, 15.

Devins, N. (2003). Explaining Grutter v. Bollinger. University of Pennsylvania Law Review, 152(1), 347-383.

Dougherty, D. S. (1999). Dialogue through standpoint: Understanding women's and men's standpoints of sexual harassment. Management Communication Quarterly, 12(3), $436-468$. 
Dougherty, D. S., Kramer, M. W., Klatzke, S. R., \& Rogers, T. K. K. (2009). Language Convergence and Meaning Divergence: A Meaning Centered Communication Theory. Communication Monographs, 76(1), 20-46.

Fairclough, N. (2010). Critical discourse analysis: the critical study of language. London: Longman.

Fairhurst, G. T., Cooren, F., \& Cahill, D. J. (2002). Discursiveness, contradiction, and unintended consequences in successive downsizings. Management Communication Quarterly, 15(4), 501. doi:10.1177/0893318902154001

Fisher v. University of Texas at Austin, No. No. 11-345 (U.S. Supreme Court July 26, 2013).

Fisher v. University of Texas at Austin (Ginsberg, dissenting), No. No. 11-345 (U.S. Supreme Court July 26, 2013).

Fisher v. University of Texas at Austin (oral arguments), No. No. 11-345 (U.S. Supreme Court July 26, 2013).

Fisher v. University of Texas at Austin (Scalia, concurring), No. No. 11-345 (U.S. Supreme Court July 26, 2013).

Fisher v. University of Texas at Austin (Thomas, concurring), No. No. 11-345 (U.S. Supreme Court July 26, 2013).

Fisher v. University of Texas at Austin: SCOTUSblog. (n.d.). Supreme Court of the United States Blog. Retrieved December 15, 2013, from http://www.scotusblog.com/case-files/cases/fisher-v-university-of-texas-at-austin/ Flagg, B. J. (2003). Diversity Discourses. Tulane Law Review, 78, 827. 
Ford Dowe, P. K. (2010). Racial attitudes in America: Post-racial in the age of Obama fails to exist (Poll). Fayetteville, AR: University of Arkansas Clinton School of Public Service. Retrieved from http://blairrockefellerpoll.uark.edu/6107.php

Foucault, M. (1965). Madness and civilization; a history of insanity in the age of reason. New York: Pantheon Books.

Foucault, M. (1971). The order of things : an archaeology of the human sciences. New York: Pantheon Books.

Foucault, M. (1977). Discipline and punish : the birth of the prison. New York: Pantheon Books.

Foucault, M. (1978). The history of sexuality. New York: Pantheon Books.

Foucault, M. (1980). Power/knowledge: Selected interviews and other writings, $1972-$ 1977. Vintage Books.

Foucault, M. (1989). The Archeology of knowledge. London [etc.]: Routledge.

Frankenberg, R. (1993). White women, race matters : the social construction of whiteness. Minneapolis: University of Minnesota Press.

Gerald, D., \& Haycock, K. (2006). Engines of inequality diminishing equity in the nation's premier public universities. Washington, D.C.: Education Trust. Retrieved from http://www.edtrust.org/dc/publication/engines-of-inequalitydiminishing-equity-in-the-nation\%E2\%80\%99s-premier-public-universities

Giddens, A. (1984). The constitution of society : outline of the theory of structuration. Berkeley: University of California Press.

Glazer, N. (1998). In defense of preference: Affirmative action is bad. Banning it is worse. New Republic, 218(14), 18-. 
Goodwin, M. (2013). The Death of Affirmative Action? Wisconsin Law Review, 2013, 715-875.

Gratz v. Bollinger (2003), No. 539 U.S. 234 (U.S. Supreme Court June 23, 2003).

Greenberg, J. (2001). Affirmative action in higher education: Confronting the condition and theory. Boston College Law Review, 43(3), 521- 621.

Grimes, D. S. (2002). Challenging the status quo? Management Communication Quarterly, 15(3), 381 -409. doi:10.1177/0893318902153003

Grimes, D. S., \& Richard, O. C. (2003). Could communication form impact organizations' experience with diversity? Journal of Business Communication, 40(1), 7 -27. doi:10.1177/002194360304000102

Grutter v. Bollinger, No. 539 U.S. 306 (U.S. Supreme Court June 23, 2003). Retrieved from http://www.oyez.org/cases/2000-2009/2002/2002_02_241/

Hall, S. (1997). The work of representation. In S. Hall (Ed.), Representation: cultural representations and signifying practices (p. 13). London; Thousand Oaks, CA: Sage in association with the Open University.

Haney-López, I. (2006). White by law : the legal construction of race. New York: New York University Press.

Hannah-Jones, N. (2013, March 18). A Colorblind Constitution: What Abigail Fisher's Affirmative Action Case Is Really About. ProPublica. Retrieved July 14, 2013, from http://www.propublica.org/article/a-colorblind-constitution-what-abigailfishers-affirmative-action-case-is-r/single\#republish

Harris, C. (1998). Whiteness as property. In D. R. Roediger (Ed.), Black on white : Black writers on what it means to be white (pp. 103-118). New York: Schocken Books. 
Hasian, M. J. (1994). Critical legal rhetorics: The theory and practice of law in a postmodern world. The Southern Communication Journal, 60(1), 44. doi:10.1080/10417949409372961

Haslett, B. B. (2013). Introductory Remarks: Structuration Theory. Management Communication Quarterly, 27(4), 596-598. doi:10.1177/0893318913504138

Heracleous, L. (2013). The Employment of Structuration Theory in Organizational Discourse: Exploring Methodological Challenges. Management Communication Quarterly, 27(4), 599-606. doi:10.1177/0893318913504498

Heracleous, L., \& Hendry, J. (2000). Discourse and the study of organization: Toward a structurational perspective. Human Relations, 53(10), 1251 -1286.

Hochschild, J. L. (1996). Facing up to the American dream: Race, class, and the soul of the nation. Princeton: Princeton University Press.

Hoffman, M. F., \& Cowan, R. L. (2010). Be careful what you ask for: structuration theory and work/life accommodation. Communication Studies, 61(2), 205-223. doi:10.1080/10510971003604026

Hoover, E. (2014, April 7). Affirmative-Action Foe Plans Campaigns Against 3 Universities. The Chronicle of Higher Education. Retrieved June 5, 2014, from http://chronicle.com/article/Affirmative-Action-FoePlans/145797/?cid=at\&utm_source=at\&utm_medium=en

Hopwood v. State of Texas (5th Circuit 1996).

Horton, C. A. (2005). Race and the making of American liberalism. Oxford, England; New York: Oxford University Press. 
Howe, A. (2013, June 2). Affirmative action on tap at the Supreme Court: In Plain English. SCOTUSblog. Retrieved July 9, 2013, from http://www.scotusblog.com/2013/06/affirmative-action-on-tap-at-the-supremecourt-in-plain-english/

Hunt, C. J. (2005). Color of Perspective: Affirmative Action and the Constitutional Rhetoric of White Innocence, The. Michigan Journal of Race \& Law, 11, 477.

Iverson, S. V. (2010). Producing diversity: A policy discourse analysis of diversity action plans. In E. J. Allan, S. V. Iverson, \& R. Ropers-Huilman (Eds.), Reconstructing policy in higher education: feminist poststructural perspectives (pp. 193-213). New York: Routledge.

Jager, S., \& Maier, F. (2009). Theoretical and methodological aspects of Foucauldian Critical Discourse and Dispositive Analysis. In R. Wodak \& M. Meyer (Eds.), Methods of critical discourse analysis (pp. 34-61). Los Angeles: Sage.

Jaschik, S. (2013, June 25). Lawyers analyze Supreme Court decision on affirmative action. Inside Higher Ed. Retrieved July 11, 2013, from http://www.insidehighered.com/news/2013/06/25/lawyers-analyze-supremecourt-decision-affirmative-action

Johnson, L. B. (1965, June 4). To Fulfill These Rights. Commencement Speech presented at the Commencement Address at Howard University, Washington, DC. Retrieved from http://www.lbjlib.utexas.edu/johnson/archives.hom/speeches.hom/650604.asp 
Kain, J. F., O’Brien, D. M., \& Jargowsky, P. A. (2005). Hopwood and the top 10 percent law: How they have affected the college enrollment decisions of Texas high school graduates (p. 52). Dallas, TX: Andrew W. Mellon Foundation.

Katznelson, I. (2006). When affirmative action was white : an untold history of racial inequality in twentieth-century America (2nd ed.). New York: W.W. Norton.

Kelly, E., \& Dobbin, F. (1998). How Affirmative Action Became Diversity Management Employer Response to Antidiscrimination Law, 1961 to 1996. American Behavioral Scientist, 41(7), 960-984.

Kelman, M. (1987). A guide to critical legal studies. Cambridge, MA: Harvard University Press.

Kennedy, R. (1986). Persuasion and Distrust: A Comment on the Affirmative Action Debate. Harvard Law Review, 99(6), 1327-1346. doi:10.2307/1341257

Kirby, E. L., \& Harter, L. M. (2001). Discourses of Diversity and the Quality of Work Life. Management Communication Quarterly, 15(1), 121 -127. doi: $10.1177 / 0893318901151008$

Kirby, E. L., \& Krone, K. J. (2002). “The Policy Exists But You Can't Really Use It”: Communication and the Structuration of Work-Family Policies. Journal of Applied Communication Research, 30(1), 50. doi:10.1080/00909880216577

Kochhar, R., Fry, R., \& Taylor, P. (2011). Wealth gaps rise to record highs between Whites, Blacks, Hispanics (p. 39). Pew Research Center. Retrieved from http://www.pewsocialtrends.org/files/2011/07/SDT-Wealth-Report_7-2611_FINAL.pdf 
Kuhn, T. (2006). A “demented work ethic" and a "lifestyle firm": Discourse, identity, and workplace time commitments. Organization Studies, 27(9), 1339 - 1358.

Kuhn, T. (2009). Positioning Lawyers: Discursive Resources, Professional Ethics and Identification. Organization, 16(5), 681-704. doi:10.1177/1350508409338886

Kuhn, T. (2012). Negotiating the Micro-Macro Divide: Thought Leadership from Organizational Communication for Theorizing Organization. Management Communication Quarterly, 26(4), 543-584. doi:10.1177/0893318912462004

Kuhn, T., \& Nelson, N. (2002). Reengineering identity. Management Communication Quarterly, 16(1), 5. doi:10.1177/0893318902161001

Lammers, J. C., \& Barbour, J. B. (2006). An institutional theory of organizational communication. Communication Theory, 16(3), 356-377.

Lawrence, C. R. (2001). Two View of the River: A Critique of the Liberal Defense of Affirmative Action. Columbia Law Review, 101, 928.

Lazar, M. M. (2007). Feminist Critical Discourse Analysis: Articulating a Feminist Discourse Praxis. Critical Discourse Studies, 4(2), 141-164. doi:10.1080/17405900701464816

Ledesma, M. C. (2013). Revisiting Grutter and Gratz in the Wake of Fisher: Looking Back to Move Forward. Equity \& Excellence in Education, 46(2), 220-235. doi:10.1080/10665684.2013.779556

LeGreco, M. (2012). Working with policy: Restructuring healthy eating practices and the circuit of policy communication. Journal of Applied Communication Research, 40(1), 44-64. doi:10.1080/00909882.2011.636372 
LeGreco, M., \& Tracy, S. J. (2009). Discourse tracing as qualitative practice. Qualitative Inquiry, 15(9), 1516-1543. doi:10.1177/1077800409343064

Leiter, W. M., \& Leiter, S. (2011). Affirmative action in antidiscrimination law and policy: an overview and synthesis. Albany, N.Y: SUNY Press.

Lemann, N. (2000). The big test: The secret history of the American meritocracy. Macmillan.

Lindlof, T. R., \& Taylor, B. C. (2011). Qualitative communication research methods. London: Sage.

Litvin, D. R. (2000). Defamiliarizing diversity (Electronic Doctoral Dissertations). UMass Amherst.

Litvin, D. R. (2006). Diversity: Making space for a better case. In A. M. Konrad, P. Prasad, \& J. K. Pringle (Eds.), The handbook of workplace diversity (pp. 75-94). London; Thousand Oaks, CA: Sage Publications.

Liu, G. (1998). Affirmative action in higher education: The diversity rationale and the compelling interest test. Harvard Civil Rights-Civil Liberties Law Review, 33, $381-442$.

López, G. R. (2003). The (racially neutral) politics of education: A critical race theory perspective. Educational Administration Quarterly, 39(1), 68-94.

Martin, J. N., \& Nakayama, T. K. (2006). Raced. In G. J. Shepherd, J. St. John, \& T. G. Striphas (Eds.), Communication as-- : perspectives on theory (pp. 75-83). Thousand Oaks, CA: Sage.

McKerrow, R. E. (1989). Critical rhetoric: Theory and praxis. Communication Monographs, 56(2), 91-111. doi:10.1080/03637758909390253 
McKerrow, R. E. (1991). Critical rhetoric in a postmodern world. Quarterly Journal of Speech, 77(1), 75. doi:10.1080/00335639109383945

McKerrow, R. E. (2011). Foucault's Relationship to Rhetoric. Review of Communication, 11(4), 253-271. doi:10.1080/15358593.2011.602103

McLaughlin, D. K., \& Stokes, C. S. (2002). Income inequality and mortality in US counties: does minority racial concentration matter? American Journal of Public Health, 92(1), 99-104.

Mease, J. J. (2012). Reconsidering Consultants' Strategic Use of the Business Case for Diversity. Journal of Applied Communication Research, 40(4), 384-402. doi:10.1080/00909882.2012.720380

Meisenbach, R. J., Remke, R. V., Buzzanell, P., \& Liu, M. (2008). “They Allowed”: Pentadic Mapping of Women's Maternity Leave Discourse as Organizational Rhetoric. Communication Monographs, 75(1), 1-24. doi:10.1080/03637750801952727

Mellor, J. M., \& Milyo, J. (2001). Reexamining the evidence of an ecological association between income inequality and health. Journal of Health Politics, Policy and Law, 26(3), 487-522.

Meyers, M., \& Ríos, D. I. A. (2012). Women in higher education : the fight for equity. New York: Hampton Press.

Miller, K. (2005). Communication theories : perspectives, processes, and contexts (2nd ed.). Boston: McGraw-Hill. 
Milner, H. R. (2008). Critical Race Theory and Interest Convergence as Analytic Tools in Teacher Education Policies and Practices. Journal of Teacher Education, 59(4), 332-346. doi:10.1177/0022487108321884

Mumby, D. K. (1987). The political function of narrative in organizations. Communication Monographs, 54(2), 113-127. doi:10.1080/03637758709390221

Mumby, D. K. (1997). Modernism, postmodernism, and communication studies: A rereading of an ongoing debate. Communication Theory, 7(1), 1-28. doi:10.1111/j.1468-2885.1997.tb00140.x

Mumby, D. K. (1997). The problem of hegemony: Rereading Gramsci for organizational communication studies. Western Journal of Communication, 61(4), 343-375. doi:10.1080/10570319709374585

Mumby, D. K. (2011). Reframing difference in organizational communication studies : research, pedagogy, and practice. Thousand Oaks: Sage.

Nakayama, T. K., \& Krizek, R. L. (1995). Whiteness: A strategic rhetoric. Quarterly Journal of Speech, 81(3), 291-309. doi:10.1080/00335639509384117

Nicotera, A. M., Mahon, M. M., \& Zhao, X. (2010). Conceptualization and measurement of structurational divergence in the healthcare setting. Journal of Applied Communication Research, 38(4), 362-385. doi:10.1080/00909882.2010.514001

Nkomo, S. M. (1992). The emperor has no clothes: Rewriting "race" in organizations. Academy of Management Review, 17(3), 487-513. doi:10.5465/AMR.1992.4281987

Office of Federal Contract Compliance Programs (OFCCP) - Facts on Executive Order 11246 - Affirmative Action. (2002). United States Department of Labor. 
Retrieved February 26, 2014, from

http://www.dol.gov/ofccp/regs/compliance/aa.htm

Okun, T. (2010). The emperor has no clothes : teaching about race and racism to people who don't want to know. Charlotte, N.C.: Information Age Pub.

Olufowote, J. O. (2008). A structurational analysis of informed consent to treatment: Societal evolution, contradiction, and reproductions in medical practice. Health Communication, 23(3), 292-303. doi:10.1080/10410230802056404

Omi, M., \& Winant, H. (1986). Racial formation in the United States : from the 1960s to the 1980s. New York: Routledge \& Kegan Paul.

Ono, K. A. (Ed.). (2005). A companion to Asian American studies. Malden, MA: Blackwell Pub.

Osei-Kofi, N., Torres, L. E., \& Lui, J. (2013). Practices of whiteness: racialization in college admissions viewbooks. Race Ethnicity and Education, 16(3), 386-405.

Owen, D. S. (2007). Towards a critical theory of whiteness. Philosophy \& Social Criticism, 33(2), 203-222. doi:10.1177/0191453707074139

Parker, P. S. (2001). African American women executives' leadership communication within dominant-culture organizations. Management Communication Quarterly, $15(1), 42$.

Perriton, L. (2009). “We Don't Want Complaining Women!” A Critical Analysis of the Business Case for Diversity. Management Communication Quarterly, 23(2), 218. Petitt, B. (2009). Borrowed Power. Advances in Developing Human Resources, 11(5), 633 -645. doi:10.1177/1523422309352310 
Phillips, N., Lawrence, T. B., \& Hardy, C. (2004). Discourse and institutions. Academy of Management Review, 29(4), 635-652.

Poole, M. S., \& McPhee, R. D. (2005). Structuration Theory. In S. May \& D. K. Mumby (Eds.), Engaging organizational communication theory \& research : multiple perspectives (pp. 171-195). Thousand Oaks, CA: Sage.

Poole, M. S., Seibold, D. R., \& McPhee, R. D. (1985). Group decision-making as a structurational process. Quarterly Journal of Speech, 71(1), 74. doi:10.1080/00335638509383719

Poster, M. (1989). Critical theory and poststructuralism: in search of a context. Ithaca: Cornell University Press.

Project on Fair Representation. (n.d.). Retrieved August 27, 2013, from http://www.projectonfairrepresentation.org/

Putnam, L., \& Nicotera, A. M. (2009). Building theories of organization : the constitutive role of communication. New York: Routledge.

Racial Integrity Act of 1924. (2012). Wikisource. Retrieved from http://en.wikisource.org/w/index.php?title=Racial_Integrity_Act_of_1924\&oldid $=4102617$

Regents of the University of California v. Allan Bakke, No. 438 U.S. 265 (U.S. Supreme Court June 28, 1978). Retrieved from http://www.law.cornell.edu/supct/html/historics/USSC_CR_0438_0265_ZO.html Rogers, R. (2011). An introduction to critical discourse analysis in education. New York: Routledge. 
Schmidt, P. (2013, June 26). "Fisher" Ruling May Open a "Wave of Litigation Against Colleges.” The Chronicle of Higher Education. Retrieved July 8, 2013, from http://chronicle.com.proxy.mul.missouri.edu/article/Fisher-Ruling-May-Opena/140015/?cid=at\&utm_source=at\&utm_medium=en

Schneyer, K. L. (1993). Talking About Judges, Talking About Women: Constitutive Rhetoric in the Johnson Controls Case. American Business Law Journal, 31(1), 117-164. doi:10.1111/j.1744-1714.1993.tb00676.x

Scott, C. R., Corman, S. R., \& Cheney, G. (1998). Development of a structurational model of identification in the organization. Communication Theory, 8(3), 298336. doi:10.1111/j.1468-2885.1998.tb00223.x

Selmi, M. (2002). Remedying societal discrimination through the government's spending power. North Carolina Law Review, 80, 1575-2121.

Silva, D., \& Sias, P. M. (2010). Connection, restructuring, and buffering: How groups link individuals and organizations. Journal of Applied Communication Research, 38(2), 145-166. doi:10.1080/00909881003639510

Solorzano, D., Ceja, M., \& Yosso, T. (2000). Critical race theory, racial microaggressions, and campus racial climate: The experiences of African American college students. The Journal of Negro Education, 69(1/2), 60-73.

Solórzano, D. G., \& Yosso, T. J. (2002). A critical race counterstory of race, racism, and affirmative action. Equity \&Excellence in Education, 35(2), 155-168.

Stowes, T. M. (2013). A call to action: Challenging diversity initiatives in the wake of Fisher v. University of Texas at Austin. International Journal of Discrimination and the Law, 13(4), 292-323. 
Supreme Court of the United States. (n.d.). Retrieved December 15, 2013, from http://www.supremecourt.gov/

Tanenhaus, D. S. (2008). Encyclopedia of the Supreme Court of the United States. Detroit: Macmillan Reference USA.

Taylor, J. R., \& Van Every, E. J. . (2000). The emergent organization: communication as its site and surface. Mahwah, NJ: Lawrence Erlbaum Associates.

Tracy, K., Martinez-Guillem, S., Robles, J. S., \& Casteline, K. E. (2011). 11 Critical Discourse Analysis and (US) Communication Scholarship: Recovering old connections, envisioning new ones. Communication Yearbook 35, 241-286.

Tyler, M., \& Cohen, L. (2010). Spaces that Matter: Gender Performativity and Organizational Space. Organization Studies, 31(2), 175-198. doi:10.1177/0170840609357381

U.S. Census Bureau Projections Show a Slower Growing, Older, More Diverse Nation a Half Century. (2012, December 12). U.S. Census Bureau. Retrieved July 19, 2013, from http://www.census.gov/newsroom/releases/archives/population/cb12243.html

Weedon, C. (1987). Feminist practice and poststructuralist theory. Oxford, UK; New York, NY, USA: B. Blackwell.

West, C., \& Zimmerman, D. H. (1987). Doing gender. Gender \& Society, 1(2), 125-151. doi:10.1177/0891243287001002002

Wieland, S. (2010). Ideal Selves as Resources for the Situated Practice of Identity. Management Communication Quarterly, 24(4), 503. 
Wise, T. J. (2010). Colorblind: the rise of post-racial politics and the retreat from racial equity. San Francisco, CA: City Lights Books.

Wodak, R., \& Meyer, M. (Eds.). (2009). Methods of critical discourse analysis. Los Angeles [et al.]: Sage.

Yanow, D. (2003). Constructing "race" and "ethnicity" in America : category-making in public policy and administration. Armonk, N.Y.: M.E. Sharpe.

Yates, J., \& Orlikowski, W. J. (1992). Genres of organizational communication: A structurational approach to studying communication and media. Academy of Management Review, 17(2), 299-326. doi:10.5465/AMR.1992.4279545

Yosso, T. J., Parker, L., Solorzano, D. G., \& Lynn, M. (2004). From Jim Crow to affirmative action and back again: A critical race discussion of racialized rationales and access to higher education. Review of Research in Education, 28, $1-25$.

Yount, M. (1993). The normalizing powers of affirmative action. In J. D. Caputo \& M. Yount (Eds.), Foucault and the critique of institutions. University Park, Pa.: Pennsylvania State University Press.

Zarefsky, D. (1980). Lyndon Johnson redefines "equal opportunity": The beginnings of affirmative action. Communication Studies, 31(2), 85-94. doi:10.1080/10510978009368044 


\section{VITA}

Marlo Goldstein Hode has never lived in any one place for more than four consecutive years, but considers Chapel Hill, NC to be home. She completed her BA in Communication from North Carolina State University in 1991. Upon graduation, she waited tables, saved money, and moved to Costa Rica. That experience lead to her first career in international education, which provided the opportunity to work and travel in many different countries. After ten years of this real-life international experience, she went back to school to earn an MA in Intercultural Communication from the University of Maryland in Baltimore County. Soon after, she embarked on a new, but related, career in conflict management providing training and mediation services to public, private, and non-profit organizations in North Carolina. Then, in 2009, she moved to Columbia, MO to earn an LLM in dispute resolution from the University of Missouri's Law School. During that time, she worked at the Chancellor's Diversity Initiative, where her interest in organizational culture and workplace issues, such as sexual harassment, grew. She decided to pursue these interests further and embarked on a four-year journey in organizational communication, finishing her doctorate in 2014. She now brings this extensive work and educational background to the city of St. Louis. To be continued... 